Nova Southeastern University NSUWorks

\title{
Predictive factors impacting intent to stay teaching for associate degree adjunct clinical nurse faculty
}

Julie Ann Woodworth

Nova Southeastern University

This document is a product of extensive research conducted at the Nova Southeastern University College of Nursing. For more information on research and degree programs at the NSU College of Nursing, please click here.

Follow this and additional works at: https://nsuworks.nova.edu/hpd_con_stuetd

Part of the Nursing Commons

All rights reserved. This publication is intended for use solely by faculty, students, and staff of Nova Southeastern University. No part of this publication may be reproduced, distributed, or transmitted in any form or by any means, now known or later developed, including but not limited to photocopying, recording, or other electronic or mechanical methods, without the prior written permission of the author or the publisher.

\section{NSUWorks Citation}

Julie Ann Woodworth. 2016. Predictive factors impacting intent to stay teaching for associate degree adjunct clinical nurse faculty. Doctoral dissertation. Nova Southeastern University. Retrieved from NSUWorks, College of Nursing. (37)

https://nsuworks.nova.edu/hpd_con_stuetd/37.

This Dissertation is brought to you by the Ron and Kathy Assaf College of Nursing at NSUWorks. It has been accepted for inclusion in Ron and Kathy Assaf College of Nursing Student Theses, Dissertations and Capstones by an authorized administrator of NSUWorks. For more information, please contact nsuworks@nova.edu. 
PREDICTIVE FACTORS IMPACTING INTENT TO STAY TEACHING FOR ASSOCIATE DEGREE ADJUNCT CLINICAL NURSE FACULTY

\author{
Presented in Partial Fulfillment of the \\ Requirements for the Degree of \\ Doctor of Philosophy in Nursing Education
}

Nova Southeastern University

Julie Ann Woodworth

2016 


\section{NOVA SOUTHEASTERN UNIVERSITY \\ HEALTH PROFESSIONS DIVISION \\ COLLEGE OF NURSING \\ FORT LAUDERDALE, FL 33328}

This dissertation, written by Julie Ann Woodworth under direction of her Dissertation Committee, and approved by all of its members, has been presented and accepted in partial fulfillment of requirements for the degree of

DOCTOR OF PHILOSOPHY

DISSERTATION COMMITTEE

Marcia J. Derby-Davis PhD, RN

Date

Chairperson of Dissertation Committee

Lynne E. Bryant, EdD, MSN, RN, CNE

Date

Dissertation Committee Member

Dana Scott Mills, PhD

Date

Dissertation Committee Member 


\section{NOVA SOUTHEASTERN UNIVERSITY \\ HEALTH PROFESSIONS DIVISION \\ COLLEGE OF NURSING \\ FORT LAUDERDALE, FL 33328}

\section{Certification}

We hereby certify that this dissertation, submitted by Julie Ann Woodworth, conforms to acceptable standards, and is fully adequate in scope and quality to fulfill the dissertation requirement for the Doctor of Philosophy degree.

\section{Approved:}

Patricia Welch Dittman, PhD, MSN, CDE Date

$\mathrm{PhD}$ in Nursing Education Program Director, College of Nursing

Marcella Rutherford, PhD, MBA, MSN Date

Dean, College of Nursing 
Copyright by Julie Ann Woodworth, 2016

All Rights Reserved 


\begin{abstract}
Background: The full-time nurse faculty shortage has resulted in nursing programs employing adjunct nursing faculty heavily into the clinical teaching component to fill the gap. Many adjunct faculty members continue to teach semester after semester; however, there is a lack of evidence to support the predictive factors that facilitate intent to stay teaching. Purpose: The purpose of this study was to better understand predictors of intent to stay teaching for associate degree (AD) adjunct clinical nurse faculty.
\end{abstract} Theoretical Framework: Frederick Herzberg's two-factor motivator-hygiene theory (1959) was utilized as a foundation to explore the factors that impact intent to stay teaching. Methods: Adjunct clinical nurse faculty employed in associate degree nursing programs during the 2015 calendar year were invited to participate in this study. Participants were surveyed utilizing the Job Satisfaction Survey, the Nurse Educators' Intent to Stay in Academe Scale, and demographic questionnaire via SurveyMonkey Web site. Results: Regression analysis indicated statistically significant relationships between job satisfaction, motivator, and hygiene factors with intent to stay score. In addition, faculty who had full-time employment outside of the adjunct position were found to have lower intent to stay scores compared to those working part time or not at all.

Conclusions: Enhancement of adjunct clinical faculty members' job satisfaction, motivator, and hygiene factors is necessary to retain this qualified group of educators. Improvement of intent to stay in the role can improve teaching and reduce costs at similar institutions of higher learning. 


\section{Acknowledgements}

The journey for completion of this dissertation was supported by many people. I would like to thank my family for their patience and understanding during the educational journey to complete the PhD. From the individual class postings and papers to the massive endeavor of writing the final dissertation, my family sacrificed time, attention, and meals with me. To my husband Mark and son, Dale, I must thank you for your support when I spent days at a time working on this research. Thanks to your support, I have finally finished this project!

Additionally I would like to thank my dissertation team members for their guidance and support throughout this process. I would like to thank Dr. Marcia DerbyDavis who inspired me to consider the study of adjunct nurse faculty and the intent to stay teaching from the initiation of her own work with full-time faculty. In addition, I am appreciative of her willingness to take on the chair position mid-completion of the dissertation. I would like to thank Dr. Lynne Bryant for her advisory support over the last 5 years and for joining my dissertation team on short notice to support my completion of this educational endeavor. She has always been supportive during times of self-doubt during this journey! A special thank you goes out to Dr. Dana Mills for his feedback from a non-nursing background and statistical guidance leading to more meaningful results. His expertise, confidence in my ability, and calming support during statistical analysis was crucial to completion of reliable findings! 


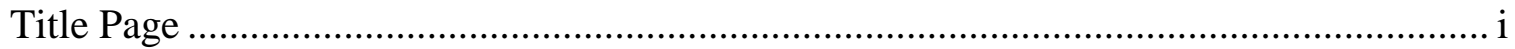

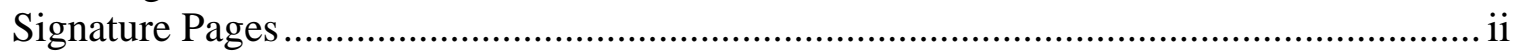

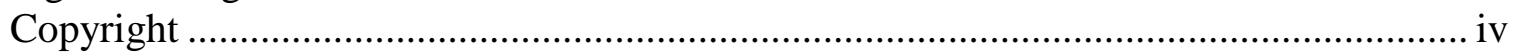

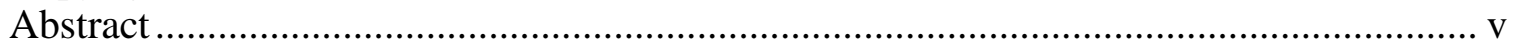

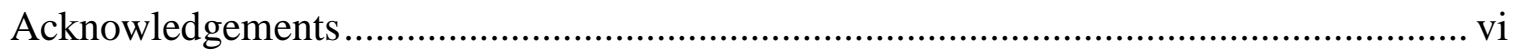

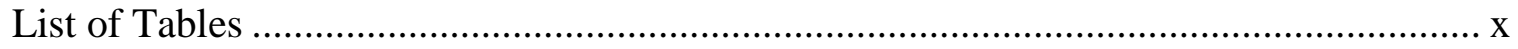

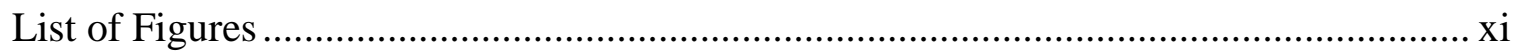

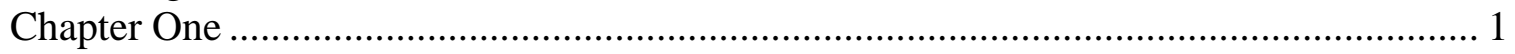

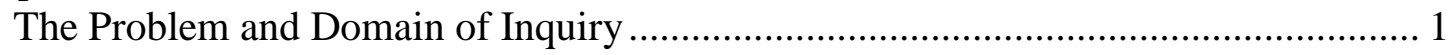

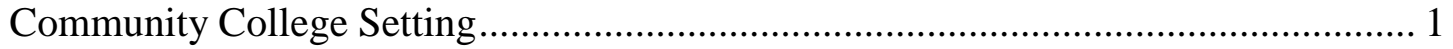

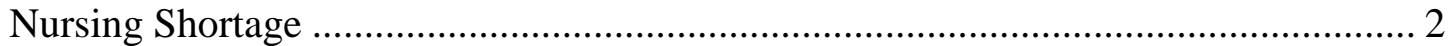

The Clinical Environment................................................................................ 3

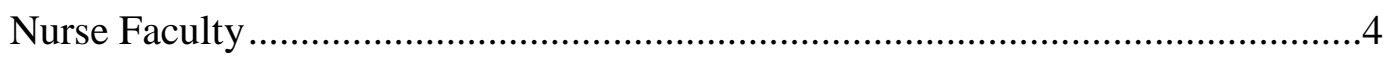

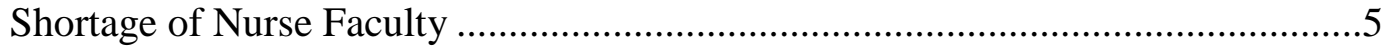

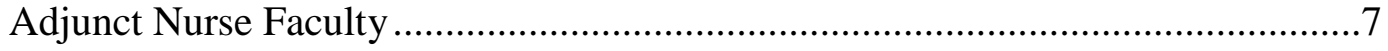

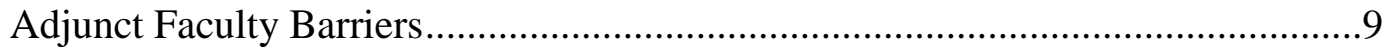

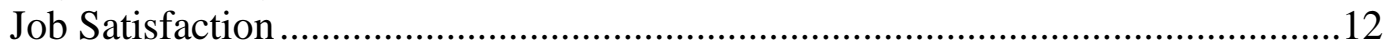

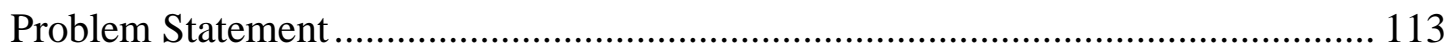

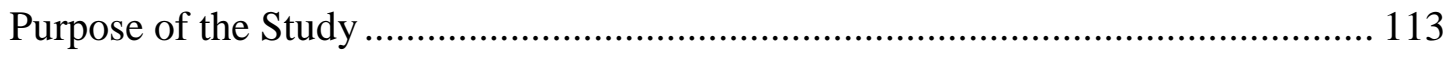

Research Questions and Hypotheses ............................................................... 14

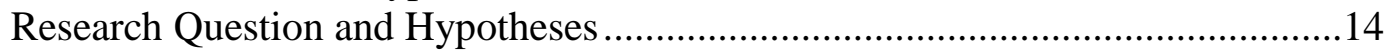

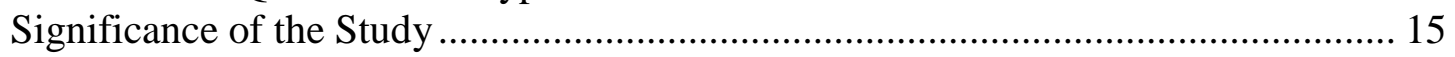

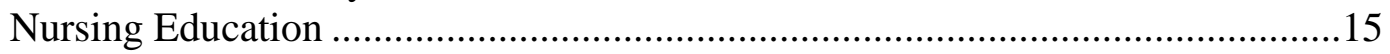

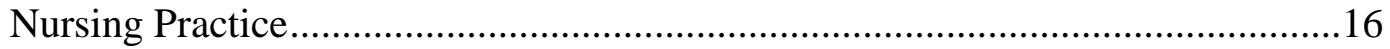

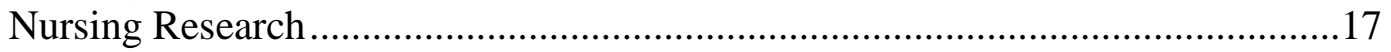

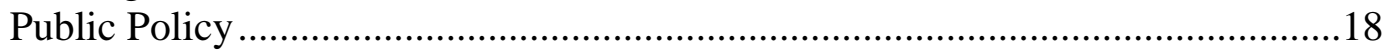

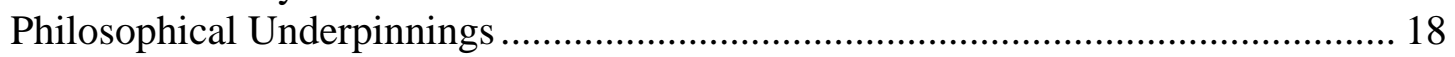

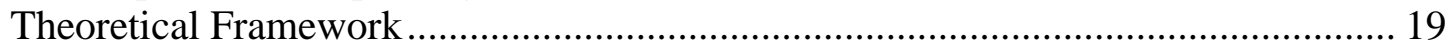

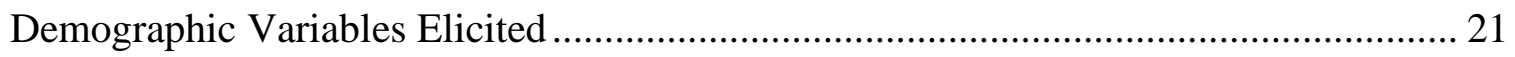

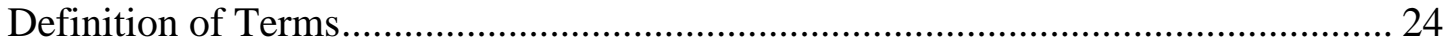

Associate Degree Adjunct Clinical Nurse Faculty ........................................24

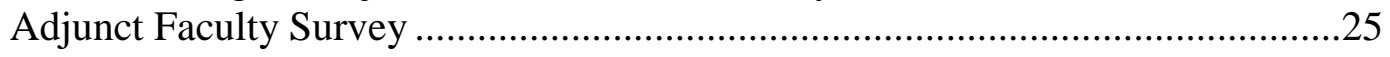

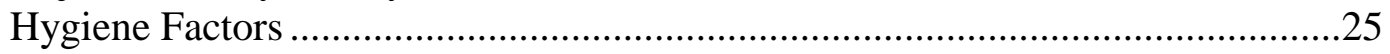

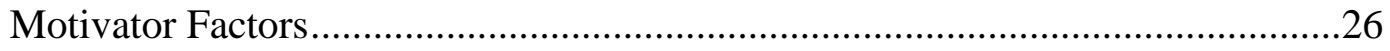

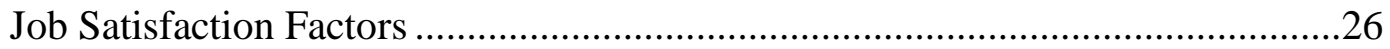

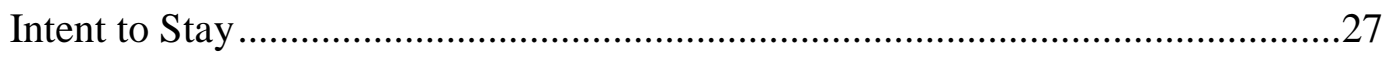

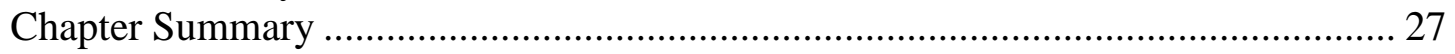

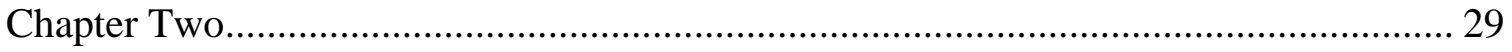

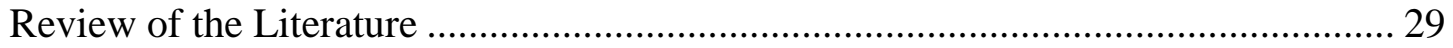

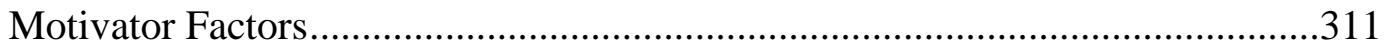

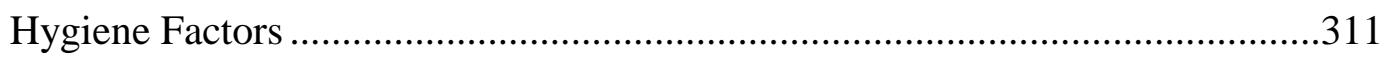

Historical Perspective .................................................................................. 322

Full-Time Faculty Teaching Across Disciplines in Higher Education .................... 333 


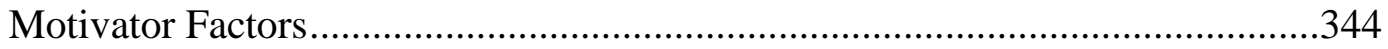

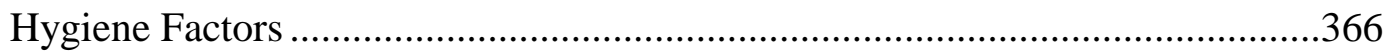

Adjunct Faculty Teaching Across Disciplines in Higher Education ......................... 388

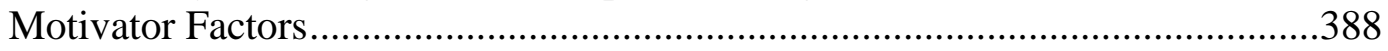

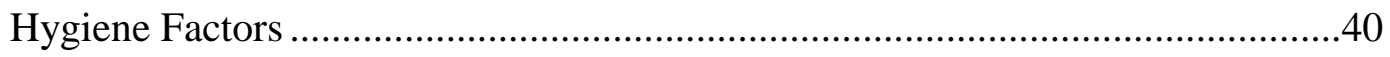

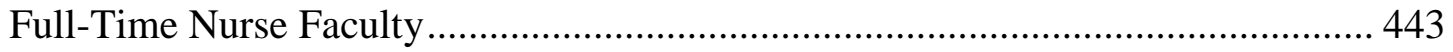

Motivator Factors....................................................................................4

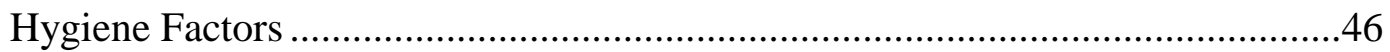

Clinical Learning Environment............................................................................. 50

Adjunct Clinical Nurse Faculty ...................................................................... 51

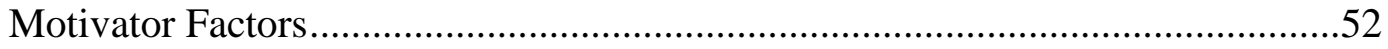

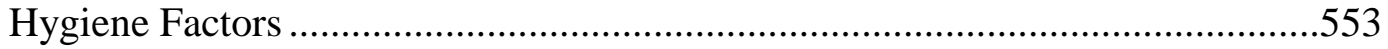

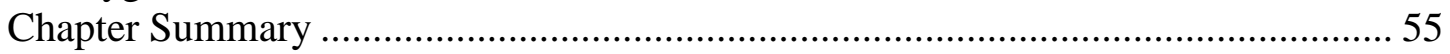

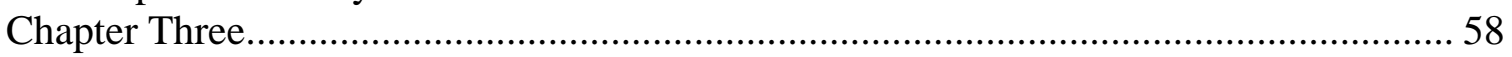

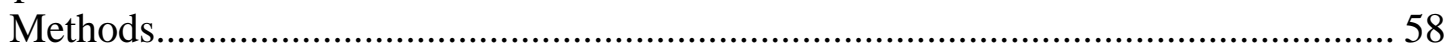

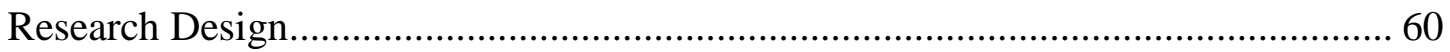

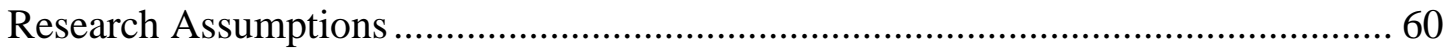

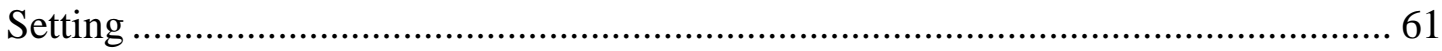

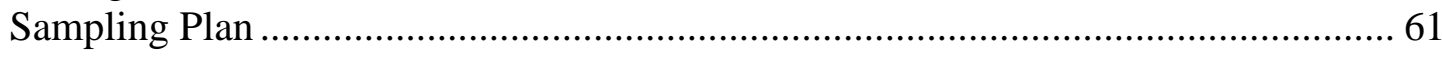

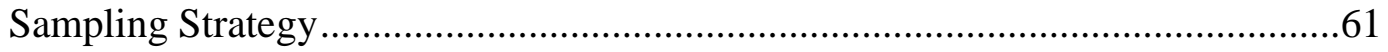

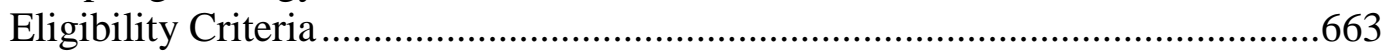

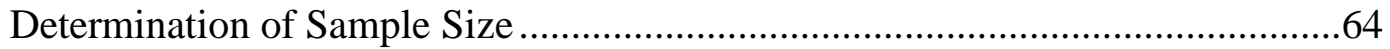

Protection of Human Subjects ....................................................................64

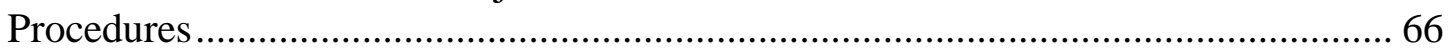

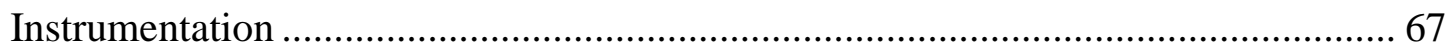

Instrument 1: The Adjunct Faculty Survey ......................................................68

Instrument 2: Nurse Educators' Intent to Stay in Academe Scale..........................69

Instrument 3: Demographic Survey ..............................................................

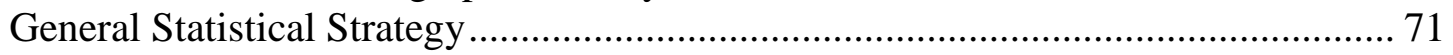

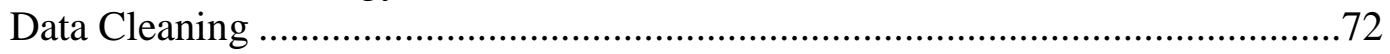

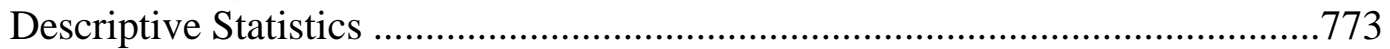

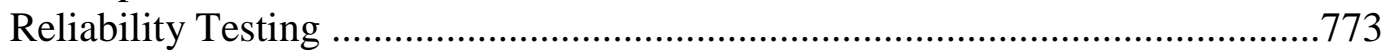

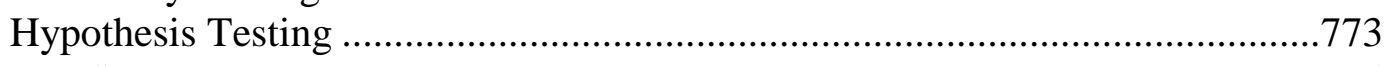

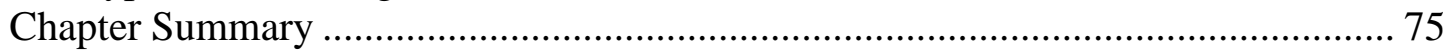

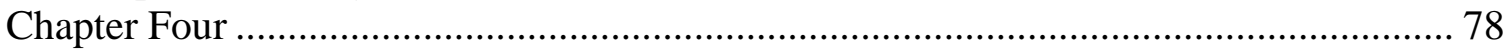

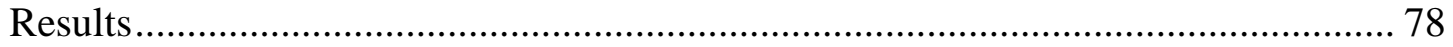

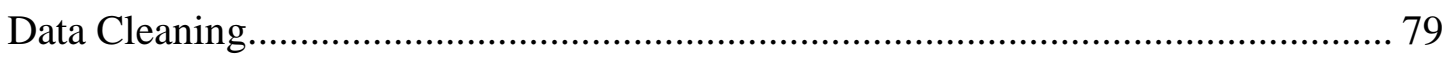

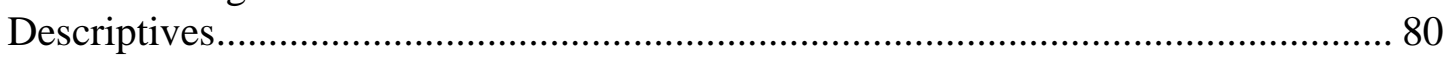

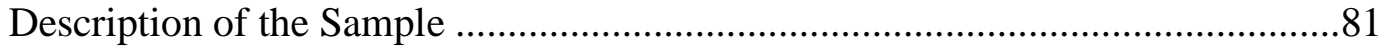

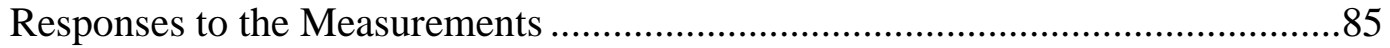

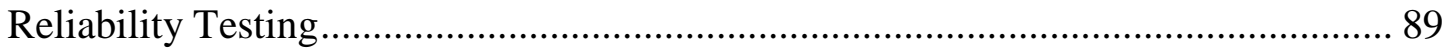

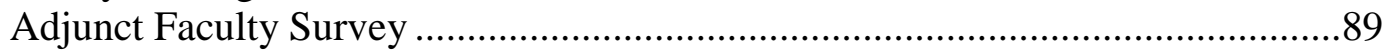

Nurse Educators' Intent to Stay in Academe Scale .............................................94

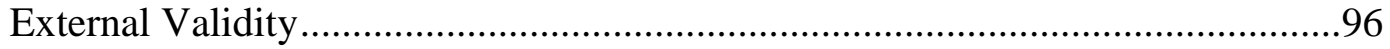

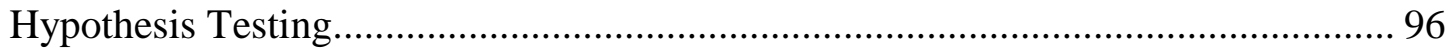

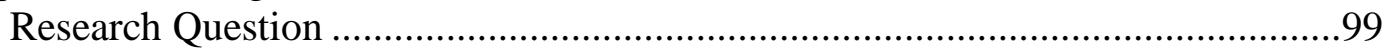




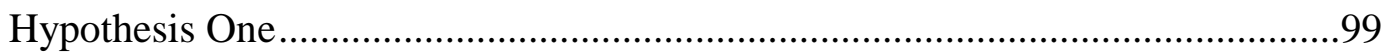

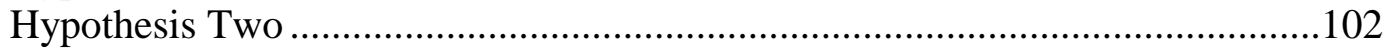

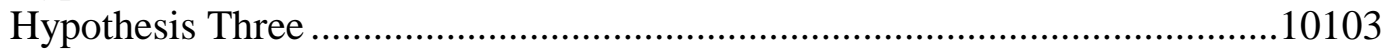

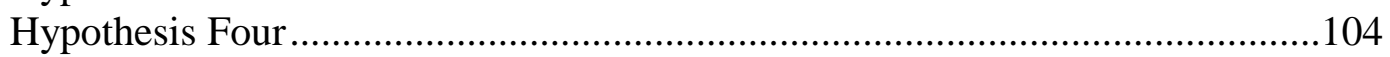

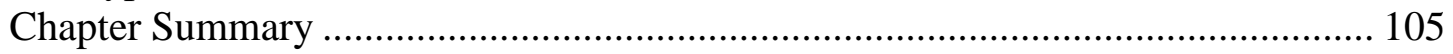

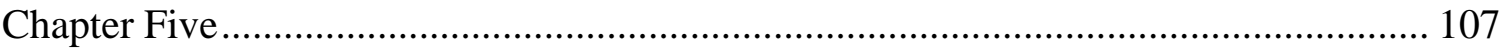

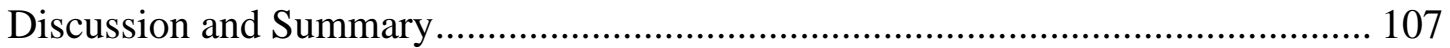

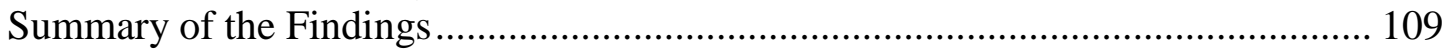

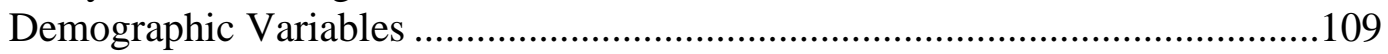

Job Satisfaction, Motivator Factor, Hygiene Factor Scores ................................112

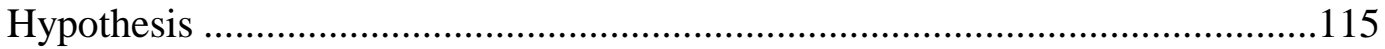

Integration of the Findings with Previous Literature ................................................ 117

Number of Years of Teaching Experience in Nursing Education ........................117

Number of Years Teaching at the Current University .......................................118

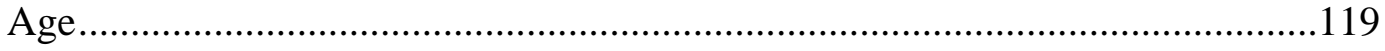

Highest Level of Education Completed............................................................120

Employment Outside of the Adjunct Teaching Position ......................................121

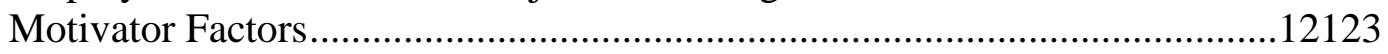

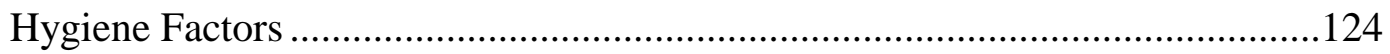

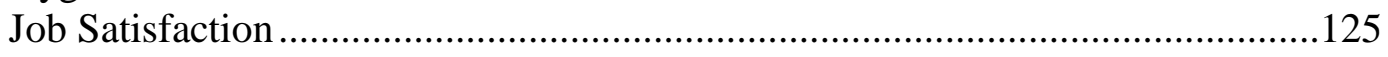

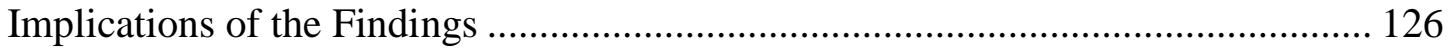

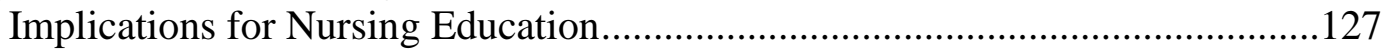

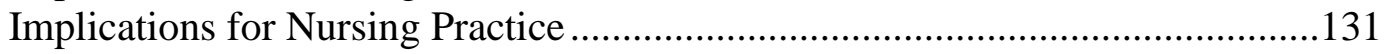

Implications for Nursing Research ...............................................................131

Implications for Public Policy ..................................................................13133

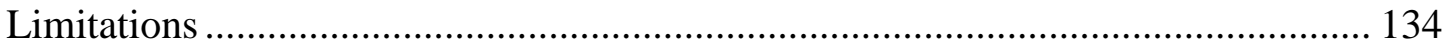

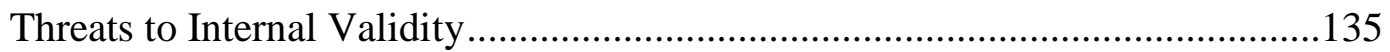

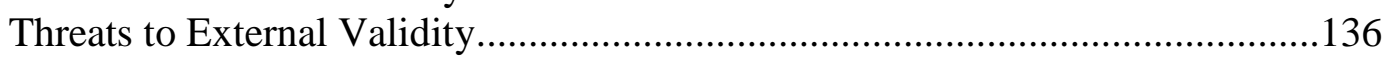

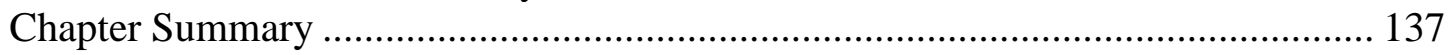

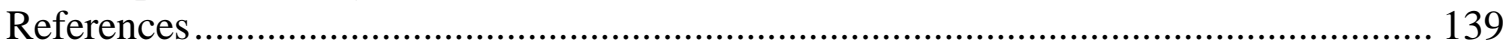

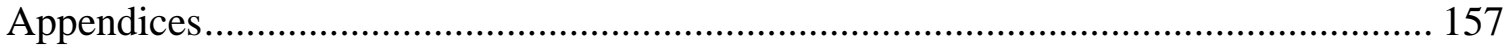

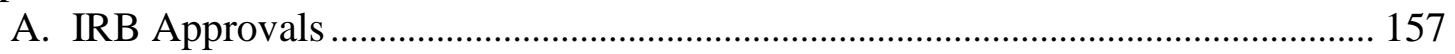

B. Permission to Utilize Adjunct Faculty Satisfaction Tool ........................................165

C. Adjunct Faculty Survey ......................................................................................... 166

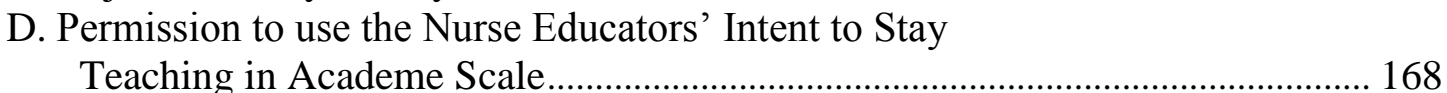

E. Nurse Educators' Intent to Stay in Academe Scale .............................................. 169

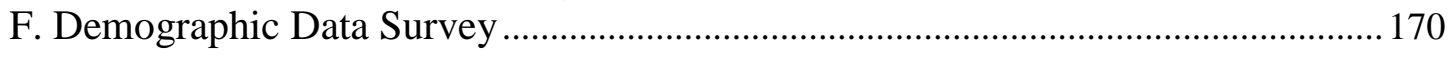

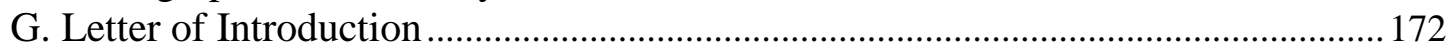


List of Tables

Table $\quad$ Page

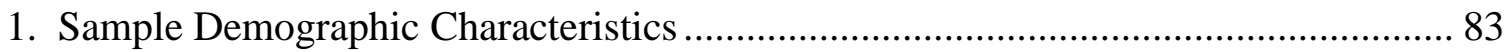

2. Descriptive Statistics and Reliability Coefficients for Each Subscale $\ldots . . . \ldots \ldots \ldots \ldots \ldots \ldots . . . . . . . . . .86$

3. Adjunct Faculty Survey Alpha Values for Each Category Within the

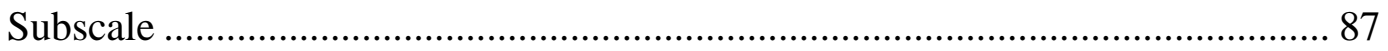

4. Internal Consistency of the Adjunct Faculty Survey ........................................... 92

5. Internal Consistency of the Nurse Educators'

Intent to Stay in Academe Scale ................................................................... 95

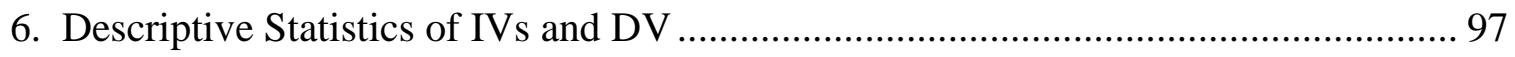

7. Job Satisfaction Score and Employment

Effect on Intent to Stay Teaching ........................................................... 101

8. Motivator Factor Summative Scoring Effect on Intent to Stay Teaching ............ 10157

9. Hygiene Factor Summative Scoring Effect on Intent to Stay Teaching ................... 104

10. Sequential Regression Analysis of Hygiene and Motivator Scores

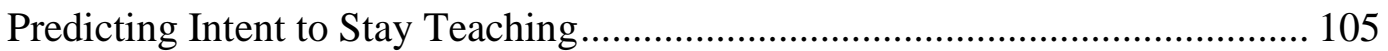




\section{List of Figures}

Figure $\quad$ Page

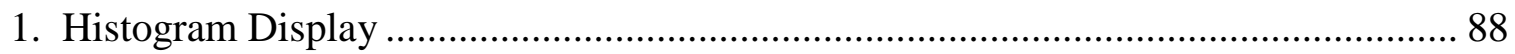




\section{Chapter One}

\section{The Problem and Domain of Inquiry}

Colleges have transitioned to a large reliance upon adjunct faculty to teach enrolled students. Schools of nursing innovatively utilize adjunct faculty to fill the gap experienced from increased student enrollments and lack of qualified full-time nursing faculty. Within nursing education, the majority of adjunct nurse faculty members are hired to teach in the clinical role and are essential to fill changing course loads each semester delivered at a cost savings (Caruth \& Caruth, 2013; Creech, 2008; Duffy, Stuart, \& Smith, 2008). Despite the importance of adjunct faculty, barriers exist to job satisfaction and intent to stay in the teaching role.

\section{Community College Setting}

In order to deliver affordable education in a financially solvent way, adjunct faculty members are heavily employed in community colleges (Clark, Moore, Johnston, \& Openshaw, 2011; Halcrow \& Olson, 2008; James \& Binder, 2011; Stenerson, Blanchard, Fassiotto, Hernandez, \& Muth, 2010). Adjunct faculty are part-time, nontenured, non-permanent faculty hired on a semester-to-semester basis, but they receive little or no benefits, health insurance, or inclusion in college governance (Caruth \& Caruth, 2013). Community colleges rely on adjunct faculty to meet the teaching needs of the college in a cost efficient manner. In the United States (US), community colleges have a significant financial impact on the economy. According to Economic Modeling Specialists International (2014), community colleges and their students contributed 809 
billion dollars into the U.S. economy in 2012, equaling over $5 \%$ of the nation's gross domestic product. The return on investment for community college education is characterized for every dollar spent on education as a net return of $\$ 3.80$ (Economic Modeling Specialists International, 2014). Strong student enrollment reflects the value of community college education. Community colleges educate nearly half of all U.S. undergraduates (American Association of Community Colleges, n.d.). Within an associate degree (AD) nursing program at a community college, a student can complete the program in as little as 2 years of study. Understandably, community colleges are having difficulty meeting the increased community demands for nursing education. In fact, community colleges turn away 3.3 qualified nursing student applicants for every one that four-year institutions refuse (Robert Wood Johnson Foundation Future of Nursing Initiative Institute of Medicine Forum on Education, 2010). Community college education and adjunct faculty members teaching within them are essential pillars of nursing education delivery.

\section{Nursing Shortage}

As a lucrative field with assurance of employment due to the nursing shortage, nursing programs have attracted an increase in applications. In response, schools of nursing have increased enrollments to mitigate the crisis of the looming nurse shortage and meet societal health care needs (Gazza \& Shellenbarger, 2010). However, the nursing shortage can be affected by an increased enrollment and subsequent graduation of nursing students (Gazza \& Shellenbarger, 2005). Yet, the anticipated nursing shortage cannot be remedied in the presence of the current nurse faculty shortage (Evans, 2013). Despite increased student enrollments, schools of nursing have turned away over 78,000 
qualified applicants with the primary reason reported as the full-time nurse faculty shortage (American Association of Colleges of Nursing [AACN], 2015). Significant factors driving the full-time nurse faculty shortage are the following: an aging workforce near retirement, limited faculty with degree credentials required to teach, higher salaries offered within the practice arena, and heavy workloads (Berent \& Anderko, 2011). The nursing shortage is expected to worsen with significant impact on patient care. The U.S. Department of Labor, Bureau of Labor Statistics (BLS, 2013) credits the increased need for registered nurses (RNs) for an emphasis on preventative care, increase in numbers of persons with chronic conditions, and aging of the large baby boomer population. In anticipation of these surges of utilization of health care resources, an increased shortage of nurses is predicted. The BLS (2013) noted an anticipated increase of $19.4 \%$ RNs needed from 2012 to 2022. This increase is significant; however, in the presence of a nurse educator shortage, little can remedy this problem. Increased reliance on adjunct nurse faculty members as a teaching resource is anticipated.

\section{The Clinical Environment}

Faculty can fulfill teaching roles in the didactic (traditional classroom and online), laboratory, and/or clinical settings. Schools of nursing report the clinical setting as the largest unfilled faculty need and most notably staffed by adjunct faculty (Creech, 2008; Duffy et al., 2008; Forbes, Hickey, \& White, 2010; Koharchik, 2014; Peters \& Boylston, 2006; Roberts \& Glod, 2013; Santisteban \& Egues, 2014; West, 2010). The significant need for clinical teaching is attributed to structured limitations for clinical learning set by state boards of nursing or individual schools of nursing with teacher to student ratios of 1:8 to 1:12 (Caton, Conner, DeWitt, Jones, \& Stubbs, 2007; Dickson, Walker, \& 
Bourgeois, 2006; Teel, 2008; West et al., 2009). This limitation requires fewer students registered for each clinical section compared to classroom or laboratory enrollments. As a result, more sections are offered and more teachers are required to accommodate the enrolled students.

\section{Nurse Faculty}

Full-time faculty members teach in the didactic (traditional classroom and online), laboratory, and clinical environments. The teaching environments are distinctive and have differing foci. Didactic teaching includes the cognitive portion of learning within the nursing program. This learning occurs in a classroom environment at the college site or via an online learning component. Theoretical knowledge is supported within the didactic component delivery. The laboratory environment is a learning setting located on-campus grounds where faculty teaches students how to perform specific psychomotor skills. Students display skill competency in the laboratory on manikins for faculty before completing the skill on a patient directly. The clinical environment is a learning setting located off-campus grounds. Faculty members supervise students at these locations as they deliver health care to patients. Clinical settings may range from inpatient to community-based settings where health care is delivered to patients directly.

In addition to teaching requirements, the full-time faculty role also includes maintenance of office hours, student advisement, scholarship, community service, and college service. Colleges have traditionally utilized full-time faculty to teach college classes because they have the pedagogical expertise, advanced degree credential, curriculum development proficiency, research involvement, scholarly writing capability, and many years of clinical experience (Creech, 2008). The Accreditation Commission 
for Education in Nursing (Accreditation Commission for Education in Nursing [ACEN], 2013) developed standards and criteria for AD professional nursing programs that require full-time faculty members hold the minimum of a master's degree with a major in nursing. Despite the attainment of the master's degree, clinical nurse experts experience difficulty transitioning from a hands-on clinical provider to nurse faculty due to little preparation for this new role (Duphily, 2011; McDonald, 2010; Schoening, 2013; Weidman, 2013).

\section{Shortage of Nursing Faculty}

Vacant nurse educator positions result from a shortage of nurse faculty. The availability of qualified nursing faculty is crucial to graduating students from nursing programs. Full-time nursing faculty shortages have been exacerbated by many factors and barriers. An aging workforce near retirement, lack of qualified faculty, salary competition in the field, heavy workloads (Berent \& Anderko, 2011), lack of administrative commitment or funds for full-time faculty lines, and lack of qualified faculty available (AACN, 2015) have contributed to the full-time nursing faculty shortage. The nursing faculty shortage is noted nationally and is documented as being critical globally (Cash, Daines, Doyle, \& von Tettenborn, 2009; McDermid, Peters, Jackson, \& Daly, 2012). The current national nursing faculty vacancy rate is $8.3 \%$ with highest rates (12.1\%) noted in the North Atlantic region of the US (AACN, 2014). This dissertation study captured participants from this noted area, more specifically the northeastern U.S. region. The BLS (2013) has predicted the nursing faculty shortage to increase to $35.4 \%$ from 2012 to 2022 , increasing the need to fill the gap with adjunct faculty. 
Aging workforce and retirement. Retirement and the aging nursing faculty population are strong factors contributing to attrition of nursing faculty and the nurse educator shortage (Bittner \& O'Connor, 2012; Caruth \& Caruth, 2013; McDonald, 2010; Roughton, 2013; West et al., 2009). Fang and Bednash (2014) examined attrition rates of full-time nursing faculty and found in one calendar year (2010-2011), the attrition rate was $11.8 \%$. A delay of retirement with continuation of employment of the aging nurse faculty workforce could extend working years with adaptations made to the faculty role and responsibilities (Falk, 2007; Foxall, Megel, Grigsby, \& Billings, 2009). Flexible scheduling, job sharing, and maintaining retirees in independent contractor or adjunct roles are suggested options to prolonging working years of qualified experienced nursing faculty.

Salary competition in the field. Nurses can earn higher salaries in the clinical practice setting compared to faculty roles. The BLS reported the mean annual wage of registered nurses as $\$ 69,790$ with a minimum education credential of the associate degree preparation (U.S. Department of Labor, 2015b). Comparatively, nursing faculty salaries averaged $\$ 70,650$ with a minimum education credential of master's degree preparation (U.S. Department of Labor, 2015a). This salary disparity continues to perpetuate the nursing faculty shortage. Salary competition contributes to nursing faculty leaving teaching positions for administrative positions or leaving academia altogether to return to clinical practice settings (AACN, 2014; Fang \& Bednash, 2014; Roughton, 2013). Yet, salary is considered less important compared to other motivator factors for nursing faculty. Faculty members are attracted to teaching for altruistic motivations like making a difference and influencing the next generation of nurses (Gazza, 2009). 
Heavy workloads. Nursing faculty workload is documented to be greater than non-nursing faculty (Kaufman, 2007a). Heavy workloads carry over into home life and affect nursing faculty work/life balance. This lack of work/life balance has contributed to the intent of full-time faculty to leave the teaching profession (Bittner \& O'Connor, 2012; Brady, 2007; Caruth \& Caruth, 2013; Garbee \& Killacky, 2008; Gazza, 2009; Roughton, 2013). Teaching responsibilities are compounded when nursing faculty has work demands of research, service, and scholarship requirements (Gazza, 2009). Another factor influencing workloads is the maintenance of clinical practice expertise outside of academic workload (Candela, Gutierrez, \& Keating, 2013; Gazza, 2009).

Other factors. Other factors considered to contribute to the nursing faculty shortage include the following: insufficient funds to hire faculty, lack of administrative commitment to full-time positions, and lack of qualified applicants being available within the geographic locale (AACN, 2015). Economic conditions have been considered the primary reason reported for limitation in colleges' abilities to hire full-time faculty (Hewitt \& Lewallen, 2010; Urwin et al., 2010). As a result of these factors, administrators recognize the lack of full-time nursing faculty and innovatively employ adjunct nursing faculty to meet the needs of nursing students and programs.

\section{Adjunct Nursing Faculty}

Adjunct faculty members are a vital teaching resource that fills the gap experienced from the lack of qualified full-time nursing faculty (Gazza \& Shellenbarger, 2010; Isaacson \& Stacy, 2009; Koharchik, 2014). The availability of adjunct faculty expands the talent pool and background of experienced, highly specialized professional nurses into teaching. Within nursing education, adjunct faculty can fill any of the 
teaching roles that full-time faculty fulfill to include the didactic, laboratory, or clinical teaching environments. In addition, adjunct faculty within nursing education may fulfill a combination of roles, depending on the needs of the program.

The clinical teaching role is most often taught by adjunct faculty. Limitations in enrollment for each clinical section results in increased numbers of sections of clinical offerings and the faculty needed to teach each section. Fortunately, adjunct clinical nursing faculty bring relevancy of current clinical practice to the clinical teaching role because they typically maintain current employment and are experts within their respective fields of nursing (Bettinger \& Long, 2010). Within nursing education, the pool of candidates available to teach in an adjunct capacity is larger in $\mathrm{AD}$ programs compared to baccalaureate degree nursing programs. Criteria established by the ACEN allows part-time faculty teaching in AD programs to hold a minimum education credential of a baccalaureate degree with a minor in nursing (BSN) with a minimum of $50 \%$ of part-time faculty holding a graduate degree with a major in nursing (ACEN, 2013). However, the minimal BSN requirement provides a larger pool of qualified candidates available and opens up opportunities to employ many more adjunct faculty. A current influx of adjunct faculty utilized across community colleges and in AD nursing programs was found. In 1998, two-year public institutions reported that $62 \%$ of instructional faculty were adjunct (U.S. Department of Education, 2002). Recent reports suggested that the number of classes taught by adjunct faculty in higher education has increased to 50\% (Caruth \& Caruth, 2013), 60\% (Charlier \& Williams, 2011), or a “majority" (Meixner, Kruck, \& Madden, 2010). The trend of college campuses hiring 
adjunct faculty is anticipated to continue and even increase (Fjortoft, Winkler, \& Mai, 2012; Landrum, 2009).

\section{Adjunct Faculty Barriers}

The experience of teaching as an adjunct faculty member is well-documented within education to include many barriers to satisfaction and retention within the role (Antony \& Hayden, 2011; Bittner \& O'Connor, 2012; Hoyt, 2012; Hoyt et al., 2008; Kramer, Gloeckner, \& Jacoby, 2014; Meixner et al., 2010; Thirolf, 2013; Valadez \& Anthony, 2001). Notably, adjunct faculty members encounter some of the same barriers that affect full-time faculty due to the nature of the academic setting. Areas found to be similar barriers among both adjunct and full-time faculty include salary compensation and heavy workloads. In addition to these barriers, adjunct faculty members report other barriers hindering their role to include the following: benefits, educational theory, and teaching experience.

Salary competition in the field. Salary compensation is a leading barrier for employment of adjunct faculty. Competition in salary is considered a barrier for faculty compared to the clinical practice setting (Brady, 2007; Caruth \& Caruth, 2013; Kramer et al., 2014; Lane, Esser, Holte, \& McCusker, 2010). This finding is similar to full-time nursing faculty because nursing education salaries are lower than clinical practice salaries. Due to lack of benefits offered to adjunct faculty members, they are considered to be paid more poorly than full-time faculty (Charlier \& Williams, 2011).

Heavy workloads. Workloads are common barriers for both full-time and adjunct faculty; however, adjunct faculty perceives the heavy workload as a result of different factors. Adjunct faculty members lack long-term employment contracts in 
higher education settings. As a result of a lack of a guaranteed employment from semester to semester, they frequently maintain employment in multiple educational institutions concurrently (Clark et al., 2011; Halcrow \& Olson, 2008; Meixner et al., 2010). Lack of job security is also found to perpetuate continued employment within the clinical practice setting (Clark et al., 2011; Duffy et al., 2008; Halcrow \& Olson, 2008; Whalen, 2009). The continuation of employment among different employers increases the workload incurred by adjunct faculty.

Benefits. Benefits are absent for adjunct faculty because adjunct faculty members typically work on a part-time basis (Caruth \& Caruth, 2013; Clark et al., 2011; Halcrow \& Olson, 2008). The lack of provided benefits is a strong cost savings to employers. With the recent passage of the Patient Protection and Affordable Care Act, employees of large companies who work 30 or more hours per week must be afforded health insurance benefits. Although it would seem to answer the problem of the lack of benefits for adjunct faculty, employers have responded by limiting the number of hours that adjunct faculty are allowed to work to 29 hours per week to avoid the expense of providing health insurance coverage (Anderson, 2014; Flaherty, 2012). This limitation of work hours continues to propagate faculty maintenance of multiple sources of employment for adjunct faculty to supplement their income.

Educational theory. An additional barrier, noted for adjunct faculty as a result of educational degree completed, is the lack of formal learning of education theory (Duffy et al., 2008; Peters \& Boylston, 2006). Within ACEN requirements, up to $50 \%$ of adjunct faculty members may hold the minimum education credential of the BSN degree (ACEN, 2013). As a result, these educators may lack formal training in educational 
theory and the teaching role. Clinical nursing faculty members are responsible to make links between theory and practice for the students that they teach. Without educational theory basis, this group of educators is disadvantaged. Despite being an expert nursing clinician, the lack of educational theory basis may contribute to feeling inadequate in this role (Allen, Ploeg, \& Kaasalainen, 2012).

Teaching experience. Adjunct clinical nursing faculty teaches students in the clinical setting and must assure attainment of student learning outcomes, provision of safe patient care, and development of safe clinical judgment (Amicucci, 2012). However, adjunct faculty members are documented to frequently lack teaching experience (Hewitt \& Lewallen, 2010; Pearch \& Marutz, 2005; Santisteban \& Egues, 2014), leading to feelings of inadequacy in the role (Allen et al., 2012). The clinical faculty role is complex, requiring strong interpersonal skills to manage students, staff nurses, and maintain patient safety (Gillespie \& McFetridge, 2006). Additionally, the off-campus location of the clinical setting leaves little academic support for adjunct clinical faculty, leading to feelings of isolation (Duffy et al., 2008; Halcrow \& Olson, 2008; Whalen, 2009). Without teaching experience and proper teaching supports available off-campus grounds, this group of faculty may leave the teaching role feeling as an outsider, isolated from common academic supports.

Other factors. Lack of dedicated office space, telephone, and computer availability are notable obstacles particular to adjunct faculty (Caruth \& Caruth, 2013; Clark et al., 2011; Halcrow \& Olson, 2008). Due to a part-time nature of employment, adjunct faculty members are not afforded dedicated office space and equipment. In addition, adjunct faculty are excluded from the college governance and decision-making 
processes (Caruth \& Caruth, 2013; Clark et al., 2011; Gazza \& Shellenbarger, 2010; Halcrow \& Olson, 2008; Roberts \& Glod, 2013). Additionally, they have little to no participation in social events or meetings (Clark et al., 2011; Halcrow \& Olson, 2008). All of these factors may lead to job dissatisfaction and leaving the teaching role typically available on campus grounds.

\section{Job Satisfaction}

Job satisfaction can be measured by retention (Pearch \& Marutz, 2005). Staff turnover is expensive with direct and indirect costs. Those costs include advertising, hiring, administrative expenses, decreased efficiency of nurses while orienting a new nurse, and overload incurred while short-staffed (Pearch \& Marutz, 2005). Despite significant barriers previously reviewed, some adjunct faculty members are retained each semester within nursing education; however, it is not known which specific factors contribute to their intent to stay in the teaching role. Satisfaction factors must be acknowledged not only to recruit these educators but to retain this dedicated workforce. Authors described a significant relationship between nursing faculty members job satisfaction and their intent to stay teaching (Derby-Davis, 2014; Garbee \& Killacky, 2008; Lane et al., 2010). However, these studies only elicited full-time faculty responses with adjunct faculty excluded. There remains a significant gap in the literature regarding the factors of job satisfaction and intent to stay teaching for $\mathrm{AD}$ adjunct clinical nursing faculty. The dissertation study investigated demographic variables and job satisfaction factors that contributed to $\mathrm{AD}$ adjunct clinical nursing faculty members' intent to stay teaching. 


\section{Problem Statement}

A limitation in nursing student graduates results in a lack of practicing nurses needed to meet the increasing needs of the nation. Nursing programs lack sufficient numbers of qualified faculty to teach these students. Increased student enrollments, limited fiscal resources, and a severe shortage of qualified nurse educators nationwide have led colleges to heavily rely on adjunct faculty to teach in the nursing program. The largest proportion of $\mathrm{AD}$ adjunct faculty teaching is attributed to the clinical component of the course that occurs at off-campus grounds.

Significant barriers for AD adjunct faculty impact job satisfaction and intent to stay teaching. Identification of these factors is necessary due to nursing faculty retirements and hiring of more adjunct faculty to replace them. Benefits from the dissertation study can be realized by the community, college, student, faculty, and patients serviced because of retaining seasoned adjunct faculty. The dissertation study investigated $\mathrm{AD}$ adjunct clinical nursing faculty demographic variables and job satisfaction factors that affected their intent to stay teaching.

\section{Purpose of the Study}

The purpose of this quantitative study was to contribute to the overall understanding of $\mathrm{AD}$ adjunct clinical nursing faculty members and to examine the relationship between demographic variables and job satisfaction factors with their intent to stay teaching. The demographic variables for this dissertation study included the following: number of years of teaching experience in nursing education, number of years employed as an adjunct at the current institution, age, and highest level of education completed. Understanding of predictors of intent to stay teaching will allow institutions 
to enhance factors to increase intent to stay and ultimately, retention of AD adjunct faculty.

\section{Research Questions and Hypotheses}

There is a paucity of research about AD adjunct clinical nursing faculty members' prediction of intent to stay teaching. The nursing faculty shortage has inspired research studies of full-time nursing faculty demographic variables and job satisfaction factors with intent to stay teaching. However, within the review of the literature for the dissertation study, no studies were identified to examine demographic variables and job satisfaction with intent to stay teaching for AD adjunct clinical nursing faculty. As a result, the following research question and hypotheses were posed to guide this dissertation study.

\section{Research Question and Hypotheses}

Research question. The research question for this study is the following: What are the predictors of AD adjunct clinical nursing faculty members' intent to stay teaching?

Research Hypothesis 1. There is a positive relationship between select AD adjunct clinical nursing faculty demographic variables (number of years of teaching experience in nursing education, number of years employed as an adjunct at the current institution, age, and highest level of education completed) and job satisfaction score with intent-to-stay-teaching score. It was further hypothesized that a negative relationship would be present for $\mathrm{AD}$ adjunct clinical nursing faculty demographic variable of outside employment status with intent-to-stay-teaching score. 
Research Hypothesis 2. There is a positive relationship between AD adjunct clinical nursing faculty members' reported level of motivator factor score and intent-tostay-teaching score after controlling for select demographic variables.

Research Hypothesis 3. There is a positive relationship between AD adjunct clinical nursing faculty members' reported level of hygiene factor score and intent-tostay-teaching score after controlling for select demographic variables.

Research Hypothesis 4. There is a positive relationship between AD adjunct clinical nursing faculty members' reported levels of job satisfaction (hygiene and motivator factor scores) and intent-to-stay-teaching score after controlling for select demographic variables.

\section{Significance of the Study}

Qualified adjunct nursing faculty members are difficult to attract into a teaching role. Barriers include the following: aging workforce and anticipated retirements, heavy workloads, lack of collegial support, lack of education credential, and competition from the clinical practice setting. Once qualified adjunct nursing faculty members are recruited and hired into nursing education, efforts must focus on their retention. The aim of the dissertation study was to reveal predictors of $\mathrm{AD}$ adjunct clinical nursing faculty members' intent to stay teaching.

\section{Nursing Education}

Nurse faculty members are an aging workforce with anticipation of retirements compounding the current faculty shortage. Adjunct faculty members are essential to AD schools of nursing to provide clinical education to students at a time of increased student enrollments, shortage of qualified educators, and limitation of teacher to student ratios in 
clinical areas (Caruth \& Caruth, 2013; Creech, 2008). The current nursing faculty shortage can be reduced and costs contained by retaining adjunct faculty from semester to semester. Nursing program leaders must identify and reduce barriers to job satisfaction and enhance methods of retention of this valuable resource of faculty. Retention of faculty has been identified as a key element to reducing this shortage (Brady, 2007; Falk, 2007). The dissertation study allowed the researcher to investigate the predictors of $A D$ adjunct clinical nursing faculty members' intent to stay teaching. An enhancement of predictors to support their intent to stay teaching would promote retention of more adjunct nursing faculty, resulting in consistency of teaching and cost savings in advertising, hiring, orientation, and training. In addition, retention of faculty enhances the consistency teaching and student learning.

\section{Nursing Practice}

The profession of nursing is experiencing a nursing shortage. Schools of nursing have experienced increased nursing student applications, enrollments, and subsequent nursing graduates entering the workforce to avert this crisis. Because of increased student enrollment in the presence of the nursing faculty shortage, it is necessary to hire more adjunct faculty to fill the need. The study of AD adjunct clinical faculty predictors of intent to stay teaching can influence the nursing practice arena. Adjunct nursing faculty members are solicited from the clinical practice setting and possess "real-world" experience. This currency of nursing practice supports adjunct faculty members as experts in their field. The hiring of qualified, expert faculty to teach within the clinical setting is essential as this setting is where students spend approximately $50 \%$ of their time learning by doing (Benner, Sutphen, Leonard, \& Day, 2010). 
The adjunct clinical nursing faculty role is typically taken on in addition to maintaining current employment at a health care agency. As a result, clinical teaching can be provided within the nurses' primary location of employment. This coordination of clinical at the nurse's primary employment site can enhance the teaching/learning experience for students but also benefit the agency with consistency of care, agency staff relations, recruitment of new hires, and improved patient outcomes. The enhanced learning experience for nursing students with the expert nurse's primary employment location (adjunct faculty) can increase nursing graduates' interest in working at the facility because of a supportive clinical learning experience. This support and increased student interest can benefit employers by making their facility the graduates' employer of choice.

\section{Nursing Research}

Investigation of $\mathrm{AD}$ adjunct clinical nursing faculty predictors of intent to stay teaching can enhance the student experience and promote further educational credentialing sought with resulting expansion of the nursing faculty profession. Positive teaching experiences can encourage adjunct faculty to continue in his/her educational journey to attain an advanced degree. Positive experiences for nursing students while enrolled in an AD program may also promote a continuation of education into a higher degree required for the nursing faculty role. An increase in nurses credentialed with advanced degree attainment can influence the pool of qualified nursing faculty workforce. This progression of degree attainment further supplies masters- and doctoralprepared nurses, which can increase nurses' interest in contributing to nursing research and evidence-based practice. 


\section{Public Policy}

The utilization of adjunct faculty for teaching is anticipated to increase despite a recent report of $80 \%$ of adjuncts teaching in the clinical setting (Duffy et al., 2008). The dissertation study indicated predictors that affect intent-to-stay factors specific to this population. Enhancement of job satisfaction factors and intent to stay teaching could alleviate both the faculty shortage and the nursing shortage. Legislative policy must be supported to enhance the number of nurse educators available to teach students. Policy implications could include a way to support and enhance adjunct clinical nursing faculty members' careers. A large disparity is acknowledged in compensation from clinical practice settings to academia with opportunities to enhance the adjunct clinical nursing faculty teaching experience. To support faculty, federal policy incentives should be available, including the following: governmental support, reimbursement for college classes completed, loan repayment programs, or scholarships. Internal college policy initiatives or government-supported programs could provide health care benefits to adjunct faculty. Non-monetary-based incentives like offering free classes at the college where the adjunct faculty is employed would support higher degree attainment for this group of educators.

\section{Philosophical Underpinnings}

The philosophical underpinnings for this dissertation study are derived from postpositivism. Auguste Comte first coined the term positivism, and he believed that a positive application of scientific knowledge came from a structured scientific method to reflect true reality (Cruickshank, 2012). Positive science proceeds in a logical manner through the study of data using the scientific method (Crotty, 2010). Positivism fits well 
when utilizing Comte's beliefs that science is based upon laws that are established and can be further studied by observations, experiments, and comparisons (Crotty, 2010).

\section{Theoretical Framework}

Frederick Herzberg's two-factor motivator-hygiene theory was developed to define the factors that motivated employees (Herzberg, Mausner, \& Snyderman, 1959). Herzberg's original study consisted of 200 male engineers and accountants who described factors contributing to satisfaction/dissatisfaction in the work environment. The needs of employees were categorized into two groupings: hygiene and motivating factors. Hygiene factors were found to be primary disruptions in the external job, whereas motivating factors intrinsically inspired employees (Herzberg et al., 1959). Respondent feedback indicated feelings of unhappiness, which were associated with conditions that surrounded doing the job and were called hygiene factors by Herzberg. Company policy/administrative practices, supervision, interpersonal relationships, working conditions, salary, status, and job security are the factors of hygiene (Herzberg, 1968). Herzberg determined that administrators must provide basic hygiene factors to prevent dissatisfaction but also provide motivators to support satisfaction in one's work. Dissatisfaction ensues when hygiene factors fall to an unacceptable level, leading to turnover. Alternatively, employees who experience positive factors will turn down other job opportunities. Improving the hygiene factors does not inherently improve job satisfaction because job satisfaction and dissatisfaction are not opposites. The opposite of job satisfaction is no job satisfaction and the opposite of job dissatisfaction is no job dissatisfaction (Herzberg, 1968). For this dissertation study, hygiene factors are 
anticipated to affect intent to stay scores. Low ratings of hygiene factors will negatively impact intent to stay scoring for adjunct clinical nursing faculty.

The factors of job satisfaction (motivators) are distinct from factors leading to job dissatisfaction. Motivator factors are suggested to enhance job satisfaction and are intrinsic to the job. Herzberg (1968) included the following factors: achievement, recognition for achievement, the work itself, responsibility, and growth or advancement. Emphasis must focus on strengthening the motivators. Motivator factors deal with integral states of mind and could improve job satisfaction when enhanced or improved. Individuals should have some control over the way a job is done to support a sense of achievement and personal growth (Herzberg, 1968). A company can expect a degree of loyalty based on employees' degree of job satisfaction. Expense to the organization of turnover and absenteeism can be countered by support of the motivator factors (Herzberg, 1968). For the dissertation study, motivator factors were anticipated to affect intent-tostay scores. High ratings of motivator factors were expected to positively impact intentto-stay scoring for adjunct clinical nursing faculty.

Herzberg's two-factor theory has been utilized as the theoretical basis by many authors (Berent \& Anderko, 2011; Derby-Davis, 2014; Evans, 2013; Hoyt, 2012; Hoyt et al., 2008; Lane et al., 2010). Hoyt, Howell, and Eggett (2007) developed a survey measured part-time faculty job satisfaction at a private university (Hoyt et al., 2008). This survey tool was further revised and utilized to measure adjunct faculty job satisfaction and include perceived loyalty to that university (Hoyt, 2012). Herzberg's theory was also utilized in studies of nursing faculty. Lane et al. (2010) surveyed fulltime community college faculty regarding satisfaction and intent to stay. Similarly, 
Derby-Davis (2014) studied full-time university nursing faculty motivator-hygiene score and intent to stay. Motivator-hygiene factors were found to positively influence full-time nursing faculty job satisfaction and intent to stay (Derby-Davis, 2014). Satisfaction factors were found to be strong indicators of nursing faculty retention and intent to stay teaching (Derby-Davis, 2014; Forbes et al., 2010; Lane et al., 2010). However, the application of Herzberg's theory to studies of adjunct nursing faculty is absent in the literature.

\section{Demographic Variables Elicited}

Demographic variables explored for the dissertation study were utilized to assess their influence on the intent-to-stay-teaching score. The demographic variables identified for the dissertation study included the following: the number of years of teaching experience in nursing education, number of years employed as an adjunct at the current institution, age, highest level of education completed, and outside employment status. These variables were chosen for inclusion based upon findings from prior research relating to the study components. Additional demographic variables included gender and ethnicity. These factors were elicited to fully understand the demographic make-up of the participant group.

An increased number of years of teaching experience in nursing education can lead to longevity and security in the teaching role. Increased number of years of teaching experience was found to positively influence full-time nurse educators' intent to stay in academe (Derby-Davis, 2014). However, Roughton (2013) found that the total number of years of full-time nursing teaching experience correlated with a higher risk to leave the role in the next year. As research was lacking for this independent variable for adjunct 
faculty, it was important to relate years of teaching experience with the intent-to-stayteaching score.

Similar to the number of years of teaching experience in nursing education, identification of years worked at an institution may suggest longevity and loyalty. Forbes et al. (2010) found over $32 \%$ of adjuncts were novices in their first semester of teaching. If a similar proportion of novice adjunct faculty were identified for the dissertation study, the potential influence on intent to stay teaching would be important to address. Adjunct faculty members had an average of 3.4 years of teaching experience (Forbes et al., 2010). However, adjunct faculty members are hired on a semester-to-semester basis and longevity may not equate in a similar way. The measure of this variable allowed a better understanding of adjunct faculty. The examination of this factor for adjunct clinical nursing faculty elicited more up-to-date information on the participant group and related to the intent-to-stay-teaching score.

Age is an important demographic variable, especially considering the average age of a master's-prepared nurse educator population is reported to be over 55 years old (AACN, 2015). As a demographic variable, age can influence the intent to stay teaching in academia score. Roughton (2013) found that increased age lowers the risk of leaving the role, which may suggest loyalty to a particular institution with an increase in the age of the nurse educator. However, increased age of the nursing faculty may increase the intent to leave the teaching role due to approaching retirement. Yet, the factor of age may also suggest good fit of employment to the individual nursing faculty. Evans (2013) found that full-time nursing faculty, age 45 years or less, found flexibility in working hours and job duties as attractive in the teaching role. Hessler and Richie (2006) found 
that younger applicants may be attracted to nursing education due to the same noted job flexibility. The demographic information of age provides meaningful insight into recruiting and retention of adjunct clinical nurse faculty and intent to stay teaching.

Highest level of education completed has been identified to influence intent to stay in contradictory ways. Higher level of education positively affected full-time nursing faculty intent to stay (Derby-Davis, 2014; Garbee \& Killacky, 2008), whereas Roughton (2013) indicated that full-time nursing faculty with higher educational degrees were $40 \%$ more likely to leave their role within 1 year. Full-time faculty members are required to minimally hold a master's degree. The faculty group elicited for the dissertation study was adjunct clinical nursing faculty with a minimum education credential of a baccalaureate degree. Faculty with the baccalaureate degree have been shown to lack formal education theory to support the teaching role. The dissertation study elicited demographic information regarding the highest level of education completed to identify the relationship with the intent-to-stay-teaching score.

Outside employment status was anticipated to affect the intent-to-stay-teaching score. Garbee and Killacky (2008) found that intent to stay teaching was significantly higher for full-time nursing faculty who worked 40 hours per week compared to those who worked 60 hours per week. If adjunct clinical nursing faculty are employed at multiple institutions, the numbers of hours per week could total to the same hours worked as full-time faculty. Bittner and O'Connor (2012) surveyed full-time and part-time nursing faculty and found that a majority of respondents worked two or more jobs with $20 \%$ reporting three or more jobs. If an adjunct faculty member works fewer hours, it may support job satisfaction within the role and intent to stay teaching. Alternatively, 
adjunct faculty members working in the clinical practice settings receive a higher salary that may influence an individual's decision in a negative manner, relating to intent to stay in academia. The solicitation of this demographic data was important to understanding the participant group and the effect on the intent-to-stay-teaching score.

Ethnicity and gender as demographic variables were important factors to consider for this participant group. Liu and Ramsey (2008) found minority faculty members were generally less satisfied in their jobs. In addition, minority faculty members were found to be more likely to leave their teaching positions (Rosser, 2004; Xu, 2008). There is a paucity of literature regarding ethnicity in the clinical nursing faculty role. Additionally, a majority of the nursing population is female gender. This finding was noted in the nursing faculty population when demographic data has been elicited. Examination of these factors demonstrated demographic make-up of the participant group that was unique to the $\mathrm{AD}$ adjunct clinical nursing faculty. Despite its omission in the literature, diversity among nurses and nursing faculty is important to the future of health care delivery (Benner et al., 2010).

\section{Definition of Terms}

Terminology utilized in a research study must be clearly understood so that research results are transparent. The theoretical and operational definitions of terms which were measured in this dissertation study are further defined.

\section{Associate Degree Adjunct Clinical Nursing Faculty}

Adjunct clinical nursing faculty (also referred to as part-time faculty) are experientially and academically qualified RNs who teach clinical skills for AD professional nursing education program. This faculty member is a clinical expert in 
professional nursing with an advanced degree (minimum of BSN), teaching only in the clinical component of the pre-licensure, AD professional nursing program on a part-time basis. Adjunct faculty members are non-tenured, non-permanent faculty hired on a semester-to-semester basis and receive little or no benefits, health insurance, or inclusion in college governance. The clinical environment is a learning setting located off-campus grounds. Faculty supervises students at these locations as they deliver health care to patients. Clinical environment settings include hospitals, nursing homes, or communitybased settings in which health care is delivered directly to patients.

\section{Adjunct Faculty Survey}

The Adjunct Faculty Survey, developed by Hoyt et al. (2007), was based on Herzberg's (1968) two-factor motivator-hygiene theory of employee motivation. Overall job satisfaction and loyalty of adjunct faculty members was elicited. Adjunct faculty satisfaction with hygiene and motivator factors was obtained utilizing subscales of the following: autonomy, classroom facilities, compensation, faculty support, personal growth, quality of students, recognition, teaching schedule, and work preference. The questions on the survey were answered on a six-point Likert scale ranging from 1 (strongly disagree) to 6 (strongly agree) using summated rating scales (Hoyt, 2012; Hoyt et al., 2007).

\section{Hygiene Factors}

Hygiene factors are primary conditions of employment and include the following: company policy/administrative practices, supervision, interpersonal relationships, working conditions, salary, status, and job security (Herzberg, 1968). Operationally, adjunct clinical nursing faculty self-assessed hygiene factors as part of their AD clinical 
teaching experience rate their satisfaction on a scale of 1 (strongly disagree) to 6 (strongly agree). The subscale items from the Adjunct Faculty Survey included the following as hygiene factors: teaching schedule, quality of students, autonomy, faculty support, classroom facilities, and honorarium. The total value for the hygiene factors scale range from a most negative self-assessment satisfaction score of 15 to a most positive self-assessment of 90 .

\section{Motivator Factors}

Motivator factors enhance job satisfaction and include the following: achievement, recognition for achievement, the work itself, responsibility, and growth or advancement (Herzberg, 1968). Operationally, adjunct clinical nursing faculty selfassessed motivator factors as part of their $\mathrm{AD}$ clinical teaching experience and rated their satisfaction on a scale of 1 (strongly disagree) to 6 (strongly agree). The subscale items from the Adjunct Faculty Survey included the following: work preference, personal growth, and recognition. The total value for the motivator factors scale ranged from a most negative self-assessment of 9 to a most positive self-assessment of 54 .

\section{Job Satisfaction Factors}

Job satisfaction is the way people feel about their jobs (Garbee \& Killacky, 2008).

Job satisfaction was measured using the Adjunct Faculty Survey (Hoyt, 2012).

Operationally, adjunct clinical nursing faculty self-assessed job satisfaction factors as part of their AD clinical teaching experience and rated their satisfaction on a scale of 1 (strongly disagree) to 6 (strongly agree). There were six questions relating to job satisfaction. The total value for the job satisfaction factors score ranges from a most negative self-assessment of 6 to a most positive self-assessment of 36 . 


\section{Intent to Stay}

Intent to stay is the likelihood to continue membership with the organization (Price \& Mueller, 1981). The intent to stay teaching in nursing education is the dependent variable for the dissertation study. Operationally, adjunct clinical nursing faculty self-assessed intent to stay teaching in their AD clinical teaching role, utilizing the Nurse Educators' Intent to Stay in Academe Scale by Derby-Davis (2014). Adjunct clinical nursing faculty rated their intent to stay on a scale of 1 (strongly disagree) to 4 (strongly agree). The intent-to-stay-teaching scale scores range from a most negative self-assessment of 13 to a most positive self-assessment of 52.

\section{Chapter Summary}

The significant economic impact of community colleges on the nation's economy has been demonstrated. Students value an affordable community college education available in their locale. The nursing shortage has been affected by the nursing faculty shortage. Retirements, aging population, workload, and qualifications were noted as significant issues for recruitment and retention of the nursing faculty workforce. As a result, adjunct faculty members have been identified to bridge the gap from lack of fulltime faculty within the nursing education arena. Barriers pertaining to the adjunct faculty workforce were also explored. Full-time nurse faculty job satisfaction and intent to stay teaching have been explored. The dissertation study fills the gap of AD adjunct clinical nursing faculty members' demographic variables and job satisfaction factors with intent to stay teaching. Finally, adjunct faculty members are predominately hired to teach in the clinical arena, accentuating their clinical expertise; however, lack of educational theory basis and teaching experience may affect this group's satisfaction and intent to stay. This 
chapter described the problem, purpose, and research questions. The dissertation study of $\mathrm{AD}$ adjunct clinical nursing faculty members' demographic variables and job satisfaction factors effect on intent-to-stay-teaching has significant relevancy to the future of nursing education. 


\section{Chapter Two}

\section{Review of the Literature}

A strong interconnectedness exists between the nursing shortage and the nursing faculty shortage. In order for nursing programs to graduate more nurses, student enrollments must increase. However, the shortage of nursing faculty has hindered the enrollment and graduation of more students. As a result, more registered nurses need to be recruited into the educational arena to fill this need. However, a lack of job satisfaction and presence of dissatisfaction themes were evident in the literature contributing to poor retention of full-time nurse faculty (Candela, Gutierrez, \& Keating, 2015; Derby-Davis, 2014; Garbee \& Killacky, 2008; Lee, 2014; Roughton, 2013; Ruel, 2009). Across disciplines in higher education, similar job satisfaction and dissatisfaction themes were found. Higher satisfaction levels in the teaching role support faculty intent to stay and subsequent retention (Rosser, 2004). Lack of satisfaction and poor retention of faculty create a gap of available qualified staff, despite increased student enrollments. In light of this gap, colleges and universities rely on adjunct or part-time faculty to teach. In fact, the new majority of teaching faculty is hired on an adjunct basis (Meixner et al., 2010). Despite the need for adjunct faculty, identification of increasing satisfaction and enhancing the intent to stay teaching for this faculty group has been overlooked. The intent to leave a position is validated as the best predictor of actual turnover (Rosser, 2004). Derby-Davis (2014) and Hoyt (2012) indicated that faculty job satisfaction scores were strongly related to intent to stay in the teaching role. 
This chapter provides a review of relevant literature regarding faculty in higher education settings and reported satisfaction and retention. The literature review included relevant literature on faculty teaching in higher education. This review explored faculty in higher education to include the full-time faculty role followed by the adjunct faculty role in disciplines other than nursing. In a narrowing effect, faculty in a full-time faculty teaching in nursing were explored, followed by the clinical teaching experience, and then most narrowly to the adjunct clinical nurse faculty experience. Inclusion criteria for this literature review required research studies to be published in the English language in a peer-reviewed journal with a publication date from 2004 to 2015 . This time frame was chosen to include relevant literature and maintain currency of the results. The literature search was completed utilizing Cumulative Index of Nursing and Allied Health Literature (CINAHL), ProQuest Dissertation and Theses, Education Source, Medline, Nursing and Allied Health, Education Index Retrospective, General Science, Humanities and Social Science Index as the electronic databases. The terms faculty, adjunct faculty, part-time faculty, nurse faculty, nursing instructor, clinical instructor, clinical nurse educator, clinical educator, retention, satisfaction, and intent to stay/intent to leave were the key words utilized for this literature search. For a source to be included in this review, the topic needed to examine faculty teaching students in the educational or clinical setting. Boolean modifiers were set to include adjunct and part-time faculty, but exclude contingent faculty due to the common overlap in responsibilities of this teaching group with those of full-time faculty. In addition, articles were excluded that referenced online teaching experiences to focus this review on the clinical teaching experience. The 
reference lists of each article reviewed was searched for additional papers to include within this review.

Herzberg's (1959) two-factor motivator-hygiene theory provides the theoretical construct for this study. Herzberg's (1959) study was originally completed by interviewing accountants and engineers to identify causes of job satisfaction and job dissatisfaction. From these studies, work dimensions were developed into the two categories of motivator and hygiene factors.

\section{Motivator Factors}

The motivator factors were job experiences that participants found satisfying and were delineated as achievement, recognition of achievement, the work itself, responsibility, and growth or advancement (Herzberg, 1968). Emphasis upon these motivator factors resulted in employee job satisfaction. The motivator factors not only supported job satisfaction but also employee retention. Turnover of employees can be countered by high ratings of the motivator factors.

\section{Hygiene Factors}

The hygiene factors were termed to identify the factors interviewees found as negative experiences and delineated as company policy/administrative practices, supervision, interpersonal relationship, working conditions, salary, status and job security (Herzberg, 1968). A low level of hygiene factors was found to lead to dissatisfaction in the role. Since the original study, Herzberg's two-factor motivator-hygiene theory has been replicated into studies relevant to the teaching and nursing arenas (Berent \& Anderko, 2011; Derby-Davis, 2014; Hoyt et al., 2008; Lane et al., 2010; Waltman, Bergom, Hollenshead, Miller, \& August, 2012). 
In keeping this literature review concentrated on the theoretical basis of Herzberg's theory, each section of the literature review focused on the satisfaction of faculty with organization of literature findings into the motivator and hygiene factors. It is noted that each motivator or hygiene factor is not evident in all faculty groupings being reviewed. Therefore, only those motivator and hygiene factors prevalent were included.

\section{Historical Perspective}

Throughout history, colleges have employed part-time (referred to as adjunct) teaching faculty (Meixner et al., 2010; Pearch \& Marutz, 2005). Historically, adjunct faculty was expert, visiting professors of high status, typically shared among universities (Wallin, 2004). They were brought in as guest speakers to add to the quality of the program with current work experience suggested to keep the curricula current. The economic recession and economic downturn sparked a striking change in the hiring practices of colleges towards adjunct faculty (Hewitt \& Lewallen, 2010; Urwin et al., 2010). The recession led to adjunct faculty being quickly hired without the benefits and pay deserved (Wyles, 1998). More illustratively, adjunct faculty members are referred to as the "invisible faculty" (Gappa \& Leslie, 1993). Community colleges are particularly challenged to meet the increasing community needs of education delivery with declining resource availability (Wyles, 1998). Significant increases are noted in the trend of hiring adjunct faculty within higher education. Reports indicated the rate of hiring adjunct faculty teaching was $18.5 \%$ in 1969 (Wilson, 2012 ), $43 \%$ in 2002 (U.S. Department of Education, 2002), and 69\% in 2009 (DiMaria, 2012).

In nursing education, deYoung and Bliss (1995) discovered an increase in the number of adjunct faculty hired in response to the inability to hire full-time faculty. The 
result was reported in 2006 by the National League for Nursing (NLN) as nearly $45 \%$ of the full-time equivalents were filled with adjunct faculty (NLN, 2011) with reports of up to $80 \%$ of clinical faculty as adjunct hires (Duffy et al., 2008). Yet, adjunct faculty bring current clinical expertise and are essential members in the staffing of the clinical teaching role in light of the nurse educator shortage (Creech, 2008; Dahlke, Baumbusch, Affleck, \& Kwon, 2012; Duffy et al., 2008; West et al., 2009). This transition of education delivery from the full-time faculty towards adjunct faculty is significant; nevertheless, studies are lacking to address this new faculty majority. Studies of demographic variables and job satisfaction factors influencing intent to stay teaching have been researched with full-time faculty; however, there were no studies found within this literature review studying these factors in AD adjunct clinical nursing faculty.

\section{Full-Time Faculty Teaching Across Disciplines in Higher Education}

Across higher education, past practice has demonstrated a substantive hiring of full-time faculty to teach in colleges and universities. However, colleges are facing a crisis of increased student enrollments, inability to hire qualified full-time faculty, and limitation of fiscal resources. This problem is recognized internationally and across disciplines within higher education. Full-time faculty members are the key component to support rigorous curriculum and student attainment of educational requirements with degree completion. Full-time faculty members are responsible to develop curriculum, meet accreditation requirements, deliver pedagogically relevant material to students, and maintain rigor of the nursing program (Benner et al., 2010). Within higher education, attracting qualified faculty is difficult; however, once recruited, investigation of factors 
influencing intent to stay teaching must become the priority to keep faculty teaching in this setting.

Within the literature review of faculty across disciplines, demographic factors were identified to affect faculty job satisfaction and intent to stay teaching. Although demographic factors do not qualify as either a motivator or hygiene factor, some authors contend that these factors impact teaching satisfaction and retention. Female faculty were reported to be significantly less satisfied compared to their male counterparts with their workload and work conditions (Liu \& Ramsey, 2008; Rosser, 2004). Female faculty were also less satisfied with benefits, salary, and job security (Rosser, 2004). Lastly, female faculty were noted to have a stronger intention to leave the current position (Xu, 2008). However, within nursing education, the majority of the workforce $(91 \%)$ is female (U.S. Census Bureau, 2013). Minority faculty members were also identified to be less satisfied in every job aspect except professional development (Liu \& Ramsey, 2008). Minority faculty members were also noted to be more likely to leave their teaching position compared to their Caucasian counterparts (Rosser, 2004; Xu, 2008). As a result, these demographic variables will be elicited from the sample group as part of the demographic survey.

\section{Motivator Factors}

The satisfaction of full-time faculty is essential to retention of this highly valued, but difficult to attract, faculty resource. Increased number of years of teaching is found to improve job satisfaction and retention results (Liu \& Ramsey, 2008). The key is to identify job satisfaction factors to support faculty to stay for an increased number of years. Job satisfaction is reported to be best supported in higher education by the 
motivator factor of the work itself. One example of this includes full-time faculty in science, technology, engineering, and mathematics (STEM); social sciences; and humanities reveal that the greatest satisfaction derived from the teaching role is related to the teaching experience and making a difference in students' lives (Waltman et al., 2012). Rosser (2004) indicated similar findings for tenured faculty of two- and four-year colleges who report a love of the position and positive interactions with students.

The motivator factor of growth or advancement is important to support satisfaction of full-time faculty. The growth of faculty is suggested to be supported by professional development. Professional development was found to promote full-time faculty satisfaction (Lodhi, Raza, \& Dilshad, 2013; Xu, 2008). Yet, professional development availability within institutions was affected by funding issues (Rosser, 2004). If there is a shortfall in funding, professional development is significantly affected or sacrificed entirely. Advancement within the academic role also became a common concern for faculty. Terms of promotion, evaluation, and career ladders were inconsistent or unclear creating anxiety for faculty during this process (Waltman et al., 2012). The process of promotion varied by institution, school, or academic unit (Waltman et al., 2012). The lack of transparency of advancement methods leads to frustration, uncertainty, and increased intent to leave.

The motivator factor of recognition for achievement was found to be a source of concern. Xu (2008) grouped faculty by teaching discipline to discover commonalities contributing to voluntary turnover. As a result of this study, enhancement of rewards and recognition of work was found to enhance retention $(\mathrm{Xu}, 2008)$. 


\section{Hygiene Factors}

Job satisfaction is supported by the hygiene factor of working conditions.

Satisfaction of full-time faculty in higher education has been studied and has been found to be enhanced by teaching schedule flexibility that allows for family responsibilities and personal life needs (Lodhi et al., 2013; Waltman et al., 2012). Working conditions in higher education refers to faculty workload. Faculty workloads vary between educational institutions; however, the four major components of scholarship are generally expected. Scholarship includes faculty fulfillment of discovery (research), integration, application, and teaching (Boyer, 1990). Excessive workloads and high amounts of required productivity of scholarly research has contributed to an increase in full-time faculty members' consideration to leave (Lodhi et al., 2013; Ryan, Healy, \& Sullivan, 2012). Other areas contributing to workload include the following: student advisement, course development planning and preparation (Rosser, 2004), committee work, faculty meetings, and teaching load (Waltman et al., 2012).

Job satisfaction among full-time faculty is strongly supported by the hygiene factors of salary and benefit packages. However, salary compensation is consistently reported across higher education settings as inadequate and is considered to negatively affect faculty job satisfaction (Lodhi et al., 2013; Waltman et al., 2012; Xu, 2008). In fact, science and math faculty report they were least satisfied with compensation (Liu \& Ramsey, 2008). Nonetheless, based on Herzberg's model (1959), improvement of hygiene factors does not increase satisfaction; it only prevents dissatisfaction. This finding is reinforced by Liu and Ramsey (2008) who found that teachers' satisfaction with compensation is not correlated with their satisfaction with work. Increasing 
teachers' compensation did not improve teacher satisfaction (Liu \& Ramsey, 2008). In consideration of the consistent reports of low salary compensation among faculty, other factors were determined to provide satisfaction. Benefit packages have been found to support faculty satisfaction in the role of educator. Fringe benefits support full-time faculty job satisfaction and subsequent retention in the teaching role (Lodhi et al., 2013; Rosser, 2004).

The hygiene factors of status and job security were commonly acknowledged in the literature. Full-time faculty noted dissatisfaction factors across disciplines within higher education referring to status (promotion), lack of respect, and lack of inclusion in decision making (Lodhi et al., 2013; Waltman et al., 2012). These items are suspected to be interrelated as promotion and tenure decisions affect the terms of employment, but faculty indicated exclusion from decision-making processes on campus. Across all discipline groups, $\mathrm{Xu}$ (2008) found that faculty consistently hoped for more participation in decision making. Terms of employment and lack of commitment from the institution were noted to lead to dissatisfaction for full-time faculty impacting job security. Rosser (2004) found that faculty members with tenure were less likely to leave their institutions due to investment of faculty time and resources to attain this status.

Job security concerns were most evident for full-time faculty lacking long-term contracts. Despite performing well in the role, full-time faculty indicated contracts of only 1 to 3 years in duration (Waltman et al., 2012). Respondents felt threatened in their positions if student enrollment was reduced or budget cuts were anticipated (Waltman et al., 2012). Therefore, job security was found to be critical in affecting full-time faculty satisfaction and resulting retention (Lodhi et al., 2013; Xu, 2008). Job security was 
supported by an increased number of years of service teaching at a college (Rosser, 2004). The longer a faculty member teaches at a college, the likelihood of that faculty leaving is reduced (Ryan et al., 2012; Xu, 2008). Subjective perceptions of job satisfaction in the work environment were predictive of faculty intent to leave and subsequent turnover. Faculty turnover has negative implications of monetary costs, reduced faculty productivity, low teacher morale, and low quality of education consequences for institutions (Liu \& Ramsey, 2008; Xu, 2008). Although retention of full-time faculty is identified as having high importance, there remains a gap of qualified full-time faculty leading to a significant need for adjunct faculty to teach.

\section{Adjunct Faculty Teaching Across Disciplines in Higher Education}

Within higher education, adjunct faculty are hired to quickly fill the gap left when full-time faculty is lacking. Some of the reasons offered to explain the increased need for adjunct faculty in higher education include shortage of educators due to retirement, hiring freezes of full-time faculty, and increases in student enrollments (Diegel, 2013; Fjortoft, Mai, \& Winkler, 2011). Adjunct faculty bring real-world experience and practical applications that enhance student learning. Caruth and Caruth (2013) identified the motivation of cost savings realized from hiring adjunct faculty is behind this trend.

\section{Motivator Factors}

Similar to full-time faculty, adjunct faculty members were attracted to the teaching role as a result of altruistic motivators, such as the love of teaching and making a difference with students (Hoyt, 2012; Hoyt et al., 2008; Thirolf, 2012). Despite this motivational commonality between full-time and adjunct faculty, vast differences were demonstrated for adjunct faculty satisfaction factors. In fact, most of the literature found 
regarding adjunct faculty focused on hygiene factors. Little support of motivator factors was found relating to adjunct faculty and included growth or advancement and recognition of achievement factors.

The motivator factor of growth or advancement opportunities were commonly recognized by researchers. Growth or advancement is supported by teacher investment in their learning and educator role enhancement. Professional development availability for adjunct faculty can facilitate growth within the teaching role and improve adjunct faculty retention. Diegel (2013) demonstrated adjunct faculty reports of adequate professional development available. However, several other authors reported the lack of professional development opportunities for adjunct faculty (Caruth \& Caruth, 2013; Clark et al., 2011; Meixner et al., 2010; Thirolf, 2012). A significant barrier noted for adjunct faculty in regard to programs or services offered at the institution is the lack of communication regarding the availability of the supports offered (Meixner et al., 2010).

The motivator factor of recognition of achievement was noted to support faculty retention. Adjunct faculty members reported the lack of acknowledgment in their role. Despite significant presence in higher education institutions, adjunct faculty members reported little recognition of their hard work (Hoyt et al., 2008). Adjunct faculty across higher education indicated lack of recognition and a feeling of being invisible (Gappa \& Leslie, 1993). Recognition of work can incur minimal fiscal investment for the employer, but it was found to result in subsequent improvement in loyalty and retention of adjunct faculty (Hoyt, 2012). 


\section{Hygiene Factors}

The hygiene factors evident in the literature review of adjunct faculty included the following: working conditions, salary, status and job security, supervision, and company policy/administrative practice. Working conditions is the first hygiene factor reviewed to receive frequent reference within the literature. Compared to their full-time counterparts, adjunct faculty members were reported to be more satisfied with their workloads (Antony \& Hayden, 2011). When considering the reduced workload for assignments of adjunct compared to full-time faculty, this finding is expected. Additionally, Hoyt et al. (2008) found that assigning a full-time workload to an adjunct faculty had a negative effect on faculty satisfaction. Retention of adjunct faculty was further supported by facilitating work/life balance and flexibility by allowing faculty to adjust hours worked (Fjortoft et al., 2012; Lodhi et al., 2013) without expectation to teach full-time equivalent loads (Hoyt et al., 2008).

Another common hygiene factor addressed in the literature was the factor of salary and benefit packages. Like full-time faculty, adjunct faculty members were largely reported to be dissatisfied with salary compensation (Caruth \& Caruth, 2013; Diegel, 2013; Hoyt, 2012; Hoyt et al., 2008; Kramer et al., 2014; Thirolf, 2012). The salary compensation for adjuncts was reported as low from two large continuing education departments (Hoyt et al., 2008), social work education (Clark et al., 2011), community colleges (Kramer et al., 2014), and in two- and four-year institutions (Antony \& Hayden, 2011). Only one study reported adjunct faculty members in higher education were satisfied with their salaries (Antony \& Hayden, 2011); however, this finding was in response to a comparison to full-time faculty salary satisfaction and based on data 
collected in 1992 to 1993. Absence of salary increases and lack of incremental increases recognized for the number of years of service was found as a precursor to dissatisfaction of adjunct faculty (Hoyt, 2012). It was suggested that adjunct faculty salary varies significantly from one discipline to another and between colleges and universities. The impact of salary compensation has been noted to produce faculty turnover (Hoyt, 2012). When reviewing salary compensation, the discussion of benefit packages frequently follows. Adjunct faculty members across educational institutions report the lack of benefits hindering satisfaction within the role (Antony \& Hayden, 2011; Hoyt, 2012; Hoyt et al., 2008; Kramer et al., 2014; Thirolf, 2012). Adjunct faculty members also reported that they would like the opportunity to receive other benefits to include tuition reimbursement, medical, and dental benefits (Antony \& Hayden, 2011). However, it is recognized that educational institutions hire adjunct faculty with a cost savings realized from avoiding these types of costs.

The hygiene factor of job security was identified as affecting adjunct faculty satisfaction. Meixner et al. (2010) reported that adjunct faculty were not guaranteed employment from semester to semester and even deactivated from email as a result. This leads to adjunct faculty being hired at the last minute, and fragmented communication with students resulting in inadequate time to prepare for the semester. Job security was, therefore, negatively impacted by a lack of commitment from the institution. This lack of job security negatively affects satisfaction in the role (Antony \& Hayden, 2011; Hoyt, 2012; Hoyt et al., 2008; Thirolf, 2012). Additionally, the lack of basic office space to meet with students and lack of campus email availability resulted in fragmented communication. The lack of job security was evident in the adjunct faculty self-report of 
continuation of employment at other jobs. Reports indicated outside employment to be common. Meixner et al. (2010) reported $73 \%$ of adjuncts were employed outside of the primary part-time teaching role.

The hygiene factor of supervision for adjunct faculty was noted across discipline types and colleges to influence retention and satisfaction. Within higher educational institutions, adjunct faculty members were provided supervision through mentoring processes to facilitate acclimation to the role. Mentoring of adjunct faculty becomes a common theme necessary for success. The availability of adjunct faculty mentoring was reported to range from being available but inadequate (Diegel, 2013) to altogether absent (Clark et al., 2011; Hoyt, 2012; Hoyt et al., 2008; Meixner et al., 2010). The lack of mentoring suggests a lack of commitment from the institution to adjunct faculty. Adjunct faculty desired the teaching observation and one-on-one meetings with the department chair for feedback (Hoyt, 2012). Yet, the amount and type of mentoring needed is individual. Most adjunct faculty members reported a desire for the observation of their teaching with feedback on their work to improve in their roles (Diegel, 2013; Hoyt, 2012). Conversely, one adjunct faculty participant indicated an acknowledged confidence from the chairperson if he or she did not regularly check on the faculty in the teaching role (Diegel, 2013), which may support research that autonomy and independence in the teaching role rated highest for adjunct faculty satisfaction (Boord, 2010; Schulz, 2009; Tomanek, 2010).

The hygiene factor of company policy/administrative practice was the basis of the next theme noted in the literature review. The lack of inclusion in faculty meetings, governance, and social events led to feelings of disconnectedness and isolation for this 
adjunct faculty group (Clark et al., 2011; Diegel, 2013; Hoyt, 2012; Thirolf, 2012). Established policies typically precluded adjunct faculty from participation in collegial meetings. The support of this interpersonal relationship would strengthen the adjunct faculty performance. The majority $(90 \%)$ of social work adjunct faculty report never or only sometimes being included in departmental faculty meetings (Clark et al., 2011). Adjunct faculty members want a voice in decisions made, planning, and inclusion to serve on committees (Hoyt, 2012). Antony and Hayden (2011) suggested bringing adjunct faculty into shared governance and voting rights in departmental decisionmaking. Again with a large presence teaching on campus, inclusion of adjunct faculty is suggested to support satisfaction.

Involving adjunct faculty into the organization at all levels was considered best practice to support satisfaction and assimilation of adjuncts into programs (Clark et al., 2011). Adjunct faculty presence within higher education is predicted to grow. Institutions must support satisfaction of this growing faculty group. Results indicated that job satisfaction was an important precursor to employee retention and resulting loyalty of faculty (Hoyt, 2012). Cultivation and retention of valued adjunct faculty is a necessary institutional investment for colleges.

\section{Full-Time Nurse Faculty}

Nursing education programs rely on full-time nurse faculty to develop curriculum, meet program and accreditation outcomes, and maintain currency and relevancy of content delivered to students. Despite a current shortage of nursing faculty, the prediction of nursing faculty leaving the teaching role is anticipated to worsen with $49 \%$ (Roughton, 2013) to 52\% (Bittner \& O'Connor, 2012) anticipated to leave in the next 5 
years. The full-time nursing faculty role is influenced by factors that promote satisfaction or dissatisfaction and affect continuation of employment within this role. A new approach has been developed to take into consideration the aging nurse educator workforce and entice full-time nursing faculty considering retirement to delay this move and stay in the teaching role (Falk, 2007).

As nurse faculty age, there is a lower risk of intent to leave (Roughton, 2013). In fact, baby boomers were reported most likely to stay in the teaching role (Candela et al., 2013). The reason for this commitment was attributed to greater expertise in the teaching role accrued over time within the role and longevity in the institution with years invested towards retirement. Dempsey (2007) noted that a strong commitment to the organization was characteristic of this age group of employees. Despite these measures to retain an aging population of nurses, retirement will eventually pull them from the teaching role. As a result, supportive mechanisms must be developed to retain the younger generations of faculty. Younger generations of nurses (Generation $\mathrm{X}$ and millennials) were more likely to leave the faculty role due to dissatisfaction (Candela et al., 2013). Although Candela et al. (2013) was unable to identify statistical significance, intent to leave the organization was stronger in younger generations of nurses due to role conflict and lack of teaching expertise. Identification of job satisfaction factors that are supportive of all generations of current nursing faculty are necessary to retain faculty in the role.

\section{Motivator Factors}

The studies of the experience of being a full-time nursing faculty in community college and university settings demonstrated that nurses enter this role for the same altruistic reasons as faculty across higher education. The motivator of the work itself is a 
positive supporter of job satisfaction. Full-time faculty reported entering the faculty role to make a difference and influence students in the profession (Duphily, 2011; Gazza, 2009; Harty, 2008; Lane et al., 2010; Weidman, 2013). However, the motivator factor of the work itself can be challenging for the novice nurse educator. Expert nurses moving into the faculty role in academia reported feeling unprepared for the teaching role (Duphily, 2011; Gazza, 2009). Unique challenges in nursing education give faculty members difficulty as they move from expert clinician into the novice nurse faculty role. This transition from expert clinician to novice nurse educator has been studied within nursing education to include both associate and baccalaureate degree programs.

In a full-time capacity, nursing faculty members are required to have a minimum education credential of a masters' degree and be experientially qualified as specialty (expert) clinicians in the field of nursing. Despite the clinical expertise and the minimum required educational credential of the master's degree, the transition causes apprehension and uncertainty for faculty (Duphily, 2011; Weidman, 2013), which may be exemplified because expert clinicians are reported to lack educational theory basis. The lack of educational theory exacerbates feelings of strain and hampers the transition to the educator role (Schoening, 2013; Weidman, 2013). This deficit was specifically reported for nurse practitioners holding a master's degree but lacking formal educational theory and preparation for the role of nurse educator (Santisteban \& Egues, 2014). Even nurse faculty members with master's degree preparation for the nurse educator role indicated feelings of incompetence and role strain (Cranford, 2013). The transition from clinical expert to novice nurse educator has been studied within the literature with nurse educator transition (NET) model created by Schoening (2013) to support nurse educators. 
The recognition for achievement is a motivator factor found to support nurse faculty satisfaction and retention. Recognition of performance and valuing contributions from faculty support full-time faculty satisfaction (Roughton, 2013). The lack of valuing faculty within this role leads to faculty losses. A mixed group of faculty participants (full-time and adjunct) in baccalaureate degree programs reported a stronger inclination to leave their jobs due to perceptions of not feeling appreciated (Tourangeau et al., 2012).

The motivator factor of growth or advancement is important to full-time nursing faculty members' satisfaction. Opportunity for promotion and career advancement is supportive of faculty satisfaction. Yet, Roughton (2013) found this factor negatively rated for full-time faculty respondents, indicating strong dissatisfaction with advancement in academia. Positive work environments, collegial working relationships, flexible work hours, and administrative support have been found to best support and retain full-time faculty (Evans, 2013; Gazza, 2009).

Responsibility is considered a motivator factor. However, full-time nursing faculty reported high amounts of stress from the responsibility associated with the teaching role (Duphily, 2011; Gazza, 2009). The high stress levels may reduce satisfaction levels within the role as full-time faculty.

\section{Hygiene Factors}

The hygiene factor of working conditions was commonly noted in the literature review to contribute to faculty satisfaction, dissatisfaction, and intent to leave the faculty role. Nurse faculty working full-time in the teaching role also reported balancing multiple jobs simultaneously. Faculty workload beyond teaching consists of the following: student advisement, committee work, scholarship activities, research, and 
service activities (Duphily, 2011; Gardner, 2014; Gazza, 2009). Heavy workloads for full-time nursing faculty were also reported as a result of overload assignments, holding multiple jobs simultaneously, and perceived workloads higher than that of other nonnurse faculty in the college (Bittner \& O'Connor, 2012; Roughton, 2013). The perception of heavy workload may be as individual as the faculty members. Full-time nursing faculty members were dissatisfied with their workload and time demands (Garbee \& Killacky, 2008; Lane et al., 2010; Roughton, 2013). Contrary to these studies is the work of Bittner and O'Connor (2012) who reported that a majority (66\%) of full-time nursing faculty members were satisfied with their workload. However, Bittner and O'Connor (2012) also noted that $71 \%$ of respondents reported nurses' workload as higher than nonnursing faculty within the same institution. This disparity in workload was attributed to the uniqueness and complexity of the nursing faculty role. Faculty perception of academic workload was a significant predictor of intent to leave (Candela et al., 2013). These heavy workloads may explain faculty members' leaving the teaching role due to lack of work/life balance flexibility (Bittner \& O'Connor, 2012).

These factors individually or collectively may produce feelings of role strain. Full-time faculty indicated role strain resulting from exhaustion, never ending work, job related functions, and multiple role expectations (Cranford, 2013). Demands on faculty time were strong factors leading to dissatisfaction (Garbee \& Killacky, 2008). Workload adjustments and flexible schedules were suggested to support retention (Cranford, 2013; Roughton, 2013). A balance of work/life and family was a high contributor to satisfaction for full-time nurse faculty (Lee, 2014; Ruel, 2009). 
Additional responsibilities and requirements can contribute to heavy workload. The type and amount of scholarship required differed from college to university settings. Boyer (1990) indicated the four faculty roles to include: teaching, discovery, application, and integration/synthesis of research. The interpretation of faculty scholarship varies based on type of educational institution. Universities typically require research completion compared to community colleges that require minimal or no research to be done. The requirement of research seemed to increase workload; however, nursing faculty members who enjoyed research activities reported having an increased intent to remain employed in educational institutions that require research (Berent \& Anderko, 2011; Tourangeau et al., 2012).

Similar to faculty across higher education, the hygiene factor of salary and benefit packages were a common factor contributing to dissatisfaction. Nursing faculty have demonstrated being paid less than faculty of other disciplines in higher education (Evans, 2013). The majority of full-time nursing faculty members reported dissatisfaction with their salary (Bittner \& O'Connor, 2012; Lane et al., 2010). In fact, 54\% of faculty reported salary received for teaching as dissatisfying or very dissatisfying (Bittner \& O'Connor, 2012). As a result, faculty salary compensation was a strong factor of dissatisfaction of the teaching role (Bittner \& O'Connor, 2012; Garbee \& Killacky, 2008; Lane et al., 2010; Roughton, 2013). Salary compensation played a major role in the fulltime faculty intent to stay teaching (Garbee \& Killacky, 2008) and was reported to be a reason why full-time nursing faculty leave the role (Bittner \& O'Connor, 2012). Tourangeau et al. (2012) reported increased faculty inclination to leave the teaching role after having salary reduced in response to budget deficits. This finding may have 
contributed to the finding that nursing faculty continue to work two or more jobs simultaneously (Bittner \& O'Connor, 2012; Cranford, 2013). Contrary to salary causing dissatisfaction, longevity in the teaching role contributes to faculty report of merit and cost of living raises supporting satisfaction (Cranford, 2013). In addition to monetary salary, compensation has been found to include benefits. Benefits were found to be a significant factor for full-time nursing faculty satisfaction (Evans, 2013). Salary and benefit package were rated as important for full-time faculty retention (Evans, 2013; Garbee \& Killacky, 2008; Roughton, 2013).

The satisfaction factor of supervision was identified as important to full-time nursing faculty. Supervision was facilitated with orientation and mentoring in the higher education setting. The importance of nursing faculty orientation, support, and mentoring was vital to retaining full-time faculty within this role (Dunham-Taylor, Lynn, Moore, McDaniel, \& Walker, 2008; Duphily, 2011; Gardner, 2014; Gazza, 2009; Sawatzky \& Enns, 2009; Schoening, 2013; Weidman, 2013), which is particularly relevant in consideration of the transition from clinical expert to novice faculty phenomenon reported in the literature. Formal or informal mentoring is necessary for novice nurse educators to observe a seasoned faculty member in the role. The initiation of mentoring for the transition to the faculty role is crucial because it has been found that faculty intent to leave is most uncertain during the first and third years of employment in nursing education (Garbee \& Killacky, 2008). Without proper orientation, support, and mentoring novice faculty members may leave the role.

In addition to mentoring and faculty support, interpersonal relationships as a hygiene factor were crucial to success as a full-time nurse educator. A formal mentoring 
program lays the foundation for the development of these interpersonal relationships. Administrative support, communication between faculty, and communication with students influenced the faculty-perceived role (Duphily, 2011; Gazza, 2009). Interpersonal relationships must be supported between peers as well as with administrative leadership personnel. As a result, support from administration is an effective retention factor for full-time faculty (Evans, 2013). Enculturation of expert nurses into novice educator roles requires this interpersonal relationship building and support. Lack of this relationship building between faculty may contribute to faculty leaving the teaching role (Duphily, 2011).

The nursing faculty shortage can be influenced by the study of job satisfaction and intent to stay. Attrition of full-time faculty provides significant barriers for the acceptance of qualified nursing students into nursing programs. Full-time faculty is responsible for shaping the future of nursing practice (Berent \& Anderko, 2011; Evans, 2013). One example was the study of full-time nursing faculty job satisfaction scoring (motivator and hygiene factors), which demonstrated a moderately positive correlation with intent to stay teaching in baccalaureate degree programs (Derby-Davis, 2014). This kind of exploration can help administrators creatively enhance the teaching experience to promote intent to stay teaching.

\section{Clinical Learning Environment}

Nursing faculty members teach students in the didactic, laboratory, and clinical settings. Many more faculty members are hired to teach in the clinical setting due to limitation in enrollment into clinical sections. Structured limitations of teacher-to-student ratios for clinical settings are established for safe delivery of direct patient care. 
Teaching within the clinical setting may be completed by full-time or adjunct nursing faculty. Increasingly, the largest influx of adjunct faculty in nursing education is found in the clinical setting (Creech, 2008; Forbes et al., 2010). The clinical setting is supervised by a nursing faculty to assure student delivery of safe patient care, compliance with agency policies and procedures, and development of critical thinking skills. The nurse faculty is the most important person involved in a student's clinical education and student success (Housel, Gandy, \& Edmondson, 2010). Clinical learning is an integral component of nursing education with settings for delivery of patient care occurring at inpatient to community-based locations. The clinical setting provides an opportunity for students to apply knowledge gained from the classroom and laboratory areas to the practice setting. The amount of responsibility is high for faculty who teach students in the clinical setting (McDermid et al., 2012). Clinical teaching is complex and requires faculty to guide students to develop problem-solving, decision-making, critical-thinking abilities as well as psychomotor and technological skills (Jamshidi, 2012). Adjunct faculty is noted to be clinically competent due to employment in the field with real-world experience supplementing student learning (Bettinger \& Long, 2010; Duphily, 2011; Landrum, 2009). As a result, these expert nurses are aware of current technologies, medications, treatments, and evidence-based science that effect patient outcomes.

\section{Adjunct Clinical Nurse Faculty}

Adjunct faculty is integral to the teaching of classes across the college campus for student completion of degree requirements. Although both full-time and adjunct nursing faculty can teach in the clinical setting, the reported majority is completed by adjunct faculty (Creech, 2008; Duffy et al., 2008; Forbes et al., 2010; Gazza \& Shellenbarger, 
2010; Wiens, Babenko-Mould, \& Iwasiw, 2014). In fact, Forbes et al. (2010) reported that adjunct nursing faculty taught at a rate of four times that of those adjuncts in the theory component in the clinical setting.

\section{Motivator Factors}

The motivator factor of the work itself becomes a frequently noted area of satisfaction for adjunct clinical nursing faculty. The experience of working as an adjunct clinical nursing faculty was fueled by the altruistic sense of shaping the developing workforce and making a difference (Duphily, 2011; Gazza \& Shellenbarger, 2010; Waltman et al., 2012; Weidman, 2013). This finding was consistent among educators in full-time and adjunct capacities across higher education as well as full-time nurse educators. The motivator factor of growth or advancement was noted for adjunct faculty who accepted an adjunct teaching position in hopes of attaining full-time status (Gazza \& Shellenbarger, 2010).

Professional development becomes an important motivator factor of growth or advancement for this faculty group, particularly in consideration of adjunct nursing faculty members' educational credentials. Roberts, Christman, and Flowers (2013) reported that $28.5 \%$ to $49.5 \%$ (Whalen, 2009) of adjunct faculty members surveyed held only the baccalaureate degree. One author reported that a majority of adjunct nursing faculty held a master's degree but lacked formal teaching or education courses (Forbes et al., 2010). Adjunct faculty members needed additional opportunities for professional growth to supplement their learning of the teaching role, particularly if their educational preparation lacks it. Yet, adjunct nursing faculty reported the lack of professional development opportunities (Forbes et al., 2010; Roberts et al., 2013). 


\section{Hygiene Factors}

The hygiene factor of working conditions was commonly noted in the literature. Studies have shown ways to keep seasoned faculty teaching in the role. Fang and Bednash (2014) reported that $11.2 \%$ of full-time faculty members who left, changed their working status to part-time positions within nursing education. Flexibility of the job with a transition to part-time hours for full-time nursing faculty with a phased retirement can entice aging faculty to stay in the teaching role longer (Foxall et al., 2009). However, a frequent concern identified by typical adjunct nursing faculty includes the hygiene factor of status and job security. Adjunct faculty in nursing education have been established as a flexible workforce that can be hired to quickly fill teaching vacancies (Bettinger \& Long, 2010; Creech, 2008; Murray, 2007). Adjunct nursing faculty reported being hired merely days before the semester was scheduled to begin (Roberts et al., 2013). Adjunct faculty members have expressed their concerns of job satisfaction within the literature pertaining to hygiene factors.

Job security was most commonly attributed to dissatisfaction. Adjunct faculty continues to fulfill the teaching role without long-term contracts or commitments (Bettinger \& Long, 2010). The practice of hiring adjuncts on a course-by-course basis with lack of commitment from the college has led to insecurity in employment. This lack of assurance of stability of employment and reported poor salaries perpetuates the adjunct faculty members' continuation of employment in their field of expertise as a supplementary income source. Whalen (2009) reported $69.2 \%$ of adjunct nursing faculty members work a second job; however, Forbes et al. (2010) reported $91 \%$ hold a full-time position outside of teaching. 
The hygiene factor of salary was also prevalent within the literature review of adjunct clinical nursing faculty. Adjunct faculty has become the pillar of delivery of affordable education in light of economic belt tightening. Adjunct faculty is an economically advantageous answer to fulfilling the increased teaching need, resulting from increased enrollments and/or shortages of qualified full-time faculty. In addition to filling needs of the educational setting in a quick fashion, adjunct faculty members were found to fill this need at a cost savings and work for little or no benefits (Bettinger \& Long, 2010). Poor salary for adjunct faculty was reported consistently within nursing education. Clinical practice salaries are reported to be higher than salaries earned in the faculty position (Bittner \& O'Connor, 2012; Derby-Davis, 2014). Therefore, from the adjunct faculty perspective, there was a pay cut from the clinical practice setting to the educator role (Garbee \& Killacky, 2008). This finding may contribute to reports of the majority of adjunct nursing faculty working a second job (Forbes et al., 2010; Whalen, 2009). A significant factor further contributing to the perceived low salary was reported from nursing faculty correcting student paperwork outside of clinical without compensation for this task (Whalen, 2009).

Little support of adjunct faculty members' hygiene factor of supervision was reported in the literature. Supervision included orientation and mentoring to support the adjunct clinical nursing faculty transition into the role. Inadequate orientation and lack of mentorship led to dissatisfaction in studies focusing on adjunct nursing faculty (Forbes et al., 2010; Roberts et al., 2013).

Similar to adjunct faculty across higher education settings, adjunct nursing faculty reported exclusion from the college governance and decision-making processes (Gazza \& 
Shellenbarger, 2010). A theme of disconnectedness became quickly apparent for adjunct clinical faculty (Cangelosi, Crocker, \& Sorrell, 2009; Forbes et al., 2010; Gazza \& Shellenbarger, 2010; Wiens et al., 2014) with a specific perception of not feeling like a true member of the faculty (Roberts et al., 2013). This adjunct nursing faculty perception of disconnectedness was accentuated by being excluded from faculty meetings (Forbes et al., 2010; Roberts et al., 2013). Upon closer review of the studies completed, particular to the adjunct clinical nursing faculty teaching experience was a theme not present within the full-time faculty experience. A theme of isolation become apparent and may be magnified in clinical nursing education where teaching occurs at off-campus grounds (Whalen, 2009).

Given the enormity of the nursing faculty shortage, the retention of qualified nursing adjuncts hired into teaching roles must become the priority. In fact, a significant turnover of adjunct nursing faculty was identified as a noteworthy finding (Forbes et al., 2010). Despite acknowledgement of the importance of adjunct clinical nursing faculty job satisfaction factors and retention, studies have only been completed in university settings (Forbes et al., 2010; Whalen, 2009). Yet, there are no studies found to address the predictors of $\mathrm{AD}$ adjunct clinical nursing faculty members' intent to stay teaching. There is a dearth of information regarding the factors leading to AD adjunct clinical nursing faculty intent to stay teaching.

\section{Chapter Summary}

A common altruistic theme was found among faculty in higher education, suggesting satisfaction derived from teaching was from the actual practice of teaching and student interaction. Motivator factors became evident across all levels of educators. 
Flexible schedules, reduced workloads (Evans, 2013; Garbee \& Killacky, 2008;

Roughton, 2013), supportive administration, collegial environments (Evans, 2013;

Garbee \& Killacky, 2008; Lodhi et al., 2013), and faculty/colleague relationships were noted as important to faculty (Garbee \& Killacky, 2008; Roughton, 2013). Satisfaction was found to be promoted for faculty with the flexibility of the job with personal lives (Waltman et al., 2012). Full-time and adjunct nursing faculty experience the overwhelming transition from the role of expert clinician to novice nurse educator (Cangelosi et al., 2009; Duphily, 2011; Gazza \& Shellenbarger, 2010; Weidman, 2013). The importance of team support and mentoring became a common theme for both fulltime and adjunct nurse educators (Cangelosi et al., 2009; Duphily, 2011; Weidman, 2013).

Factors that more likely led to faculty dissatisfaction were the hygiene factors. Most commonly found hygiene factors within the literature include the following: salary compensation and benefits, job security, working conditions, supervision, and company policy/administrative practices. Barriers that contributed to adjunct faculty dissatisfaction included the terms of employment (lack of job security) and a sense of a lack of respect from colleagues with exclusion from university governance activities (Waltman et al., 2012). Intention to leave a faculty position was found to stem from issues regarding the following: compensation, retirement, flexibility of work/life balance, and career advancement (Bittner \& O'Connor, 2012; Roughton, 2013).

Intent to leave or more positively stated, the intention to stay teaching, is important to maintain faculty consistency and the highest level of learning for students. Studies of adjunct faculty satisfaction and intent to stay (loyalty) have been studied 
within disciplines outside of nursing (Couch, 2014; Hoyt, 2012); however, these studies took place in private, religiously affiliated institutional settings. Within nursing education, the majority of studies of nursing faculty satisfaction and intent to stay teaching have addressed the full-time nursing faculty workforce (Candela et al., 2015; Derby-Davis, 2014; Garbee \& Killacky, 2008; Lee, 2014; Roughton, 2013; Ruel, 2009). Community colleges are particularly challenged to meet the increasing community needs of education delivery with declining fiscal resource availability, which leads to the increased hiring and reliance on adjunct faculty. There remains a paucity of research to address the satisfaction and intent to stay teaching of adjunct clinical nursing faculty teaching in the community college, despite the notable increase in employment of these staff members. 


\section{Chapter Three}

\section{Methods}

Many scientific studies have researched job satisfaction in of faculty teaching in higher educational institutions (Antony \& Hayden, 2011; Baker, Fitzpatrick, \& Griffin, 2011; Bittner \& O'Connor, 2012; Boord, 2010; Cashwell, 2009; Harty, 2008; Kramer et al., 2014; Lane et al., 2010; McNeil-Hueitt, 2003; Schulz, 2009; Tomanek, 2010; Wagoner, 2007; Whalen, 2009). However, despite the knowledge gained regarding job satisfaction, faculty loyalty (or intent to stay teaching) is a current problem that has been studied limitedly. Within nursing education, job satisfaction and intent to stay teaching of full-time nurse faculty has been studied by Candela et al. (2013), Derby-Davis (2014), Garbee and Killacky (2008), Lee (2014), Roughton (2013), and Ruel (2009). Despite the significant growth noted in hiring of adjunct faculty, studies specific to this teaching group regarding satisfaction and intent to stay teaching are sparse in higher education (Couch, 2014; Hoyt, 2012) and remains absent within the nursing literature. The purpose of this study was to address this significant gap in the nursing education literature related to $\mathrm{AD}$ adjunct clinical nursing faculty predictor factors of intent to stay teaching. This study investigated the relationship between specific demographic variables and job satisfaction factor scores, motivator, and hygiene factors with the intent-to-stay-teaching score. Regression analysis was utilized to determine if a relationship existed between $\mathrm{AD}$ adjunct clinical nursing faculty characteristics (number of years of teaching experience in nursing education, number of years employed as an adjunct at the current institution, age, 
highest level of education completed, and outside employment status) and job satisfaction factors with intent to stay teaching. Job satisfaction factors were rated by participants after author permission was obtained (Appendix B), using the Adjunct Faculty Survey (Appendix C). Intent to stay teaching in academia was rated by participants after author permission was obtained (Appendix D), using the Nurse Educators' Intent to Stay in Academe Scale (Appendix E). Additionally, demographic variables were collected using a researcher developed demographic survey (Appendix F). A quantitative survey approach, using an electronic survey, was most appropriate as an efficient tool to gather data from a large number of adjunct faculty at multiple institutions. This survey delivery method provided an opportunity to study a sample and utilize the gathered numeric data to inference findings to a population (Creswell, 2009). College administrators can utilize these findings to guide hiring practices, plan training, and provide appropriate support for adjunct clinical nurse faculty to promote intent to stay (retention). The resulting reduction in turnover could save time, money, and resources for colleges.

Adjunct faculty members are hired to teach in the classroom, laboratory, and/or clinical settings with a large variation of responsibilities found between these roles. To best reduce confounding variables within this study, participants for this study were limited to $\mathrm{AD}$ faculty who only taught in the clinical component of the course. Additionally, teaching in AD nursing programs varies amongst colleges; therefore, for consistency, this study solicited participants specifically from programs that are accredited by the ACEN in the northeastern US. The research question for this study was: What are the predictors of AD adjunct clinical nurse faculty intent to stay teaching? 


\section{Research Design}

The research design chosen for this study was a quantitative, descriptive, nonexperimental, correlational design because it allowed practical study of a situation as it naturally occurs and provide opportunities to describe relationships between variables (Polit \& Beck, 2012). Furthermore, correlation is a commonly utilized method that provides useful information regarding relationships between variables (Trochim \& Donnelly, 2008). The population for this study included AD adjunct clinical nursing faculty teaching in an ACEN-accredited RN nursing program. Adjunct faculty were deemed eligible to participate if they taught in the clinical component of an $\mathrm{AD}$ registered nursing program within 100 miles of the researcher during the 2015 calendar year. A purposive sampling technique was utilized for this study to specifically recruit adjunct clinical nursing faculty. The Adjunct Faculty Survey, Nurse Educators' Intent to Stay in Academe Scale, and demographic survey were the research instruments utilized for this study. These surveys were compiled into one instrument to measure AD clinical nursing faculty demographic variables of interest, job satisfaction ratings, and intent-to-stayteaching score. The survey questionnaire was distributed using email correspondence including a link to the SurveyMonkey Web site platform. This Web-based survey tool was chosen primarily due to the ease of accessibility for the target population. Data were collected over a 28-day period.

\section{Research Assumptions}

There are a number of assumptions identified with respect to research, instrumentation, and study participants. Underlying this study were the basic assumptions supporting quantitative research. The theoretical foundation selected as the 
framework for the study was assumed to be sound and accurately reflected the adjunct clinical nursing faculty phenomena being studied. It was also assumed that the phenomena under investigation were clearly defined, the variables were measureable, and the instruments measuring the variables were valid and reliable. It was assumed that the instruments Adjunct Faculty Survey and Nurse Educators' Intent to Stay in Academe Scale survey accurately measured the constructs purported to measure. Participants were presumed to comprehend and respond to the survey in similar and congruent ways with honesty and truthfulness. Individuals were anticipated to understand test items similarly with responses anticipated to remain stable over time.

\section{Setting}

The setting for this study was mid-sized AD registered professional nursing programs, which have earned ACEN national accreditation status in the northeastern US. The ACEN is responsible for the specialized accreditation of nursing education programs and is the only national accrediting body for associate degree programs in the US. Clinical nursing adjunct faculty teaching exclusively within the clinical component of the $\mathrm{AD}$ registered professional nursing program within 100 miles of the researcher were eligible to participate in this study.

\section{Sampling Plan}

\section{Sampling Strategy}

The target population for this study was adjunct clinical nursing faculty, teaching in an $\mathrm{AD}$ professional nursing program. The hiring of adjunct faculty is not new to academia; however, a significant increase has been noted. The National Center for Education Statistics (NCES) indicated that $22 \%$ of the faculty were adjunct status in 1970 
compared to 50\% reported in 2011 (NCES, 2012). Noteworthy within nursing education, Duffy et al. (2008) reported $80 \%$ of faculty hired into clinical teaching roles were adjunct status. After attainment of institutional review board (IRB) approval, the Department Head/Director/Chairperson or designee of the AD nursing program was contacted directly through a publically available email address to ask for dissemination of the study information and survey link to adjunct clinical nursing faculty employed in the institution during 2015. The email contained a letter of introduction (Appendix G), which identified the name of the researcher, the organization of affiliation, the purpose of the research, population of interest, the risk and benefits of the study, and assurance of anonymity. The email clearly explained that participation in the study was completely voluntary and with consent attained by indicating "yes," acknowledging consent on the first survey question. The email contained the link that connected to the survey on the SurveyMonkey Web site. A follow up email was sent to the Department Head/Director/Chairperson or designee 2 weeks following the first for re-dissemination of the information and survey link to adjunct clinical nursing faculty once again. The Web site survey remained available for 2 more weeks at which time the survey was closed and data securely downloaded directly from the SurveyMonkey secure server into Microsoft Excel. After data cleaning and reverse coding of negatively worded questions, results were imported into Statistical Package for the Social Sciences (SPSS) for analysis.

To yield the most information about the phenomenon under study, nonprobability, purposive, convenience sampling strategy was utilized. Purposive sampling is the most commonly used non-random sampling method to access a target population (Trochim \& Donnelly, 2008). The target population chosen for this study was AD 
adjunct clinical nursing faculty in the northeastern US because of the significant increase in hiring and utilization of this group to teach in nursing programs.

Purposive sampling let to the potential to have selection bias in this study. Despite the risk of selection bias, the use of this type of sampling focused the study to reveal results relevant to the target population. The population for this study was AD adjunct clinical nursing faculty who self-selected to participate by answering questions on the research instruments via the provided link. Although all participants included within this study were AD adjunct clinical nursing faculty, demographic variables were elicited to better identify characteristics of the surveyed sample. The measurement of variables affecting the intent-to-stay-teaching score was important to identify and enhance the teaching experience for adjunct clinical nursing faculty.

\section{Eligibility Criteria}

Inclusion criteria. Participants were adjunct nursing faculty, teaching exclusively in a clinical setting (in the 2015 calendar year) in an AD professional nursing program within 100 miles of the researcher in the northeastern US. Because adjunct faculty could teach in didactic, laboratory, or clinical settings, only faculty who had a clinical assignment in which they supervised students in the clinical component of the course were asked to participate. Other criteria included that participants had an active email account and must be English language literate.

Exclusion criteria. Adjunct faculty members were excluded from the study if they had not taught in an AD professional nursing program in a clinical capacity within the current calendar year. Faculty who did not hold a current teaching assignment in an AD professional nursing program offered in the northeastern US, faculty whose current 
teaching assignment included didactic or laboratory teaching and clinical assignment, faculty who were not teaching a clinical assignment, and faculty who did not possess English language literacy skills were excluded from the study.

\section{Determination of Sample Size}

Power analysis. Tabachnick and Fidell (2007) suggested the sample size to be greater than $50+8$ times the number of predictors. For this study, the sample size was determined to be at least $98(50+[8 \times 6])$. However, Polit and Beck (2012) suggested a power analysis is a better way to determine a sample size. An a priori power analysis using $\mathrm{G}^{*}$ Power 3.1 was conducted (Heinrich-Heine Universität Düsseldorf, 2014), using a $F$ test: Linear multiple regression fixed model $R^{2}$ deviation from zero. The power analysis was needed to reduce the Type II errors and strengthen validity (Polit \& Beck, 2012). Polit and Beck (2012) support the use of an alpha error probability level of 0.05 . A large effect $(f=0.35)$ was utilized with 6 predictors and an alpha error probability of 0.05 and power of 0.95 to determine that the sample size of 67 participants. The use of an appropriate sample size helps quantitative researchers achieve statistical validity (Polit \& Beck, 2012).

\section{Protection of Human Subjects}

An IRB expedited review approval was obtained from Nova Southeastern University and participating colleges (if IRB was available) prior to initiation of the study. If an IRB was not available at the participating college, Department Head/Director/Chairperson approval was attained. After IRB approval (or Department Head/Director/Chairperson approval), the participating program Department Head/Director/Chairperson was contacted to facilitate survey distribution via email. In 
order to protect the confidentiality of participants in this study, informed consent information was included and thoroughly explained in the introductory email letter. Informed consent was attained by the first question of the survey, authorizing consent. Participants were assured that they could withdraw from the study at any time by exiting the survey. However, as responses were anonymous, there was no way to identify and remove responses once they were submitted and pooled with other responses. Responses were viewed only by the researcher. Findings were reported using group averages in aggregate form only.

Risks and benefits of participation. This research poses limited risks for subjects with consent attained from indicating consent in the first question and subsequent participation in the survey (Polit \& Beck, 2012). Adverse consequences were considered minimal for participants in this study. Adjunct clinical nursing faculty members could feel a certain amount of psychological discomfort as a result of thinking of their employment and rating their job satisfaction, motivator, hygiene factors, and intent to stay teaching. This discomfort may be exhibited in the form of stress or feelings of guilt or nervousness as they participated in the survey. Participants were informed that they could withdraw from the study at any time should those feelings occur. Participation in this study was strictly voluntary, and refusal to participate or withdraw from the study had no penalties. There were no costs or compensation for participation in this study. Participants were informed that findings from the study may be utilized to help nursing leaders understand adjunct clinical nursing faculty demographic variables and job satisfaction factors with intent to stay teaching. The risk of loss of confidentiality 
was minimized by all responses being anonymous and results accessible only by the principle investigator.

Data storage. There was one principle investigator for this study with access to the electronic data findings. All data collected from this study was secured in a password-protected computer, which was stored in a locked file cabinet in the researcher's home to maintain the integrity of the study. The researcher is solely responsible to maintain all data for a period of 3 years, following completion of this study. The researcher is responsible to destroy all survey data results after the three-year period has expired by permanently deleting all computer files.

\section{Procedures}

Following Nova Southeastern University and individual participating college IRB approval (or Department Head/Director/Chairperson approval), the Department Head/Director/Chairperson or designee were contacted for distribution of the study information. A letter of introduction identified the name of the researcher and the organization of affiliation. Furthermore, the letter described the purpose of the research, population of interest, the risks and benefits of the study, and assurance of anonymity. The Department Head/Director/Chairperson or designee distributed the email with letter of introduction and link to the survey to all adjunct clinical nursing faculty employed within their institutions for participation. The survey, housed on the SurveyMonkey Web site, took approximately 15 minutes for participants to complete.

Approximately 2 weeks following the first email and survey dissemination, a follow-up email was sent to the Department Head/Director/Chairperson or designee of the AD professional nursing program. The email asked the Department 
Head/Director/Chairperson or designee to re-disseminate the survey information and link to the adjunct clinical nursing faculty one last time to capture additional participants. The survey remained available for 2 more weeks at which time the survey was closed and data were securely downloaded directly from SurveyMonkey secure server into Microsoft Excel and imported into SPSS for analysis.

Data analysis occurred utilizing the statistical package SPSS 21.0. Prior to analysis, all data were assessed for missing data or outliers. For the demographic questions, dummy coding was utilized for analysis as it was the simplest method for coding categorical data. Dummy coding is utilized when the researcher wants to compare the predictor variables in a group to that as the reference (Trochim \& Donnelly, 2008). Dummy coding was used for the predictor variables with two or more categories to include the following: number of years of teaching experience in nursing education, number of years employed as an adjunct at the current institution, age, highest level of education completed, and outside employment status.

\section{Instrumentation}

The Adjunct Faculty Survey developed by Hoyt (2012) and the Nurse Educators' Intent to Stay in Academe Scale survey by Derby-Davis (2014) were utilized with the authors' permission. The Adjunct Faculty Survey instrument was adapted to have an addition of the word "clinical" to the survey with the author's permission to best acknowledge the study of clinical nursing faculty. A demographic questionnaire was designed to elicit a participant's response to ascertain descriptive information regarding the following: number of years of teaching experience in nursing education, number of years employed as an adjunct at the current institution, gender, age, highest level of 
education completed, ethnicity, and outside employment status. Questions from all survey instruments were combined and presented as one questionnaire to the participants. Instrument 1: The Adjunct Faculty Survey.

The Adjunct Faculty Survey, developed by Hoyt et al. (2007) and later revised by Hoyt (2012), was analyzed for internal consistency and reliability. This tool was created to best elicit adjunct faculty job satisfaction and loyalty (or intent to stay) based on Herzberg's two-factor theory. The hygiene and motivator factors were the basis for the questions in this tool that evaluated adjunct faculty reasons for teaching, faculty support and development, teaching methods, satisfaction, and loyalty. The instrument is comprised of 33 questions. A minimum score rating of 33, indicating strongly disagree, and maximum rating of 198, indicating strongly agree, were possible ratings for these factors. Within the survey, there were negatively worded questions included in the instrument to control for participant tendency to agree with all items regardless of the content. All negatively worded questions were reverse coded during data cleaning.

Validity. The original survey was found to be reliable and valid with a Cronbach's alpha of 0.85 (Hoyt et al., 2007). The final survey had nine subscales and two dependent variables for 33 questions. Scores were collected for each of the factor variables that measured hygiene and motivator factors that were correlated with the overall job satisfaction rating and loyalty (intent to stay). The Adjunct Faculty Survey is suggested to have internal consistency and validity. The exploratory factor analysis was done to establish convergent validity (Hoyt, 2012).

Reliability. The Cronbach's alpha estimates reliability of a measure and internal consistency to determine how the items relate to each other (Trochim \& Donnelly, 2008). 
A Cronbach's alpha with a higher result indicates a stronger association between the variables with 0.7 being an acceptable level to 0.89 for each of the variables (Hoyt, 2012). These results fulfill the conditions of reliability and use for this dissertation study.

Scoring. The instrument is scored on a six-point Likert scale for each item. Descriptors range from 1 (strongly disagree) to 6 (strongly agree) with 5 (agree), 4 (somewhat agree), 3 (somewhat disagree), and 2 (disagree). Questions from the survey were categorized into subscales to include the following: overall job satisfaction, loyalty, recognition, work preference, personal growth, autonomy, faculty support, honorarium, quality of students, teaching schedule, and classroom facilities. Scores for each of the factor subscales were calculated by summing the value of the responses for each of the questions and dividing by the total number of questions in that subscale. A mean score for each factor category and an overall mean score was calculated, with higher scores indicative of feelings of agreement with respondent's satisfaction with that subscale.

\section{Instrument 2: Nurse Educators' Intent to Stay in Academe Scale}

The Nurse Educators' Intent to Stay in Academe Scale survey, created by DerbyDavis (2014) is a 13-item, self-report instrument developed to explore the factors that predict nursing faculty members' intent to stay in academe. This study utilized the instrument for implementation to best identify AD adjunct clinical nursing faculty members' perception of the clinical and academic environment relevant to their teaching experience.

Validity. This tool was developed by Derby-Davis (2014) on the basis of literature review. The survey was further reviewed by four expert nurse educators to confirm face and content validity. 
Reliability. Derby-Davis (2014) estimated high reliability of this survey tool. A Cronbach's alpha of 0.898 was revealed when utilized for full-time nursing faculty working in academia in Florida. Again, utilizing 0.7 as an acceptable Cronbach's alpha (Polit \& Beck, 2012), this tool was considered to meet the conditions of reliability for this dissertation study.

Scoring. The survey scoring included a rating scale of 1 (strongly disagree) to 4 (strongly agree). The total minimum score for this instrument is 13 , indicating strongly disagree with a maximum score of 52, indicating strongly agree. Scores were calculated by summing the value of the responses for each of the questions.

\section{Instrument 3: Demographic Survey}

A demographic survey was created by the researcher to elicit information regarding participants of this study. This survey asked participants to provide background information, including the number of years of teaching experience in nursing education, number of years employed as an adjunct at the current institution, gender, age, highest level of education completed, ethnicity, and outside employment status. Demographic questions provided descriptive statistics regarding the sample group. However, gender and ethnicity data were exclusively elicited for this purpose. Gender options included choice of male or female. Ethnicity category choices included the following: White, Black or African-American, American-Indian or Alaska Native, Asian, Native Hawaiian or other Pacific Islander, multiple races, or other (please specify). In addition to understanding the demographic make-up of this faculty group, the purpose of this survey was to use the information collected for comparative statistical analyses. Each subsequent demographic variable was chosen for analysis due to relevance 
anticipated with the dependent variable of intent to stay teaching. Survey questions eliciting the number of years of teaching experience in nursing education and the number of years employed as an adjunct at the current institution asked participants to reveal their response in years (rounded to the nearest whole number). Responses to these questions included the following categories: less than 1 year, 1 to 2 years, 3 to 4 years, 5 to 6 years, or more than 6 years. The demographic question regarding participant age asked participants to indicate their age in years. The results of reported age were utilized to identify the mean age of the participant group and to categorize participant age for analysis.

Other demographic questions elicited the highest level of education completed and outside employment status. The highest level of education completed identified the proportion of adjunct clinical nurse faculty with the qualifications of a BSN, Master's Degree in Nursing, master's degree in another field, Doctor of Nursing Practice (DNP), and those with a Doctor of Philosophy $(\mathrm{PhD})$ degree. The survey question regarding outside employment status was useful in understanding the employment status of adjuncts outside of their adjunct positions at the institution. Choices included the following: no employment outside of this adjunct position, work another part-time job in academia, work another part-time job in the field, work full-time outside of this employment, or other (please specify).

\section{General Statistical Strategy}

A consolidated questionnaire was developed from all three survey instruments for use in this study. The Department Head/Director/Chairperson or designee of identified AD nursing programs were sent an email after IRB approval or Department 
Head/Director/Chairperson approval for dissemination of the email introductory letter and survey link to all currently employed adjunct clinical nursing faculty in their institutions during the 2015 calendar year. After all data were collected, descriptive and comparative analysis was used to analyze AD clinical nursing faculty demographic variables and job satisfaction with influence on the intent to stay teaching. Survey responses were exported from the secure SurveyMonkey Web site into Microsoft Excel and uploaded into SPSS. The SPSS software was housed securely on a passwordprotected computer secured in a locked office. Demographic data was aggregated for reporting. Assessment of normality, linearity, and homoscedasticity between the dependent variable scores and errors of prediction should be and were tested (Tabachnick \& Fidell, 2007). The variables were assessed for normality by evaluating the distribution of the sample obtained. Linearity was established by assessing the relationship between the dependent variable and the independent variables. Homoscedasticity was established when there was an equal variance in the scores of dependent and independent variables. Lastly, independence was confirmed when each value was independent and not related to any other predictor value (Tabachnick \& Fidell, 2007). Prior to data analyses, diagnostic methods were conducted to assure none of these assumptions were violated.

\section{Data Cleaning}

All data was visually examined for completeness before entry into SPSS (Polit \& Beck, 2012). All negatively worded questions were reverse coded to accurately reflect respondent's answers. In addition, a quality check was conducted to assure accuracy of data transcription. 


\section{Descriptive Statistics}

Prior to analysis, all data were assessed for missing data or outliers. Descriptive statistics were utilized to present data regarding the sample of adjunct clinical nursing faculty participating in this study. A frequency distribution was observed in chart form using descriptive statistics for frequency, means, standard deviations, and ranges to support the assumption that variables are distributed normally (Polit \& Beck, 2012). Descriptive statistics described the sample and provided means and measures of central tendency for the variable scores.

\section{Reliability Testing}

The responses to the question items were entered into SPSS and analyzed, utilizing multiple regression analysis to identify correlations of the subscale items with intent to stay teaching. A Cronbach's alpha reliability coefficient score was calculated on the data using SPSS 21.0 software. Alpha coefficients were considered to assess the extent of internal consistency between items of the instrument acceptable with a result of 0.7 with a statistical significance of $p \leq 0.05$ as significant to reduce Type I error (Polit \& Beck, 2012). Research hypotheses were evaluated with a null hypothesis accepted with alpha coefficients less than the postulated value.

\section{Hypothesis Testing}

Research Hypothesis 1. There is a positive relationship between the AD adjunct clinical nursing faculty demographic variables (number of years of teaching experience in nursing education, number of years employed as an adjunct at the current institution, age, and highest level of education completed) and job satisfaction score with intent-to-stayteaching score. It was further hypothesized that a negative relationship was present for 
AD adjunct clinical nursing faculty demographic variable outside employment status with the intent-to-stay-teaching score. The inclusion of multiple independent variables, also called predictor variables, can improve identification of a relationship with a dependent variable (Polit \& Beck, 2012). This relationship was tested by means of multiple regression analysis with dummy coding. Categorical variables are coded as dichotomous dummy variables to assure that the results are interpretable (Polit \& Beck, 2012). Multiple correlation coefficients explain the extent of the correlation of one variable with another. The $R$ varies from 0.00 to 1.00 showing the strength of the relationship between several categorical independent variables (demographic variables) and a dependent variable (intent to stay teaching). The $R^{2}$ allows a manor for a researcher to evaluate the proportion of variance accounted for by the independent variables (Polit \& Beck, 2012). A correlation was considered significant with a $p$ value of less than or equal to .05.

Research Hypothesis 2. There is a positive relationship between adjunct faculty reported levels of motivator factor scores and intent-to-stay-teaching score after controlling for select demographic variables. This hypothesis was tested using multiple regression analysis. The independent variables were the subscale levels of motivator factor scores. The dependent variable was the intent-to-stay-teaching in academe score. Multiple regression is a statistical method utilized to analyze the relationship between a dependent variable and several independent variables (Tabachnick \& Fidell, 2007). This test can be used to better understand a phenomenon and explore the importance of the independent variables (Polit \& Beck, 2012). Correlation coefficients explain the extent of one variable associated with a variation of another variable (Polit \& Beck, 2012). A correlation coefficient was represented as $R^{2}$ with the accuracy of prediction represented. 
This variability was expressed in a percentage with a higher percentage indicating a stronger correlation with a $p$ value of less than or equal to .05 considered significant.

Research Hypothesis 3. There is a positive relationship between faculty reported levels of hygiene factor score and intent-to-stay-teaching score after controlling for select demographic variables. This hypothesis was tested using multiple regression analysis. The independent variables were the subscale levels of hygiene factor scores. The dependent variable was the intent-to-stay-teaching score. A multiple regression analysis is most appropriate for this research hypothesis with a $p$ value of less than or equal to .05 considered statistically significant.

Research Hypothesis 4. There is a positive relationship between levels of reported hygiene and motivator scores and intent-to-stay score after controlling for selected demographic variables. A multiple regression analysis was conducted to identify how the hygiene and motivator scores predicted intent to stay. The independent variables were the motivator and hygiene variables. The dependent variable was the intent to stay teaching. Multiple linear regression analysis was used to determine if a significant relationship existed between the variables. A correlation was considered significant (meaning not due to chance) with a $p$ value of less than or equal to .05 .

\section{Chapter Summary}

This chapter described the research design and methodology that was utilized in this study. This study was developed to address a significant gap in the nursing education literature regarding AD adjunct clinical nursing faculty demographic variables and job satisfaction factors that impacted intent to stay teaching. This quantitative, descriptive, non-experimental, correlational study tested four hypotheses: 
1. There is a positive relationship between select $\mathrm{AD}$ adjunct clinical nursing faculty demographic variables (number of years of teaching experience in nursing education, number of years employed as an adjunct at the current institution, age, and highest level of education completed) and job satisfaction score with intent-to-stay-teaching score. It was further hypothesized that a negative relationship would be present for $\mathrm{AD}$ adjunct clinical nursing faculty demographic variable of outside employment status with intent-to-stayteaching score.

2. There is a positive relationship between $\mathrm{AD}$ adjunct clinical nursing faculty reported subscale levels of motivator factor scores and intent-to-stay-teaching score after controlling for select demographic variables.

3. There is a positive relationship between $\mathrm{AD}$ adjunct clinical nursing faculty reported subscale levels of hygiene factor scores and intent-to-stay-teaching score after controlling for select demographic variables.

4. There is a positive relationship between $\mathrm{AD}$ adjunct clinical nursing faculty reported levels of job satisfaction (hygiene and motivator factor scores) and intent-to-stay-teaching score after controlling for select demographic variables.

After IRB approval or permission was received to complete the study, an email was sent to the Department Head/Director/Chairperson asking for dissemination of the email introductory letter and survey link to adjunct clinical nursing faculty employed in the institution during the 2015 calendar year. Data was collected specifically from AD professional nursing programs in the northeastern US within 100 miles of the researcher. 
Consideration for the protection of the individuals who chose to participate was assured throughout the entirely of the study. Data was collected utilizing a survey format maintained on a secure SurveyMonkey Web site. Results were analyzed, utilizing the statistical measure identified in the study. Results were reviewed to identify significant correlations between the independent variables and the dependent variable. 


\section{Chapter Four}

\section{Results}

This chapter describes the process for the data collection, reported descriptive statistics, hypothesis testing, and results of the data analyzed for the research question tested. The purpose of this quantitative, descriptive, non-experimental, correlational study was to contribute to the overall understanding of AD adjunct clinical nursing faculty and examine the relationship between the demographic variables, job satisfaction, motivator, and hygiene scores with intent-to-stay-teaching score.

Study implementation took place during the fall semester of 2015. The data for this study were collected using the Adjunct Faculty Survey (2012) and the Nurse Educators' Intent to Stay in Academe Scale survey (Derby-Davis, 2014). In addition, demographic data was collected from all participants. The instruments were combined and presented to participants as a single questionnaire and was administered through the online survey platform SurveyMonkey. Six associate degree nursing programs in the northeastern US within 100 miles of the researcher were contacted and agreed to participate in the research study. The Department Head/Director/Chairperson distributed the email introductory letter and link to the online survey via email to all adjunct clinical nursing faculty members employed during the 2015 calendar year. After 2 weeks, a reminder email was sent and distributed one more time to achieve the highest potential response rates (Polit \& Beck, 2012) and capture all potential participants. After 2 additional weeks, the minimum participant levels were attained and the survey was 
closed. A total of 112 adjunct clinical nursing faculty members were sent the email and link to the survey. Sixty-nine participants agreed to take part in the study. However, of the 69 participants, only 52 completed the questionnaire in its entirety. The resulting participant group numbered 52 for a total response rate of 46\%. Polit and Beck (2012) reveal response rates of greater than $65 \%$ reduces the risk of bias; however, lower rates of response are considered the norm for mailed surveys with Internet survey responses often being lower than the mailed surveys. Informal feedback from Department Heads/Directors/Chairpersons to the researcher indicated that some adjunct faculty members reported being too new to the role and did not feel that they had the ability to complete the entire survey.

\section{Data Cleaning}

During this study, 69 surveys were collected. Responses were downloaded directly from the SurveyMonkey secure server into Microsoft Excel format and examined for completeness. Responses were reviewed to identify any surveys lacking responses (Polit \& Beck, 2012). Fifty-two participants completed the questionnaire in its entirety; however, 61 participants completed the demographic portion of the survey only. Purposeful coding of missing variables was completed to preserve data collected for analysis in SPSS (Polit \& Beck, 2012).

All negatively worded questionnaire items in the Adjunct Faculty Survey were reverse coded as directed by the author to establish a clear indication of the survey participant's responses. Demographic variable responses were dummy coded to compare the predictor variables to the group referenced, utilizing regression analysis. As the data entry process may result in transcription error (Polit \& Beck, 2012), the entered data was 
subsequently rechecked for accuracy and completeness. Consistency checks were completed to internally evaluate the consistency and accuracy of entered data to support data verification (Polit \& Beck, 2012). After verification, data was uploaded into SPSS version 21 for statistical analysis. The data were analyzed using descriptive, correlational, and multiple regression analysis procedures.

The first step in the data analysis procedures was for the purpose of identifying demographic characteristics of the participant group. The satisfaction factor, motivator factor, hygiene factor, and intent-to-stay score responses were summed. The summed scores were utilized for the analysis. Data was entered into SPSS and analysis was conducted to identify any potential outliers. The data were assessed for potential violations of the basic assumptions of normality utilizing frequency tables, histograms, boxplots, scatterplots, quartile-quartile plots (Q-Q plots), multicollinearity, DurbinWatson, kurtosis, and Shapiro-Wilk statistics (Tabachnick \& Fidell, 2007). Additionally, all data were screened via SPSS software for univariate and multivariate outliers (Tabachnick \& Fidell, 2007), including multivariate normality, multicollinearity, and singularity.

\section{Descriptives}

The purpose of this quantitative, descriptive, non-experimental, correlational study was accomplished by surveying adjunct clinical nursing faculty teaching in AD nursing programs in the northeastern US. Drawing from a target population of 112 adjunct clinical nursing faculty members teaching in AD nursing programs, 61 adjunct clinical faculty members completed the demographic portion of the study. The descriptive statistics were computed to describe the sample characteristics. The survey 
provided demographic data regarding the adjunct clinical nursing faculty members' number of years teaching experience in nursing education, number of years employed as an adjunct at the current university, age, highest level of education completed, gender, ethnicity, and employment status outside of the adjunct position. By gathering this information the researcher was better able to understand the participant group.

\section{Description of the Sample}

Years of teaching experience in nursing education. The attributes of the participants who responded to this survey were described by the demographic data responses. Participants were asked the number of years of teaching experience in nursing education. Fourteen $(23 \%)$ out of the 61 participants indicated that they had more than 6 years of experience, and $14(23 \%)$ indicated 3 to 4 years of experience teaching in nursing education. An additional 13 (21.3\%) indicated less than one year, $12(19.7 \%)$ indicated 5 to 6 years, and eight $(13.1 \%)$ indicated 1 to 2 years of experience teaching in nursing education.

Years teaching within the current institution. Next, participants were asked the number of years employed at the current institution. Results indicated that 21 $(34.4 \%)$ out of 61 participants had 3 to 4 years of employment at the current institution, followed by 17 (27.9\%) with less than 1 year. An additional eight (13.1\%) participants had taught for more than 6 years, eight $(13.1 \%)$ for 1 to 2 years, and seven $(11.5 \%)$ for 5 to 6 years at the current institution.

Age. In addition to identifying the number of years of teaching experience in nursing education and the number of years employed at the current institution, participant age was elicited. The purpose of eliciting participant age is informative to understanding 
the make-up of the participant group. Of this participant group, participant's ages ranged from 23 to 76 with a mean age of 46.38. The age of the participants was categorized into generational groups frequently referred to within the literature. Twenty-four (39\%) out of the 61 participants were found to belong to the baby boomer generational group followed by $23(38 \%)$ noted in the Generation X group, $13(22 \%)$ in the millennial generational group, and one (2\%) from the veteran generational group. Alternatively, categorization of participant ages by typical age groupings was also completed and demonstrated a majority were between 45 to 54 years old, followed by ages 55 to 64,25 to 34,35 to 44,24 years and younger, and 65 years or older (see Table 1). 
Table 1

Sample Demographic Characteristics

\begin{tabular}{|c|c|c|}
\hline Characteristic & $n$ & $\%$ \\
\hline \multicolumn{3}{|l|}{ Age } \\
\hline 24 and under & 2 & 3.2 \\
\hline $25-34$ & 11 & 18 \\
\hline $35-44$ & 6 & 9.8 \\
\hline $45-54$ & 24 & 39.3 \\
\hline $55-64$ & 17 & 27.9 \\
\hline 65 and over & 1 & 1.6 \\
\hline \multicolumn{3}{|l|}{ Highest level of education completed } \\
\hline Baccalaureate Degree in Nursing & 18 & 29.5 \\
\hline Master's Degree in Nursing & 39 & 63.9 \\
\hline Master's Degree in another field & 2 & 3.3 \\
\hline $\mathrm{PhD}$ in Nursing & 0 & 0 \\
\hline DNP & 2 & 3.3 \\
\hline \multicolumn{3}{|l|}{ Gender } \\
\hline Male & 2 & 3.3 \\
\hline Female & 59 & 96.7 \\
\hline \multicolumn{3}{|l|}{ Ethnicity } \\
\hline White & 57 & 93.4 \\
\hline Black/African-American & 1 & 1.6 \\
\hline American Indian or Alaskan Native & 0 & 0 \\
\hline Asian & 1 & 1.6 \\
\hline Native Hawaiian or other Pacific Islander & 0 & 0 \\
\hline From multiple races & 2 & 3.3 \\
\hline Some other race & 0 & 0 \\
\hline \multicolumn{3}{|l|}{ Outside Employment Status } \\
\hline No employment outside of adjunct position & 12 & 19.7 \\
\hline Work another part-time job in academia & 7 & 11.5 \\
\hline Work another part-time job in the field & 7 & 11.5 \\
\hline Work full-time outside of this employment & 30 & 49.2 \\
\hline Other & 5 & 8.2 \\
\hline Total & 61 & 100 \\
\hline
\end{tabular}

Note: $N=61$.

Highest level of education completed. In addition to identification of participant age, the highest level of education completed was elicited. A majority of participants indicated that they held a Master's Degree in Nursing, followed by the Baccalaureate Degree in Nursing, master's degree in another field, and DNP (see Table 1). One 
participant indicated that she held both a Master's Degree in Nursing and a master's degree in another field. This participant was included in the grouping reported as master's degree in nursing.

Gender and ethnicity. In addition to identification of the highest level of education completed, adjunct clinical nursing faculty gender and ethnicity makeup was elicited. The identification of the gender and ethnicity demographic is helpful to understanding the participant group. Gender responses indicated that a majority of participants were female gender with only two reported as male gender (see Table 1). Ethnicity data reported that the majority of participants were of the White race, followed by multiple races, Black, and Asian ethnicity (see Table 1).

Current employment status. Building upon the demographic variables of number of years in nursing education, number of years employed at the current institution as an adjunct, age, highest level of education completed, gender and ethnicity, the survey elicited data regarding the outside employment status of adjunct participants. The purpose was to gain a better understanding of the employment status of adjunct clinical nursing faculty teaching outside of the adjunct position in the associate degree nursing program. A majority of the participants indicated that they worked another full-time job, followed by no employment outside of the adjunct position, another part-time job in the field, part-time job in academia, and "other" employment statuses (see Table 1). Participants reported other outside employment statuses to include the following: maintaining more than two jobs (reported by three participants), working full-time and part-time (reported by one participant), and working per diem (reported by one participant). 


\section{Responses to the Measurements}

Adjunct faculty survey. The Adjunct Faculty Survey by Hoyt (2012) consisted of 33 items grouped into three categories for this study to evaluate job satisfaction, motivator factors, and hygiene factors in the teaching role. Of the 33 total questions, the Adjunct Faculty Survey contained six questions measuring overall job satisfaction, nine questions measuring motivator factors, and 18 questions measuring hygiene factors.

Participants rated each item on a scale of 1 (strongly disagree) to 6 (strongly agree). The processes utilized for this dissertation study were consistent with those utilized in the past for this instrument.

Job satisfaction. Questions were grouped according to the category in each subscale. The first subscale was job satisfaction. The total summed score possible included a minimum of six to a maximum of 36 for the satisfaction score questions. The mean satisfaction score was 29.42 (see Table 2). 
Table 2

Descriptive Statistics and Reliability Coefficients for Each Subscale

\begin{tabular}{|c|c|c|c|c|c|c|c|}
\hline & $N$ of items & $\begin{array}{l}\text { Minimum } \\
\text { value }\end{array}$ & $\begin{array}{l}\text { Maximum } \\
\text { value }\end{array}$ & $M$ & Variance & $S D$ & $\alpha$ \\
\hline $\begin{array}{l}\text { Motivator factor score } \\
(N=57)\end{array}$ & 9 & 26 & 52 & 43.65 & 26.55 & 5.15 & .73 \\
\hline $\begin{array}{l}\text { Hygiene factor score } \\
(N=53)\end{array}$ & 18 & 53 & 97 & 77.09 & 111.40 & 10.55 & .81 \\
\hline $\begin{array}{l}\text { Job satisfaction score } \\
(N=53)\end{array}$ & 6 & 18 & 36 & 29.42 & 22.32 & 4.73 & .86 \\
\hline $\begin{array}{l}\text { Intent to Stay score } \\
(N=52)\end{array}$ & 13 & 27 & 49 & 38.33 & 33.24 & 5.77 & .83 \\
\hline
\end{tabular}

The questions from this survey that related to satisfaction included overall job satisfaction and loyalty categories. Table 3 reveals the alpha values for these categories to be .72 and .86 respectively. 
Table 3

Adjunct Faculty Survey Alpha Values for Each Category Within the Subscale

\begin{tabular}{lccc}
\hline & Current Study & Hoyt Study & Hoyt et al. Study \\
& .72 & $(2012)$ & $(2008)$ \\
\hline Overall job satisfaction & .86 & .78 & .85 \\
Loyalty & .45 & .74 & $*$ \\
Autonomy & .72 & .73 & .82 \\
Classroom facilities & .90 & .80 & .85 \\
Compensation & .82 & .89 & .94 \\
Faculty support & .85 & .77 & .86 \\
Personal growth & .58 & .72 & $*$ \\
Quality of the students & .58 & .79 & .87 \\
Recognition & .60 & .82 & .87 \\
Teaching schedule & .62 & .62 & .67 \\
Work preference & & .69 & \\
\hline
\end{tabular}

Note: The Hoyt et al. study in 2008 did not have questions for loyalty and personal growth.

Motivator factor score. The next subscale from the Adjunct Faculty Survey was the motivator score. The total summed score possible for this sub-scale was a minimum of 9 to a maximum of 54. Results from this study indicated the mean motivator score of 43.65 (see Table 2). The questions from this survey tool that addressed motivator score include personal growth, recognition, and work preference. Table 3 reveals the alpha values of $.85, .58$, and .62 , respectively.

Hygiene factor score. The final subscale was the hygiene score. The total summed score possible for this sub-scale was a minimum of 18 to a maximum of 108 . 
Results from this study indicated the mean hygiene score of 77.09 (see Table 2). The questions from the survey tool that addressed the hygiene score are included (see Table 3) with their associated alpha value: autonomy (.45), classroom facilities (.72), compensation (.90), faculty support (.82), quality of students (.58), and teaching schedule (.60). The standard deviation for the hygiene factor score was noted to be high with a value of 10.554. This large standard deviation is explained by the large range of possible scores for this factor and resulting minimum score of 53 and a maximum score of 97. Additionally, the hygiene factor score included 18 items in comparison to the other subscales, including nine items for motivator factor, six items for job satisfaction, and 13 items for intent-to-stay score (see Table 2). As a result of these influences, the standard deviation for the hygiene factor score is twice that of the other subscale scores.

Additional review of the hygiene factor score via histogram (Figure 1) indicated a normal curve and normal distribution. As a result of this review, the hygiene factor scores were recognized as acceptable for this dissertation study.

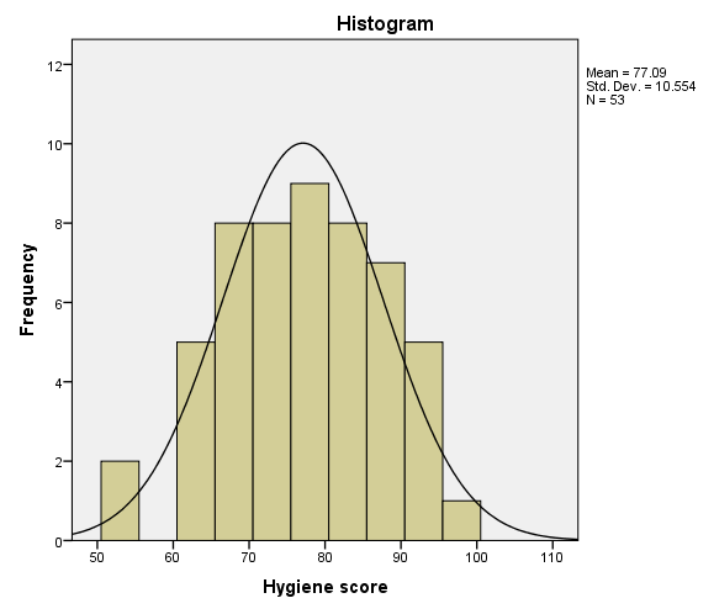

Figure 1. Histogram display. Histogram display of participant responses to hygiene factor score with normal curve overlay revealing normative distribution of data. 


\section{Nurse educators' intent to stay in academe scale survey. The Nurse}

Educators' Intent to Stay in Academe Scale survey developed by Derby-Davis (2014) was utilized to identify the participant group's (adjunct clinical nursing faculty) intent to stay in the teaching role. This tool consists of 13 items where participants rated each item on a rating scale of 1 (strongly disagree) to 4 (strongly agree). The overall score for this tool ranged from a minimum of 13 to maximum score of 52. The mean intent to stay score was 38.33 (see Table 2). Higher score results equated to stronger levels of intent to stay in the teaching role. In order to run this analysis, the summed data for each of the questions were loaded into SPSS and analyzed utilizing the scale analysis feature.

\section{Reliability Testing}

\section{Adjunct Faculty Survey}

The first tool utilized for this research study was the Adjunct Faculty Survey. In order to determine if the surveys were internally consistent, it was necessary to estimate if the tools were reliable to measure the findings they were intended to measure (Polit $\&$ Beck, 2012). Reliability of each subscale was measured by conducting a Cronbach's alpha analysis in SPSS. A normal range of Cronbach's alpha is .00 to +1.00 (Polit \& Beck, 2012) with a higher value indicating more reliable results. The significance level was set for an alpha level of .05 or less (Munroe, 2005). In order to run the analysis, raw data were loaded into SPSS and analyzed using the scale analysis feature.

Questions were grouped according to categories for scale analysis to be conducted. The categories included the following: overall job satisfaction, loyalty, autonomy, classroom facilities, compensation, faculty support, personal growth, quality of the students, recognition, teaching schedule, and work preference. Results from each 
of the categories from the dissertation study showed consistency with prior studies utilizing the Adjunct Faculty Survey (see Table 3). Alpha ratings from the dissertation study noted to be lower compared to prior studies, which included autonomy, quality of the students, recognition, and teaching schedule. After review of the areas of differences, it seemed possible that the differences may lie in the setting of the research being completed at community colleges compared to the prior studies being completed at university settings. Community colleges offer open admission for students with a range of abilities (Murray, 2007). Open admissions offers educational opportunities for students with varied academic backgrounds, allowing any high school graduate who is eligible to attend (The College Board, n.d.). Nursing programs typically hold higher enrollment criteria; however, the type of educational setting noted as a community college may have affected adjunct faculty members' impression of the quality of the students. Additional consideration of the study population chosen for this study was specific to faculty teaching only in the clinical arena. Prior studies investigated satisfaction and intent to stay for adjunct faculty teaching in university settings in the classroom arena (Bittner \& O'Connor, 2012; Hoyt, 2012; Hoyt et al., 2008). Flexibility in autonomy and teaching schedule is known to the researcher to be lacking for clinical faculty as full-time faculty typically chose the textbooks, develop syllabi, and decide the content and clinical experiences of the curriculum being taught. Adjunct faculty members typically do not have input into these processes as their responsibilities are primarily to the clinical setting. Lastly, the category of recognition was also noted to have a low alpha by adjunct clinical nursing faculty. This finding is supported in the 
literature commonly referring to adjunct faculty as the invisible faculty (Gappa \& Leslie, 1993).

Internal consistency. The coefficient alpha (Cronbach's alpha) was utilized to determine the internal consistency of each category for the tools in the dissertation research study. The Adjunct Faculty Survey had three subscales (see Table 2), including the following: job satisfaction score (consisting of overall job satisfaction and loyalty), motivator factor score (consisting of personal growth, recognition, and work preference), and hygiene factor score (consisting of autonomy, classroom/clinical facilities, compensation, faculty support, quality of the students, and teaching schedule). The subscale of job satisfaction included six questions and showed a Cronbach's alpha of .86 . The subscale motivator factor score included nine questions and showed a Cronbach's alpha of .73. The subscale hygiene factor score included 18 questions and showed a Cronbach's alpha of .81. The results indicated that the Adjunct Faculty Survey scores (see Table 3) were consistent with the original study by Hoyt et al. (2008) and a more recent study by Hoyt (2012). Each question within the Adjunct Faculty Survey was additionally evaluated for item-total reliability and alpha if the item were to be deleted (see Table 4). 
Table 4

Internal Consistency of the Adjunct Faculty Survey

\begin{tabular}{|c|c|c|}
\hline & $\begin{array}{c}\text { Corrected } \\
\text { Item-Total } \\
\text { Correlation } \\
\end{array}$ & $\begin{array}{l}\text { Alpha if } \\
\text { Deleted }\end{array}$ \\
\hline \multicolumn{3}{|l|}{ Job Satisfaction Subscale } \\
\hline I am completely satisfied with my job teaching as an adjunct faculty member at the university. & .76 & .82 \\
\hline I am dissatisfied with aspects of my job as an adjunct faculty member. & .37 & .90 \\
\hline Considering everything, I have an excellent job as an adjunct faculty member. & .79 & .82 \\
\hline I would highly recommend teaching at the university to other qualified people. & .82 & .80 \\
\hline I would prefer to teach somewhere else instead of at the university. & .64 & .84 \\
\hline I am very proud to tell others that I teach at the university. & .69 & .83 \\
\hline \multicolumn{3}{|l|}{ Motivator Factor Subscale } \\
\hline I really enjoy teaching courses. & .60 & .68 \\
\hline I almost always look forward to teaching courses. & .61 & .68 \\
\hline I would prefer to do work other than teaching. & .27 & .73 \\
\hline $\begin{array}{l}\text { I have enhanced my teaching ability by learning several new teaching methods or techniques during this past } \\
\text { year. }\end{array}$ & .39 & .71 \\
\hline My teaching skills and abilities have substantially improved this past year. & .52 & .69 \\
\hline I am putting in extra time and effort to become a better teacher. & .58 & .69 \\
\hline I am often thanked for teaching here. & .51 & .69 \\
\hline I rarely receive any appreciation for teaching part time at the university. & .06 & .79 \\
\hline Adjunct faculty is recognized for their teaching contribution at the university. & .40 & .71 \\
\hline \multicolumn{3}{|l|}{ Hygiene Factor Subscale } \\
\hline I am required to teach at times that are inconvenient for me. & .26 & .81 \\
\hline The times that I teach my classes (clinical) work well with my other commitments. & .42 & .80 \\
\hline The time scheduled for my classes (clinical) has been convenient. & .37 & .80 \\
\hline I am completely satisfied with the quality and caliber of students in my classes (clinical). & .38 & .80 \\
\hline Students lack motivation or the academic skills to succeed in my courses. & .44 & .80 \\
\hline Students here are highly engaged and very interested in their academic work. & .35 & .80 \\
\hline I have a lot of freedom to develop and modify course content to meet the needs of my students. & .44 & .79 \\
\hline
\end{tabular}

(continued) 


\begin{tabular}{|c|c|c|}
\hline & $\begin{array}{c}\text { Corrected } \\
\text { Item-Total } \\
\text { Correlation }\end{array}$ & $\begin{array}{l}\text { Alpha if } \\
\text { Deleted }\end{array}$ \\
\hline I have a satisfactory level of autonomy to select material or texts for my courses. & .19 & .81 \\
\hline I would like more freedom to determine the content, materials, or texts for my courses. & .27 & .80 \\
\hline $\begin{array}{l}\text { Full-time faculty or department chairs on the main campus are always available and accessible to me when I need } \\
\text { assistance. }\end{array}$ & .38 & .80 \\
\hline $\begin{array}{l}\text { Full-time faculty and department chairs on the main campus lack interest and care very little about my success as } \\
\text { a teacher. }\end{array}$ & .37 & .80 \\
\hline $\begin{array}{l}\text { I feel very comfortable requesting assistance from full-time academic faculty or department chairs on the main } \\
\text { campus when I have questions. }\end{array}$ & .48 & .79 \\
\hline The classroom (clinical) space where I meet with students could be improved. & .38 & .80 \\
\hline The classroom (clinical) where I teach have multimedia equipment that adequately meets pedagogical needs. & .33 & .80 \\
\hline The classroom (clinical) space where I teach is excellent. & .58 & .79 \\
\hline I feel that I am well compensated for my teaching. & 60 & .78 \\
\hline I am paid fairly for the amount of work I do to teach courses. & .54 & .79 \\
\hline I am dissatisfied with the pay I receive for teaching courses. & .37 & .80 \\
\hline
\end{tabular}


The Cronbach's alpha for each subscale of the Adjunct Faculty Survey was greater than .70 and considered to be acceptable (Polit \& Beck, 2012). Each question within the survey was reviewed for alpha value if the item was deleted. Only one question in the satisfaction subscale and one question in the motivator subscale would yield a higher alpha if deleted. However, the impact of the improved alpha was minimal. If variables are considered for deletion, Tabachnick and Fidell (2007) suggest doing so based on logical grounds. Therefore, to preserve the integrity of the instrument and intent of the study, all items were maintained.

\section{Nurse Educators' Intent to Stay in Academe Scale}

The Nurse Educators' Intent to Stay in Academe Scale survey consisted of 13 questions and showed an overall Cronbach's alpha of .83. The Cronbach's alpha for the Nurse Educators' Intent to Stay in Academe Scale was found to be acceptable with a value greater than .70 as a benchmark (Polit \& Beck, 2012). Additionally, each question within the Nurse Educators' Intent to Stay in Academe Scale survey was evaluated for item-total reliability and alpha if the item were to be deleted (see Table 5).

A review of each question's Cronbach's alpha if deleted was compared to the overall Cronbach's alpha. This review found individual question's alpha value to be comparative to those found if the item were to be deleted. After review, all items were maintained as the Cronbach's alpha was above .70. The integrity of the instrument for the dissertation study was maintained in its original context. As a result, no items were deleted and all items were maintained for analysis. 
Table 5

Internal Consistency of the Nurse Educators' Intent to Stay in Academe Scale

\begin{tabular}{lcc}
\hline & $\begin{array}{c}\text { Corrected } \\
\text { Item-Total } \\
\text { Correlation }\end{array}$ & $\begin{array}{c}\text { Alpha if } \\
\text { Deleted }\end{array}$ \\
\hline I would lose more than I gain if I changed my profession as a nurse educator in academe. & .46 & .82 \\
I have invested too much of myself in nursing education to consider changing professions. & .48 & .82 \\
I plan to continue my career in nursing education. & .68 & .81 \\
I have other options, but they are not as attractive as working as a nursing educator in academe. & .39 \\
Leaving my position as a nurse educator in academe would have many negative consequences. & .52 & .83 \\
The sense of success that I receive from working with students keeps me working as a nurse educator in academe. & .53 & .82 \\
I would miss the academic environment if I left nursing education. & .59 & .82 \\
The autonomy that I have as a nurse educator would be lost if I left academia. & .65 \\
I would miss the flexibility of my work schedule if I left nursing academe. & .62 \\
I would miss the opportunity to participate in research if I left nursing academe. & .82 \\
I would miss the interactions with my colleagues if I left nursing academe. & .30 \\
I plan to remain in academia beyond my retirement years. & .28 \\
If I had to redo my career choices I would choose nursing academe again. & .81 \\
\hline
\end{tabular}




\section{External Validity}

When examining potential threats to validity, it was important to address potential threats to validity and sources of error. The researcher took into consideration the potential impact on the external validity of the findings. First, the sampling strategy was a purposive convenience sample, which meant that the absence of a randomized sample could introduce sampling error (Polit \& Beck, 2012). Therefore, it was possible that the views of the adjunct clinical nursing faculty members who participated in this survey may not completely and accurately represent those views of adjunct clinical nursing faculty in areas outside of the northeastern US. In addition, the sample was limited to associate degree nursing programs, so the responses may not represent those views of adjunct clinical nursing faculty from other types of nursing programs. Another source of error in this study could be a possible non-response bias due to the distribution of the survey message via email and a small sample size as noted with a $46 \%$ response rate.

\section{Hypothesis Testing}

Prior to data being analyzed, the assumptions for parametric statistical testing must be achieved (Tabachnick \& Fidell, 2007), which included computational and visual inspection processes. As previously mentioned, the data were assessed for normality utilizing histograms, boxplots, scatterplots, Q-Q plots, multicollinearity, Durbin-Watson, kurtosis, Shapiro-Wilk, and univariate and multivariate outliers (Tabachnick \& Fidell, 2007). The mean, standard deviation, skewness, kurtosis, and standard error of kurtosis for each scale measured is revealed in Table 6. 
Table 6

Descriptive Statistics of IVs and DV

\begin{tabular}{lcccccc}
\hline & $M$ & $S D$ & Skewness & Kurtosis & $S E$ & $p$ \\
\hline Years of teaching experience & 3.10 & 1.46 & -.14 & -1.30 & .60 & $<.01$ \\
Years at current institution & 2.69 & 1.35 & .22 & -.99 & .60 & $<.01$ \\
Age & 46.38 & 11.90 & -.43 & -.31 & .60 & $<.01$ \\
Highest level of education completed & .80 & .65 & .96 & 2.72 & .60 & $<.01$ \\
Outside employment & 2.15 & 1.31 & -.60 & -1.05 & .60 & $<.01$ \\
Satisfaction score & 29.42 & 4.73 & -.71 & -.05 & .64 & $<.01$ \\
Motivator factor score & 43.65 & 5.15 & -1.73 & 3.60 & .62 & $<.01$ \\
Hygiene factor score & 77.09 & 10.55 & -.22 & -.54 & .64 & .74 \\
Intent to Stay score & 38.33 & 5.77 & .20 & -.63 & .65 & .18 \\
& & & & & & \\
\hline
\end{tabular}

The variation noted in the mean of each scale was explained by the number of questions and measurement in the survey attributed to that measure. To test for normality, the measure of kurtosis was divided by the standard error with findings supporting acceptable levels of kurtosis ranging between -2 to +2 (George \& Mallery, 2010) for all measures except the following: the number of years of teaching experience in nursing education, highest level of education completed, and motivator factor summative score.

The three areas that did not meet acceptable levels of kurtosis were further studied by histogram. The number of years of teaching experience in nursing education, highest level of education completed, and motivator factor summative score were visualized and noted to have moderate kurtosis and skewness of the data. After review it was concluded that the number of years of experience teaching in nursing education, highest level of 
education completed, and motivator factor summative scoring data was not normally distributed. A review of each factor was completed.

The highest level of education completed by adjunct clinical nursing faculty was noted to be skewed to the left on histogram. However, the distribution of degree attained cannot be evaluated in this manner due to the BSN being the minimum degree required to teach, and the MSN is the preferred degree to teach in an associate degree program. The higher levels of education of master's degree in another field and DNP degree do not reflect the requirements to teach within this type of program and skewed the data.

The number of years of teaching experience in nursing education showed a skew to the right on the histogram with the majority of participants reporting more than 6 years of experience. The histogram indicated that a disproportionate amount of adjunct faculty members have many years of experience teaching within nursing education. This finding was not anticipated because of the literature review for this study demonstrated significant numbers of novice nurse faculty members with less than 2 years of experience teaching within nursing education. In review of novice years, the range of choices for this factor was very narrowly focused as less than 1 year and 1 to 2 years of experience. A combination of these two categories would better reflect the accepted understanding of novice nurse educators.

Additionally, the motivator factor summative scoring histogram demonstrated that the distribution curve is skewed to the right. This curve indicated that a disproportionate number of study participants have high ratings of motivator factor scoring. The motivator factor demonstrated moderate kurtosis, producing a skew to the right with a 
value of 5.77 found. This finding supported internal motivation for nurse faculty who take on the teaching role.

Next, data was analyzed for calculating adjunct faculty perception for each of the variables measured by the survey. Utilizing the Shapiro-Wilk test of normality, data was determined to be normally distributed with all variables meeting the expected $p$ value of less than .05 except the hygiene factor summative score ( $p$ value of .74) and intent-to-stay summative score ( $p$ value of .18). Upon identification of the Shapiro-Wilk findings, the histogram was visualized for each item. Despite the Shapiro-Wilk result, the histogram for each scale revealed data was well-distributed.

\section{Research Question}

The research question "What are the predictors of AD adjunct clinical nurse faculty intent to stay teaching?" was answered using multiple regression analysis.

\section{Hypothesis One}

Hypothesis one suggested that there would be a positive relationship between select AD adjunct clinical nursing faculty demographic variables (number of years of teaching experience in nursing education, number of years employed as an adjunct at the current institution, age, highest level of education completed) and job satisfaction score with intent-to-stay-teaching score. It was further hypothesized that a negative relationship would be present for $\mathrm{AD}$ adjunct clinical nursing faculty demographic variable of outside employment status with intent-to-stay-teaching score. The null hypothesis would reveal no relationship between the demographic variables and the intent-to-stay-teaching score. The alternative hypothesis would reveal a statistically significant relationship between the demographic variables and the intent-to-stay score. 
This hypothesis was tested using stepwise multiple regression analysis with dummy coding of the demographic variables. Dichotomous variables were transformed into dummy variables for use in multivariate statistical analysis, typically using codes of zero and one (Polit \& Beck, 2012). The transformed nominal dummy variables were entered into the regression analysis for interpretation. Assumptions were tested by examining normal probability plots of residuals and scatter diagrams of residuals versus predicated residuals. No violations of normality, linearity, or homoscedasticity of residuals were detected. In addition, box plots revealed no evidence of outliers.

To test the hypotheses, a stepwise multiple regression analysis was performed between the dependent variable (intent to stay) with the independent variables (number of years teaching experience in nursing education, number of years employed as an adjunct at the current university, age, highest level of education completed, and employment status outside of the adjunct position) and job satisfaction score. In order to run this analysis, the summed data for each of these subscales were loaded into SPSS and correlated with the summed data responses for intent to stay utilizing regression analysis.

The statistical (stepwise) method revealed that job satisfaction explained a significant amount of the variance in the value of intent to stay teaching $(F[1,50]=$ $20.34, R^{2}=.29, R^{2}$ Adjusted $\left.=.28, p<.01\right)$. It was also found that full-time employment outside of the adjunct clinical nurse faculty position explained a significant amount of the variance in the value of intent to stay teaching $\left(F[2,49]=14.51, R^{2}=.37, R^{2}\right.$ Adjusted $=$ $.35, p<.01)$. Table 7 provides detailed predictor variable results. 
Table 7

Job Satisfaction Score and Employment Effect on Intent to Stay Teaching

\begin{tabular}{lccccccccc}
\hline & $R$ & $R^{2}$ & Adj. $R^{2}$ & B & SEB & $\beta$ & $F$ & $t$ & $p$ \\
\hline $\begin{array}{l}\text { Job satisfaction } \\
\text { score }\end{array}$ & .54 & .29 & .28 & .73 & .15 & .58 & 20.34 & 5.04 & $<.01$ \\
$\begin{array}{l}\text { Full-time } \\
\text { employment }\end{array}$ & .61 & .37 & .35 & -3.32 & 1.31 & -.29 & 14.51 & -2.54 & $<.01$ \\
\hline
\end{tabular}

Note: $N=52$.

Together, those two factors contributed to $35 \%$ of the variability in intent to stay teaching. However, no significant relationship was found between part-time employment in academia or in the field, employment at two or more jobs, and no outside employment with intent to stay. Other predictor factors of educational level (to include BSN, MSN, master's degree in another field, and DNP), years of teaching experience in nursing education, years of employment within the current institution, and age revealed no significant relationship with intent to stay teaching.

The results of the stepwise multiple regression indicated that a positive relationship $(p<.01)$ was seen between job satisfaction and intent-to-stay-teaching score when reviewing the standardized regression coefficient (beta) and unstandardized (B) regression coefficient, $t$ value, and $p$ value (see Table 7). A negative standardized regression coefficient (beta) and negative unstandardized (B) regression coefficient and negative $t$ value (see Table 7) was observed. It was appropriate to infer that a statistically significant negative relationship exists between outside employment status with intent to stay teaching. Therefore, working a full-time job outside of the adjunct clinical nursing position in academia had a negative effect on intent to stay teaching. Despite these findings, it was necessary to fail to reject the null hypothesis for hypothesis one due to 
the remaining variables (number of years of teaching experience in nursing education, the number of years employed as an adjunct at the current institution, age, and highest level of education completed), identifying no statistically significant relationship.

\section{Hypothesis Two}

Hypothesis two predicted that there was a positive relationship between AD adjunct clinical nursing faculty reported level of motivator factor score and intent-to-stayteaching score after controlling for select demographic variables. The null hypothesis would reveal no relationship between the motivator factor score and intent-to-stayteaching score. The alternative hypothesis would reveal a statistically significant relationship between motivator score and intent to stay score.

To test this hypothesis, a hierarchical multiple regression was completed to control for the independent demographic variables and examine the relationship being tested (motivator factor score) with intent to stay. This procedure allowed the researcher to control for other variables and demonstrate whether bivariate relationships are spurious. Participant demographics were entered into the first block consisting of the following: number of years teaching experience in nursing education, number of years employed as an adjunct at the current university, age, highest level of education completed, and employment status outside of the adjunct position. Results of the summed score of the motivator factors were entered into the second block. Using the sequential (hierarchical) method, it was found that motivator factor score explained a significant amount of the variance in the value of intent-to-stay-teaching score $(F[6,45]=$ 5.34, $R^{2}=.34, R^{2}$ Adjusted $\left.=.42, p<.01\right)$. The results identified that the summed scores of motivator factor scoring had a large effect on intent to stay teaching when holding the 
demographic variables constant. A large effect is reported for an adjusted $R^{2}$ value of .30 or larger (Polit \& Beck, 2012). As a result of this analysis, the null hypothesis was rejected and the alternative hypothesis was accepted. Table 8 outlines the results of motivator factor summary data with intent to stay teaching.

Table 8

Motivator Factor Summative Scoring Effect on Intent to Stay Teaching

\begin{tabular}{lccccccccc}
\hline & $R$ & $R^{2}$ & Adj. $R^{2}$ & B & SEB & $\beta$ & $F$ & $t$ & $p$ \\
\hline Motivator score & .65 & .42 & .34 & .62 & .13 & .55 & 21.55 & 4.64 & $<.01$ \\
\hline
\end{tabular}

Note: $N=52$.

\section{Hypothesis Three}

Hypothesis three predicted that there was a positive relationship between AD adjunct clinical nursing faculty reported level of hygiene factor score and intent-to-stayteaching score after controlling for select demographic variables. The null hypothesis would reveal no relationship between the hygiene factor score with intent-to-stayteaching score. The alternative hypothesis would reveal a statistically significant relationship between the hygiene factor score with intent-to-stay-teaching score.

To test this hypothesis, a hierarchical multiple regression was completed to control for the demographic variables and to examine the relationship of the independent variable being tested (hygiene factor score) with intent to stay. The participant demographics were entered into the first block consisting of the following: number of years teaching experience in nursing education, number of years employed as an adjunct at the current university, age, highest level of education completed, and employment status outside of the adjunct position. Interactions involving a summed score of the 
hygiene factors were entered into the second block. Using the sequential (hierarchical) method, it was found that hygiene factor score explained a significant amount of the variance in the value of intent-to-stay-teaching score $\left(F[6,45]=3.71, R^{2}=.33, R^{2}\right.$ Adjusted $=.24, p<.01)$. The results identified the hygiene factor scoring had a large effect on intent to stay teaching. As a result of this analysis, the null hypothesis was rejected and the alternative hypothesis was accepted. Table 9 shows the effect that hygiene score had on intent to stay score.

Table 9

Hygiene Factor Summative Scoring Effect on Intent to Stay Teaching

\begin{tabular}{lccccccccc}
\hline & $R$ & $R^{2}$ & Adj. $R^{2}$ & B & SEB & $\beta$ & F & $t$ & $p$ \\
\hline Hygiene score & .58 & .33 & .24 & .26 & .07 & .48 & 13.09 & 3.62 & $<.01$ \\
\hline
\end{tabular}

Note: $N=52$.

\section{Hypothesis Four}

Hypothesis four predicted that there would be a positive relationship between AD adjunct clinical nursing faculty reported levels of job satisfaction (hygiene and motivator factor scores) and intent-to-stay score after controlling for select demographic variables. The null hypothesis would reveal no relationship between the hygiene and motivator factor scores with intent-to-stay score. The alternative hypothesis would reveal a statistically significant relationship between the hygiene and motivator factor scores with intent-to-stay score.

To test this hypothesis, a hierarchical multiple regression analysis was completed to control for the independent demographic variables to examine the relationship being tested (motivator and hygiene factor scores) with intent to stay. Again, participant 
demographics were entered into the first block consisting of the following: number of years teaching experience in nursing education, number of years employed as an adjunct at the current university, age, highest level of education completed, and employment status outside of the adjunct position. Interactions involving a summed score of the motivator and hygiene factors were entered into the second block. Using the sequential (hierarchical) method, it was found that the motivator and hygiene factor score explained a significant amount of the variance in the value of intent-to-stay-teaching score $(F[7,44]$ $=4.88, R^{2}=.44, R^{2}$ Adjusted $\left.=.35, p<.01\right)$. As a result of this analysis, the null hypothesis was rejected and the alternative hypothesis was accepted. The results identified in Table 10 reveal a large effect with an adjusted $\mathrm{R}^{2}$ greater than .30 identified as a large effect by Polit and Beck (2012) on the intent-to-stay teaching score.

Table 10

Sequential Regression Analysis of Hygiene and Motivator Scores Predicting Intent to Stay Teaching

\begin{tabular}{lccccccc}
\hline Variable & B & SEB & $\beta$ & $t$ & $R^{2}$ & Adj. $R^{2}$ & $p$ \\
\hline Motivator factor & .48 & .17 & .43 & 2.88 & & & \\
Hygiene factor & .11 & .09 & .20 & 1.28 & & & \\
& & & & & .44 & .35 & $<.01$ \\
\hline
\end{tabular}

Note: $N=52$.

\section{Chapter Summary}

This chapter examined the results of this research study with regard to adjunct clinical nurse faculty demographic factors and satisfaction with intent-to-stay teaching scores. This study analyzed the data of 61 adjunct clinical nurse faculty members who participated in the survey available online in the fall of 2015. 
Upon examining the relationship between demographic variables and satisfaction score with intent to stay scores, it was observed that full-time employment and satisfaction summed rating had a statistically significant impact on intent to stay teaching. There was not a statistically significant relationship noted between other levels of outside employment, number of years of teaching experience in nursing education, number of years employed as an adjunct at the current institution, age, or highest level of education completed. Analysis of the relationship between study participant's motivator factor, hygiene factor, and combined motivator and hygiene factor scoring did provide a statistically significant result impacting intent to stay teaching. Hierarchical regression analysis was completed with all three measures producing a large effect on intent to stay teaching.

The following chapter will provide a discussion and summary of the results of the dissertation study and whether or not they support the philosophical and theoretical framework that was presented in Chapter 1. A discussion about the meaning of the results of the dissertation study; comparison between the dissertation study's results and findings reported by other researchers; and the implications for nursing education, nursing practice, nursing research and public policy will be presented. Lastly, limitations of this study and considerations for future studies will be explored. 


\section{Chapter Five}

\section{Discussion and Summary}

This final chapter presents a summary of the study and important conclusions drawn from the data. In addition, the dissertation's findings are compared to those reported by other researchers and the implications of the dissertation research as it relates to nursing practice, nursing education, public policy, and nursing education. It provides a discussion of the implications for action, limitations, and recommendations for further research.

Concerns regarding the lack of qualified nursing faculty to teach nursing students are foremost in the minds of nurse educators, administrators, communities, and regulatory bodies. In response to the nurse faculty shortage, increased student enrollments, and increased societal needs for graduating more nurses, colleges hire adjunct faculty to fill the gap left from the lack of full-time faculty. Most frequently, adjunct faculty members are hired to teach in AD nursing programs in the clinical arena. Despite this noted trend in hiring practice, little research has been done to identify adjunct clinical nursing faculty members' satisfaction in the role and intent to stay teaching with a notable lack of research applied to associate degree nursing programs. Largely, research studies have been conducted to address satisfaction or intent to stay teaching with full-time nursing faculty in baccalaureate degree-granting institutions (Candela et al., 2013; Derby-Davis, 2014; Garbee \& Killacky, 2008; Lee, 2014; Roughton, 2013; Ruel, 2009). Despite a 
large reliance on adjunct clinical nursing faculty, the lack of research on factors supporting intent to stay in the role could propagate increased turnover of this faculty group. Therefore, it is essential and appropriate to study the predictive factors of $\mathrm{AD}$ adjunct clinical nursing faculty members' intent to stay teaching.

No previous studies have investigated predictor factors of $\mathrm{AD}$ adjunct clinical nursing faculty intent to stay teaching. The purpose of this quantitative, descriptive, nonexperimental, correlational study was to contribute to the overall understanding of $\mathrm{AD}$ adjunct clinical nursing faculty and examine the relationship between the demographic variables and job satisfaction factors with intent to stay teaching. The philosophical underpinning of this study was post-positivism, which supports research to identify factors that may influence outcomes (Creswell, 2009). The dissertation study was guided by Herzberg's two-factor motivator-hygiene theory (Herzberg et al., 1959), which framed the dissertation study to investigate adjunct clinical nursing faculty members' predictive factors of intent to stay teaching. Predictive factors of demographic variables, job satisfaction, hygiene, and motivator factor score were elicited. Herzberg categorized the needs of employees into hygiene and motivator factors. Motivator factors positively affected the employee experience and support retention. Hygiene factors were suggested to prevent dissatisfaction and motivator factors supported satisfaction in one's work (Herzberg et al., 1959). Dissatisfaction will occur when hygiene factors fall to an unacceptable level, leading to turnover. The expense of turnover of employees can be countered by satisfaction. The results from this dissertation study support Herzberg's theory finding job satisfaction, hygiene factor, and motivator factor scores strongly affected intent-to-stay scores. 


\section{Summary of the Findings}

The dissertation study examined the predictors of AD adjunct clinical nursing faculty members' intent to stay teaching. The findings support Herzberg's' theoretical framework as motivator and hygiene factors have been found to support satisfaction in the job and intent to stay teaching. The following section shows study participants' demographic characteristics, job satisfaction, motivator factor, and hygiene factor scores influence on intent-to-stay scores. Intent to stay teaching in academe results for AD adjunct clinical nursing faculty were found to be strongly affected by job satisfaction scores, motivator scores, and hygiene scores.

The final sample consisted of 52 adjunct clinical nursing faculty members who taught in an AD nursing program within a 100-mile radius of the researcher in the northeastern US. The internal consistency of the overall Adjunct Faculty Survey and the Nurse Educators' Intent to Stay in Academe Scale survey were noted to be acceptable. The results of this dissertation study found demographic variables were unable to consistently predict intent to stay; however, job satisfaction, motivator factor, and hygiene factor scores had a significant effect on intent to stay teaching in academia. These findings will be first elaborated upon and then compared with previous studies.

\section{Demographic Variables}

The demographic variables elicited for the dissertation study analysis predicted intent to stay and include the following: number of years of teaching experience in nursing education, number of years at the current university, age, highest level of education completed, and outside employment. 
The first demographic variable examined was number of years of teaching experience in nursing education. A review of the number of years of teaching experience in nursing education indicated that the largest percentage of study participants had 3 to 4 years of experience and more than 6 years of experience in nursing education. A large disparity was noted in the established literature regarding the number of participants who were experienced compared to those who were novices. Educators were considered novices until the teacher gained 2 years of experience (Weidman, 2013). It was recognized that the scale used to elicit this factor separated novice years into less than 1 year and 1 to 2 years of experience. To obtain a better idea of the number of novices in the participant group, responses of less than 1 year were combined with those with 1 to 2 years of experience. The result was over one third of the entire participant group were novices. The newly formed novice group of participants was larger than any other group in the dissertation study and is in agreement with the literature findings.

The next demographic variable elicited was related to number of years at the current university and indicated that the majority of participants had been employed for 3 to 4 years, followed by those with less than 1 year of employment. These results indicate that a large portion of the participant group is newly hired to this adjunct position. This finding was expected, considering that adjunct faculty is hired from semester-to-semester with employment status vulnerable to student enrollment and college staffing needs.

The next demographic variable elicited was participant age. Data were categorized into generational groupings to ascertain a better idea of the results. The majority of participants were in the baby boomer generational age category, followed by the Generation X grouping. These results are similar to those by Candela et al. (2013) 
and Candela et al. (2015). The data were then re-categorized to place data into commonly identified age groupings with the age group of 45 to 54 having the largest number of participants. These findings indicate that this participant group is representative of the general population of nurse faculty. Findings published from the AACN demonstrated that the average age of a master's-prepared, nursing faculty professor, associate professor, and assistant professor were 57.1, 56.8, and 51.2 years, respectively (AACN, 2015). Additional analysis demonstrated the mean age of participants from this dissertation study is 46.38 years old. Again, this value is congruent with data from NLN (2010b) from a 2009 faculty census, which noted that over 57\% of part-time educators and $76 \%$ of full-time educators were over the age of 45 .

A review of the dissertation study participants' highest level of education completed indicated that the largest percentage of adjunct faculty earned a Master's Degree in Nursing, followed by those having completed a baccalaureate degree. This finding is similar to national faculty census data that reports the majority of nurse faculty are prepared with a master's degree, inclusive of all types of nursing programs. Formal educational preparation is obtained by completing a Master's Degree in Nursing. However, the attainment of a master's degree in nursing could have varying foci, such as education, nurse practitioner, and administrative tracks. Within the accrediting ACEN standards for associate degree programs, the master's degree is preferred and the baccalaureate degree is the minimum degree required to teach. As a result, it is believed that the highest degree earned as reported by the dissertation sample is reflective of the general population of associate degree clinical nurse faculty. 
A review of employment status outside of the adjunct clinical nursing teaching role indicates that the majority of participants maintained full-time employment, followed by no outside employment. The anticipation of outside employment was expected due to the nature of adjunct faculty work to be on a temporary, semester-tosemester basis. It is recognized that the lack of assurance of employment within the institution requires adjunct faculty to maintain alternative income from another source. Although participants were expected to maintain employment outside of this adjunct position, the majority working on a full-time basis was unexpected. The outside employment demographic factor was the first to produce a statistically significant result with the regression analysis on the intent-to-stay dependent variable. It was demonstrated that full-time employment outside of the adjunct clinical nursing teaching position produced a statistically significant negative impact on intent to stay teaching. It is anticipated that participants who indicated that they maintained outside employment on a full-time basis most likely maintained those positions in the field of nursing. Compensation and benefits are significantly better in the clinical practice setting and could affect the intent to stay teaching in academia in a negative way. Additionally, the amount of hours worked in a week cumulatively between the full-time role and the adjunct clinical faculty position may affect work/life balance and the resulting intent-tostay score.

\section{Job Satisfaction, Motivator Factor, and Hygiene Factor Scores}

A review of participant responses showed that the majority of faculty indicated high levels of job satisfaction, motivator factor, and hygiene factor scores in the teaching role. The summed scores of job satisfaction, motivator factor, and hygiene factor scores 
positively affected the intent-to-stay-teaching score, both individually and collectively. The regression analysis predicted support of adjunct clinical nursing faculty higher levels of intent-to-stay-teaching with high levels of job satisfaction, motivator factor, and hygiene factor scores. These findings suggest that satisfaction derived from job satisfaction, motivator, and hygiene factors must be the foundation of which employment is built. These findings complement Herzberg's two-factor motivator-hygiene theory. Although the hygiene factors are not suggested to enhance loyalty and job satisfaction, a level of satisfaction with these factors is necessary to avoid employee dissatisfaction (Herzberg et al., 1959). Herzberg (1968) also suggests that strengthening the motivator factors would produce the most impact for employees. The dissertation study supports high ratings of motivator and hygiene factors supported job satisfaction and intent to stay. A degree of loyalty can be inferred as a result of the support of motivator factors (Hoyt, 2012).

Yet, in review of this dissertation's findings, it was found that many of the Cronbach's alpha value results were not at the level from previous studies by Hoyt (2012) and Hoyt et al. (2008). Particular to the subscale of motivator factors, the category of recognition and work preference ranked lower than established studies. As a result, it is surmised that these factors must be enhanced and supported by employers to promote job satisfaction and intent-to-stay scores. This improvement can result in cost savings in reduction of employee turnover with hiring, orientation, and training of new employees.

In addition, the subscale of hygiene factors had categories that fell below the established studies to include the following: autonomy, classroom (clinical) facilities, quality of the students, and teaching schedule. As Herzberg (1968) suggested, 
dissatisfaction ensues when hygiene factors fall to an unacceptable level leading to turnover. The participants' rating of autonomy as a hygiene factor was anticipated to be low due to the lack of input from clinical faculty into decision making regarding the nursing program. It could be inferred from this result that adjunct faculty should have more impact on decision making within the nursing program.

Yet, some of the hygiene factors can be explained by the nature of AD nursing programs being delivered within community colleges. The hygiene factor quality of the students is predetermined by the college when accepting and registering students for classes at the community college. This factor is not controlled by the adjunct nursing faculty. Minimal admissions criteria (referred to open admissions) are developed for admission into a community college. However, additional criteria may be required for students to be accepted into a nursing program with a large variation of those admissions criteria noted by Gilmore (2008) and Schmidt and MacWilliams (2011). Nevertheless, adjunct nurse faculty members' impression of the quality of the students may be affected by the student's enrollment within a community college.

In addition to the factor quality of students, the factor clinical facilities are difficult to control. The classroom (clinical) facilities and teaching schedule are not controlled by adjunct nursing faculty as they are hired to fill predetermined clinical site openings. The nature of the role of clinical nursing faculty requires teaching to be completed off-campus grounds at the clinical site. Clinical teaching can be completed at inpatient (nursing home or hospital setting) or outpatient (community-based) settings. As a result, the factor of clinical facilities are predetermined and not created by the adjunct faculty member. 
The final factor that is difficult to control is teaching schedule. Typically, the teaching schedule is not determined by the adjunct nursing faculty. Adjunct faculty members are hired to teach in a clinical setting in which the nursing program determines a teaching need and available clinical site. It is believed that the nature of hiring of adjunct clinical nursing faculty and the arena of teaching in the clinical setting explain the reasons these factors rated below established studies.

The rating of compensation for this dissertation's results compared similarly to established studies. This finding was unexpected due to literature support across all educational institutions suggesting that salary is substandard within educational institutions, particularly in comparison to clinical practice setting pay rates. This finding may reflect acknowledgement and acceptance of lower pay rates within the educational setting for work performed. It is noted that many faculty complete the teaching role in educational institutions for altruistic reasons and compensation is found to be secondary to that role. Once again, this finding supports Herzberg's theory (1968), suggesting that direct improvement of the hygiene factors like compensation does not inherently improve job satisfaction.

\section{Hypothesis}

Hypothesis one suggested that there would be a positive relationship between select AD adjunct clinical nursing faculty demographic variables (number of years of teaching experience in nursing education, number of years employed as an adjunct at the current institution, age, highest level of education completed) and job satisfaction score with intent-to-stay-teaching score. After analysis of the data, it was found that none of these demographic variables predicted the intent to stay. The result was an inability to 
fail to reject the null hypothesis; therefore, the null hypothesis was accepted. However, the job satisfaction score maintained a statistically significant impact on intent to stay teaching. When considering these results, it is reasonable to expect that increased job satisfaction would support intent to stay teaching. Within the first hypothesis, it was further hypothesized that a negative relationship would be present for AD adjunct clinical nursing faculty demographic variable of outside employment status with intent-to-stay teaching score. This hypothesis was supported for adjunct faculty who maintained fulltime employment outside of the adjunct position. A negative relationship was found with intent to stay for adjunct clinical nursing faculty who maintained outside employment on a full-time basis. Again, this finding was expected as outside work requirements increase workload and affects work/life balance, which affects intent to stay teaching. Two specific factors, including satisfaction and full-time outside employment, produced statistically significant relationships with intent to stay. However, the null hypothesis was accepted due to a lack of all identified variables influencing intent to stay teaching.

Hypothesis two suggested that there is a positive relationship between $\mathrm{AD}$ adjunct clinical nursing faculty members' reported level of motivator factor score and intent-tostay-teaching score after controlling for select demographic variables. The motivator subscale consisted of questions pertaining to personal growth, recognition, and work preference. This hypothesis was supported by the dissertation study. The null hypothesis was rejected, and the alternative hypothesis was accepted, indicating a statistically significant relationship between motivator factor score and intent-to-stay score. Findings indicate a statistically significant relationship between motivator factor score and intent to stay teaching. 
Hypothesis three suggested that there is a positive relationship between AD adjunct clinical nursing faculty members' reported level of hygiene factor score and intent-to-stay-teaching score after controlling for select demographic variables. The hygiene subscale consisted of questions pertaining to the following: autonomy, classroom facilities, compensation, faculty support, quality of students, and teaching schedule. The hypothesis for the dissertation study was supported. The null hypothesis was rejected, and the alternative hypothesis was accepted, indicating a statistically significant relationship between hygiene factor scoring and intent to stay teaching.

The fourth and final hypothesis suggested that there is a positive relationship between AD adjunct clinical nursing faculty members' reported levels of job satisfaction (hygiene and motivator factor scores) and intent-to-stay score after controlling for select demographic variables. This hypothesis was also supported for the dissertation study. The null hypothesis was rejected, and the alternative hypothesis was accepted, indicating a statistically significant relationship between hygiene and motivator factor scoring with intent to stay.

\section{Integration of the Findings with Previous Literature}

\section{Number of Years of Teaching Experience in Nursing Education}

This dissertation study found the majority of participants had 3 to 4 years and more than six years of experience. This finding indicates a more experienced adjunct clinical nursing faculty workforce. However, a better understanding of the novice participant group was necessary and recognized by combining results of participants with less than 1 year and with 1 to 2 years of teaching experience for a total of $34.4 \%$. The newly created category more clearly showing novice faculty now surpassed as the 
majority of all groups. This result is less than Whalen (2009) reported with a majority $(56 \%)$ of adjuncts who had been teaching for 2 years or less. Yet, the dissertation study is in line with Forbes et al.'s (2010) reporting that $32 \%$ of adjunct nursing faculty members were novices who were teaching in their first semester of the program.

The literature review completed for this dissertation study found an abundance of literature regarding the novice nurse educator group. The early years as a novice nurse educator are crucial to intent to stay teaching. In fact, according to Garbee and Killacky (2008), the highest rates of intent to leave the teaching role occurred in the first and third years of employment. It has been noted that novice nurse faculty reported feeling unprepared for the role as a nurse educator (Duphily, 2011), which is supported by Cangelosi et al. (2009) who suggested that nurses proficient in clinical practice are not necessarily proficient in teaching those skills to others. Administrators must consider the implications of hiring novice nurse educators and consider extra support needed for this teaching faculty group. Authors suggest mentoring programs for novice nurse educators to support and retain this group of educators (Bell-Scriber \& Morton, 2009; McDonald, 2010; Weidman, 2013). Despite the significant proportion of novice faculty, this dissertation study was unable to make a prediction of number of years of experience in nursing education and intent to stay.

\section{Number of Years Teaching at the Current University}

This dissertation study found the majority of participants reported 3 to 4 years of experience $(34.4 \%)$, followed by those with less than 1 year experience $(27.9 \%)$ at the current university. The number of years of teaching at the current university is found to have direct implications for full-time faculty who are seeking promotion and tenure 
compared to adjunct faculty (as this study has focused). In fact, Rosser (2004) found that full-time tenured faculty members were less likely to leave due to more status, time, and resources invested with increased number of years dedicated to the institution. Similarly, a prior study with full-time faculty indicated that the number of years in the position had a significant and negative impact on the intent to leave the position (Rosser \& Townsend, 2006). Yet, it is recognized that this same process of promotion does not pertain to adjunct faculty. These same indications may not be relevant to adjunct faculty members as they are hired on a semester-to-semester basis and are subject to student enrollment and the needs of the program. If enrollment does not support a need for adjunct faculty members, they are not rehired, which may explain why Thirolf (2013) reported that increased years of service for part-time faculty members had a negative impact on their love for teaching. This dissertation study was unable to make prediction of intent to stay teaching based on the demographic data of number of years employed at the current institution.

\section{Age}

This dissertation study found the average age of adjunct clinical nursing faculty to be 46.38 years old. Cranford (2013) found the average age of full-time nursing faculty to be 50.6 years old. Gappa and Leslie (1993) suggested that part-time faculty tended to be younger than full-time faculty. The NLN (2010) indicated that over 57\% of part-time faculty members were over the age of 45 in a 2009 faculty census survey. The findings from the dissertation study agree with the above findings. Age and proximity to retirement for full- and part-time faculty have a significant influence on intent to remain employed (Tourangeau et al., 2012). As full-time faculty members age, there is a 
stronger commitment to the institution and increased intent to stay (Cranford, 2013;

Roughton, 2013). The lack of prediction of age with intent to stay noted from this dissertation study could be related to the explicit study of adjunct faculty without inclusion of full-time faculty.

Age as a demographic variable is also relevant related to generational grouping. Candela et al. (2013) reported that the millennial generation was revealed to have the greatest intent to leave. These findings are concerning for nurse faculty as the average age of the nursing workforce is increasing with millennials leaving the teaching role. The majority of participants from the dissertation study were found to be in the baby boomer generational category. Candela et al. (2013) found that baby boomers indicated a greater desire to remain in the faculty role compared to the other generational groupings. This finding could suggest that intent to stay would improve if participants are from the baby boomer generational category. Candela et al. (2013) reported generational membership had a statistically significant influence on intent to stay in the faculty role. However the findings from the dissertation study and those reported by Derby-Davis (2014) were unable to predict participant age influencing intent to stay.

\section{Highest Level of Education Completed}

This dissertation study found the majority of adjunct clinical nursing faculty held the master's in nursing degree, followed by the baccalaureate degree (29.5\%). Despite the majority of adjunct nursing faculty in the dissertation study were found to have master's degree preparation, there are reports that master's-prepared educators lacked formal teaching or education courses (Forbes et al., 2010). This lack of formal training may affect intent to stay teaching. The proportion of BSN-prepared faculty found in the 
dissertation study is in alignment with a study by Carlson (2015), which found a large portion (33\%) of adjunct faculty with the BSN as the highest level of education completed. No previously identified studies examined adjunct clinical nursing faculty members' highest degree earned with intent to stay teaching. This dissertation study did not find statistically significant relationships to predict intent to stay teaching; however, Derby-Davis (2014) found that the highest level of education completed had a positive relationship with the intent to stay. Yet, it is surmised that attainment of a higher educational degree like a $\mathrm{PhD}$ degree opens the opportunity to teach in higher educational institutions like universities. This mobility could affect the intent-to-stay scores. Roughton (2013) found that faculty holding a higher nursing degree had a $40 \%$ higher risk of leaving the teaching role within the next year, which may also explain why Wagoner (2007) found that part-time faculty members with higher degrees were less satisfied overall with their positions.

\section{Employment Outside of the Adjunct Teaching Position}

Outside employment is an important variable to understanding intent to stay for adjunct clinical nursing faculty. This dissertation study found that the majority of participants (80.3\%) reported holding two or more jobs. Although outside employment was anticipated, the majority reported holding full-time positions outside of the adjunct position (49.2\%) was an unexpected finding. These outside employment results are in alignment with authors who reported 52.5\%, (Gappa \& Leslie, 1993), 69\% (Whalen, 2009), 73\% (Meixner et al., 2010), and 91\% (Forbes et al., 2010) of part-time faculty maintained full-time outside employment. Adjunct faculty members have other commitments and frequently maintain employment in more than one college or university 
(Forbes et al., 2010). This finding is not unique to adjunct nursing faculty, and it is also noted for full-time faculty. A large portion (79\%) of full-time nursing faculty members has been reported to maintain a second job sometime in their careers with $40 \%$ reported maintaining current outside employment (Cranford, 2013). Bittner and O'Connor (2012) surveyed both full-time and part-time participants and found that $57 \%$ reported holding two jobs with $19 \%$ reporting three jobs or more. This finding can be attributed to poor salary compensation reported by faculty. Hoyt (2012) found that $53 \%$ of adjunct faculty maintained employment outside of the adjunct position; however, it did not represent the nursing education field.

The potential impact of maintaining employment at multiple jobs can affect work/life balance. Authors contended that creation of work/life balance and flexibility was found to support retention of faculty (Cranford, 2013; Fjortoft et al., 2012; Lodhi et al., 2013; Roughton, 2013). Furthermore, a work/life imbalance due to heavy workload was thought to contribute to turnover (Bittner \& O'Connor, 2012; Hoyt et al., 2008). Kaufman (2007b) reported that nursing faculty typically work in excess of 50 hours per week. Tourangeau et al. (2012) found that full- and part-time faculty indicated that working more hours than a typical full-time job affected intent to stay teaching. These findings were supported by this dissertation study. This dissertation study revealed a statistically significant negative impact of maintaining full-time employment outside of the adjunct position on intent to stay teaching. One innovative way to create a balance and retain full-time faculty anticipating retirement is a phased transition into an adjunct status (Foxall et al., 2009), which would retain experienced full-time faculty in a partial retirement role. 


\section{Motivator Factors}

Herzberg (1968) found the motivator factors to include the following: achievement, recognition for achievement, the work itself, responsibility, and growth or advancement. The Adjunct Faculty Survey measured the motivator subscale with questions addressing personal growth, recognition, and work preference categories. This dissertation study found the motivator factor of personal growth rated higher than the prior study utilizing this measure (Hoyt, 2012). The motivator factors personal growth and recognition provide strong support of intent to stay. A strong affinity for teaching, feeling respected and valued, and anticipation for a full-time job were the reasons found in a study by Carlson (2015) for part-time faculty wanting to continue working at the school of nursing.

In the dissertation study, the motivator factors of recognition and work preference rated lower than prior studies (Hoyt, 2012; Hoyt et al., 2008). These findings are congruent with findings from Lane et al. (2010), which found a lack of recognition from others, creating a negative impact upon satisfaction for associate degree nursing faculty. Hessler and Ritchie (2006) found that rewards for work effort and flexibility are supportive of nurse faculty retention. Administrative support with recognition of faculty performance and improvement was a significant predictor of intent to stay (Candela et al., 2013; Candela et al., 2015). These findings are concerning, particularly considering that motivator factors are noted to support job satisfaction and loyalty to the organization (Herzberg, 1968). It would seem that adjunct clinical nursing faculty members in AD nursing education are not recognized for their work and may be hesitant to teach in future semesters as a result. However, authors have identified the motivator factors for both 
full- and part-time faculty had the strongest influence over intent to stay teaching (Carlson, 2015; Gappa \& Leslie, 1993; Hoyt, 2012; Hoyt et al., 2008; Thirolf, 2012; Tourangeau et al., 2012; Waltman et al., 2012). In baccalaureate and graduate degree programs, Derby-Davis (2014) found a significantly positive relationship between motivator factors and intent-to-stay scores. Similarly, this dissertation study found a statistically significant positive relationship between motivator factors and intent-to-stayteaching score for $\mathrm{AD}$ adjunct clinical nursing faculty.

\section{Hygiene Factors}

Company policy/administrative practices, supervision, interpersonal relationships, working conditions, salary, status, and job security are the factors of hygiene (Herzberg, 1968). The Adjunct Faculty Survey measured the hygiene factor subscale with questions addressing the following categories: autonomy, classroom (clinical) facilities, compensation, faculty support, quality of the students, and teaching schedule. This dissertation study found the hygiene factors of autonomy, classroom facilities, quality of the students, and teaching schedule revealed lower alpha values compared to established studies using the same tool (Hoyt, 2012; Hoyt et al., 2008). Similarly, Ryan et al. (2012) found that increased stress levels (to include autonomy, teaching workload, unprepared students, and work/life balance) were related to increased intent to leave the teaching role. Life and family conflicts contributed to part-time faculty members' most cited reasons to consider leaving the teaching role (Candela et al., 2015). The hygiene factors of compensation and faculty support demonstrated similar alpha values compared to established studies. Lane et al. (2010) also studied AD nursing faculty and found 
compensation, working conditions, organizational influence, and relationships with other faculty contributed to job satisfaction.

The hygiene category results from the dissertation study rating lower than established studies are unique to the community college setting in which AD nursing programs are typically delivered. The rating of the quality of students may be uniquely affected due to community colleges offering open enrollment to students. The autonomy, classroom/clinical facilities, and teaching schedule category results may also be uniquely affected in this study due to AD adjunct clinical nursing faculty teaching at a clinical setting at off-campus grounds. It is typical for full-time faculty to maintain the responsibility to develop and maintain the curriculum. There is a lack of adjunct faculty input into syllabi, choice of clinical locations, and times offered to students as this planning occurs many months before the semester starts. Adjunct faculty input could prove difficult as Roberts et al. (2013) reported that adjunct faculty members are hired merely days before the start of the semester, which could result in these factors influencing intent to stay in a negative way. Nevertheless, this dissertation study found a statistically significant positive relationship between overall hygiene factor scoring with intent-to-stay-teaching score.

\section{Job Satisfaction}

Herzberg's (1968) two-factor theory suggests that job satisfaction is the result of both motivator and hygiene factors. In full-time faculty, the higher level of overall satisfaction directly affected the intent to stay or leave the institution (Al-Omari, Qablan, \& Khasawneh, 2008; Rosser, 2004; Ruel, 2009). Nursing studies of full-time faculty of BSN programs found that job satisfaction was related to increased likelihood of intent to 
stay within the 1 year (Garbee \& Killacky, 2008; Roughton, 2013) and at 5 years (Garbee \& Killacky, 2008). Science and math teachers' job satisfaction was found to improve with the number of years of teaching reported with dissatisfaction leading to faculty exiting the role earlier (Liu \& Ramsey, 2008). However, Altuntaş (2014) and Waltman et al. (2012) found that job satisfaction was less for faculty working on employment terms, including an appointment or contract basis. The appointment and contract terms described above are typically utilized for adjunct faculty employment.

This dissertation study found that adjunct clinical nursing faculty members were generally satisfied with their jobs with a mean value of job satisfaction of 29.42 (with the potential range of responses between 6 and 36). This finding concurs with reports of part-time clinical nursing faculty members in BSN programs who were generally satisfied with their teaching, according to Whalen (2009). Associate degree faculty members indicated similar results with the majority (> 81\%) agreed or strongly agreed that they were satisfied with their jobs; however, the results reflected full-time faculty surveyed (Baker et al., 2011). Similar to Derby-Davis (2014) and Hoyt (2012) this dissertation study revealed a statistically significant relationship between job satisfaction and intent to stay teaching.

\section{Implications of the Findings}

The participants in this dissertation research study were adjunct clinical nursing faculty teaching in associate degree nursing programs in the northeastern US. During the national economic recession in the 1990s, part-time faculty members were hired to cover increased student enrollment and faculty retirement (Gappa \& Leslie, 1993). Since that time, increased hiring practices of adjunct faculty members have become common, 
providing college institutional resources who are quickly hired, cost effective, and experts within their fields. Within nursing education, the majority of adjunct faculty members are hired to teach in the clinical setting. The practice of hiring practicing nursing experts into the clinical portion of nursing education has become common practice to fill the needs of the program (Weidman, 2013; West et al., 2009). The findings of this dissertation study help to better understand the factors that influence the intent to stay teaching. The acknowledgement of these factors could influence academic leaders' ability to foster satisfaction and loyalty to the institution (Hoyt, 2012).

\section{Implications for Nursing Education}

Calls from nursing leaders urge nurse educators to best prepare nursing students for the future of health care (Benner et al., 2010; IOM, 2010). Administrators must consider the implications of hiring novice nurse educators and consider orientation (Baker et al., 2011) and mentoring programs (Dunham-Taylor et al., 2008; Hessler \& Ritchie, 2006) to support and retain this group of educators. Mentoring programs for adjunct faculty are documented to support positive experiences for adjunct faculty and nursing students alike (Hessler \& Ritchie, 2006).

Review of the demographic variable findings from this dissertation study revealed no statistically significant impact of the number of years of teaching experience in nursing education, number of years employed as an adjunct at the current institution, age, and highest level of education completed with intent to stay teaching. However, recognition of adjunct faculty members' number of years of service with incremental salary increases may affect intent to stay. The demographic variable of employment status outside of the adjunct position did reveal a negative impact for the factor of 
working full-time on intent to stay teaching. Although hiring practices based on these demographic variables would not be feasible, selective hiring practices by administrators may prefer hiring of adjunct faculty with part-time or no outside employment. Avoidance of hiring adjunct faculty with known full-time employment outside of the position is anticipated to affect intent to stay teaching and have an impact on hiring, orientation, and training costs for the college. Retaining adjunct nursing faculty from semester to semester can result in reduced expenses for the college in advertising, hiring, orienting, and training costs.

A predicted nursing shortage (Gazza \& Shellenbarger, 2010) and an aging nursing faculty resource with a predicted nursing faculty shortage worsening (Evans, 2013) creates a perfect storm for the nursing education field. In order to increase student enrollment and subsequent graduation of those students, increased hiring practices of additional nursing faculty is anticipated. Adjunct nursing faculty is anticipated to fill the gap where a void of qualified full-time nursing faculty exists to meet the needs. A nationwide trend has been noted for hiring adjunct clinical faculty to teach the increased numbers of nursing students in clinical settings (West et al., 2009). Upon hire, orientation programs are needed to help adjunct faculty with the transition to this role. Comprehensive orientation programs for all adjunct faculty should include the following: communication, mentoring, and professional development to help retain this workforce and potentially reduce the nursing faculty shortage (Forbes et al., 2010).

The results from this dissertation study found that the motivator factors of recognition and work preferences rated lower than established studies. Alternatively, the motivator factor personal growth rated higher than established studies. Motivator factors 
were found to enhance job satisfaction and loyalty to the organization and are intrinsic to the job (Herzberg, 1968). Results from this dissertation study found that all of the motivator factors (recognition, work preference, personal growth) strongly affected intent to stay teaching. These factors are essential to retaining adjunct clinical nursing faculty. These findings suggest that adjunct clinical nursing faculty are intrinsically motivated to provide education to the students. It also suggests that these faculty group members do not feel appreciated nor recognized for their work. Acknowledgement could be improved by providing outstanding adjunct faculty awards (Pearch \& Marutz, 2005), teaching awards, or gratitude by framed certificate or gift certificate with a modest stipend (Murray, 2007).

Hygiene factors of autonomy, classroom (clinical) facilities, quality of students, and teaching schedule from this dissertation study rated lower than established studies by Hoyt (2012) and Hoyt et al. (2008). These findings may be a result of the educational setting being completed within AD nursing programs and particular to the clinical learning environment. The clinical teaching arena is most affected by increased enrollment as a result of direct patient care being provided to acutely ill patients. As a result, state boards of nursing and individual schools of nursing have established limitations of faculty-to-student ratios in the clinical setting. The limited enrollment in the clinical setting requires more faculty to teach in this area.

The hygiene factor of autonomy may be improved by the inclusion of adjunct faculty into the nursing program's decision-making processes regarding types of learning opportunities, clinical sites, and shifts offered. Additionally, inclusion of adjunct faculty into all nursing program, college, and governance meetings would increase these faculty 
members' sense of autonomy and support inclusion in these decision-making activities. In addition, inclusion and valuing of adjunct faculty feedback regarding provision of clinical learning would improve clinical learning for faculty and students. Although inclusion in the academic culture is important, inclusion of part-time faculty into social events is suggested to foster socialization (Hessler \& Ritchie, 2006) and improve intent to stay (Carlson, 2015).

Salary competition from the field will likely remain a concern for adjunct clinical nursing faculty due to competition from the clinical practice setting. However, a consideration to pay adjunct faculty for time spent correcting papers and attending meetings would offset these activities contributing to the low salary perceived (Whalen, 2009). The perception of completing work outside of the clinical day, like correcting papers without pay, further perpetuates a workload imbalance (Carlson, 2015). Hygiene factors of compensation and faculty support for this dissertation sample were similar to studies completed by Hoyt (2012) and Hoyt et al. (2008).

As a result of the regression analysis from this dissertation study, a strong relationship was found between hygiene factors and intent to stay teaching. Hygiene factors are important, according to Herzberg et al. (1959). Although they may not improve job satisfaction, poor ratings of hygiene factors affect dissatisfaction with the job (Herzberg et al., 1959). A result of low ratings of hygiene factors is anticipated to affect the faculty members' intent to stay teaching. Promotion of job satisfaction with support of motivator and hygiene factors must become the priority to retain this workforce. This dissertation study demonstrates that promotion of higher levels of motivator, hygiene, and satisfaction scores enhanced adjunct clinical nurses' intent to stay teaching. Future 
qualitative and quantitative research is needed to examine the impact of administrative leadership retention strategies on adjunct faculty members' job attitudes and intent to stay. Administrators have an opportunity to influence motivator-hygiene factors and influence intent to stay.

\section{Implications for Nursing Practice}

The profession of nursing provides a central role in the delivery of patient care. The clinical practice arena requires an increase in nursing graduates to meet the future needs of the large baby boomer generation now seeking health care resources (BLS, 2013). In order to facilitate increased graduation of nursing students, increased teaching resources are needed. Adjunct clinical nursing faculty members are solicited from the field of nursing and possesses real-work experience. Currency of nursing practice supports student learning and enhances patient care within the clinical setting. Hospital partnerships with area colleges and sharing of expert nurses between these roles would increase job satisfaction. Additionally, the coordination of adjunct nursing faculty teaching clinically at the primary employment site can enhance staff relations and increase the potential of hiring students to that clinical agency upon graduation. The Future of Nursing report calls for a workforce to be better equipped to meet future health care demands (IOM, 2010), and this type of coordination could facilitate this effort. In addition, consistency of health care delivery at an agency familiar to the adjunct clinical instructor would improve patient satisfaction and patient outcomes.

\section{Implications for Nursing Research}

Improvement of ratings of intent to stay for adjunct clinical nursing faculty can improve nursing students' learning experiences in the clinical settings. The results from 
this dissertation study support that high levels of job satisfaction, motivator, and hygiene scores support intent to stay. Improvement of intent to stay and resulting retention of adjunct clinical nursing faculty can improve learning for nursing students.

The results of this dissertation research offer a basis for future nursing research. Future quantitative research studies focusing on adjunct clinical AD nursing faculty predictors of intent to stay should be repeated with larger sample sizes to confirm these results. Further extension of this dissertation study into other geographic areas throughout New York State, and subsequently the US, is needed to extend pedagogical understanding of this phenomenon beyond this local area.

Future research is recommended to expand beyond the clinical teaching arena. Additional study of adjunct nursing faculty who teach in the college laboratory or didactic areas (traditional classroom and online) would add to the breadth of knowledge regarding adjunct faculty predictors of intent to stay teaching. It is recommended that a quantitative study be conducted for the purpose of understanding adjunct nursing faculty teaching in the laboratory or classroom areas. A closer examination of each of these teaching settings could reveal differences from those found of clinical adjunct faculty. Perhaps the learning environment for adjunct nursing faculty varies based on teaching setting.

Research is recommended to identify the causal factors and motivation of adjunct faculty working full-time outside of this adjunct assignment. A qualitative study could ascertain adjunct clinical nursing faculty members' primary reason for teaching and further support understanding of the incentive for this faculty group's reason for teaching. A deeper understanding through study of adjunct nursing faculty working full-time 
outside of the adjunct position can be undertaken to expand upon findings from this dissertation study. These types of study could offer an opportunity to better understand the motivation for this faculty group to teach as an adjunct within an AD program.

Finally, research is suggested through a quantitative study to examine the job attitudes of adjunct clinical nursing faculty teaching in $\mathrm{BSN}$ programs compared to $\mathrm{AD}$ programs to determine if there are significant differences based on program type and setting. Extension of this type of study into BSN nursing programs would provide substantiating data to affect intent-to-stay-teaching scores for all adjunct nurse faculty members. A comparison of adjunct faculty from AD and BSN programs could provide insight as to significant differences between these teaching settings.

\section{Implications for Public Policy}

Utilization of adjunct faculty for clinical teaching is anticipated to increase as the nursing shortage and nursing faculty shortage continues (NCES, 2012). The large baby boomer generation is accessing health care resources and requiring more nurses to meet the needs of the community. Enhancement of job satisfaction factors and intent to stay would enhance teacher retention and reduce the faculty shortage. The results of this dissertation study provide support of job satisfaction, motivator, and hygiene factors to improve intent to stay teaching. Legislative lobbying efforts need to secure resources to support retention and adjunct faculty development. Policies could also enhance retention with incentive programs for nurses furthering their education through grants, scholarships, and loan-forgiveness programs. Non-monetary incentives to include tuition waiver from the community college employer could also enhance faculty development and job satisfaction of this essential faculty group. Additionally, nursing faculty 
mentorship program development (financially supported by grant funding) would secure mentorship models and personnel committed to this supportive element for adjunct faculty.

\section{Limitations}

Findings from this dissertation study were limited in transferability due to the type of analysis completed. Although regression analysis may reveal relationships among variables, it does not imply causal relationships (Tabachnick \& Fidell, 2007). Although the relationships between the variables are important in predicting intent to stay, the underlying reason for the established relationships remains unknown with this type of analysis. The limitation of understanding the reason for the relationship between the independent variables and the dependent variable remains unknown.

Small sample size of 52 participants may also contribute to additional limitations for this dissertation study. A source of error in this study was a possible non-response bias due to the distribution of the survey message via email, leading to the resulting $46 \%$ response rate. In addition, there were no benefits or rewards offered for participation in this survey. Monetary or gift card incentive may have increased participant response rates. Additionally, the questionnaire consisted of 53 questions, which may have led to the number of incomplete surveys. Although only 52 participants completed the entire survey, 61 completed the demographic portion, and 69 completed the first question providing consent for the survey. Participant fatigue could explain the noted dropout rates found here. The survey could be revised to increase response rates and elicit intentto-stay scores if this portion of the survey was located earlier in the questionnaire. 


\section{Threats to Internal Validity}

Threats to internal validity affect the extent to which a researcher is able to make valid inferences that an independent variable is affecting the dependent variable and that the relationship between the two is not the result of extraneous or confounding variables (Polit \& Beck, 2012). Common threats to internal validity include the following: history, maturation, regression, selection, mortality, diffusion of treatment, compensatory/resentful demoralization, compensatory rivalry, testing, and instrumentation (Creswell, 2009). The design utilized for this dissertation study was the descriptive correlational type. The use of this kind of design does not require the researcher to control for history, maturation, regression, mortality, diffusion of treatment, compensatory/resentful demoralization, compensatory rivalry, testing, and instrumentation (Polit \& Beck, 2012). These threats were controlled because the survey for this dissertation study was administered at a one-time administration, avoiding a lapse of time or retesting opportunities to influence participant input.

Yet, one of the main threats in a descriptive correlational study is the selection threat or selection bias due to the inability to randomize subjects (Trochim \& Donnelly, 2008). This dissertation study utilized a voluntary convenience sample. The Department Head/Director/Chairperson or designee self-selected whether or not to disseminate the email with introductory letter and survey link to adjunct clinical nursing faculty employed at their institution, and adjunct clinical nursing faculty self-selected whether or not to complete and submit the survey. Therefore self-selection bias is a possible cause of sampling bias for this dissertation study. The Department Head/Director/Chairperson or designee who chose to forward the email and survey link to their adjunct clinical 
nursing faculty may lead different programs from those who did not forward it. Adjunct clinical nursing faculty members who participated in the survey could be extremely unhappy with their teaching assignment or conversely very happy with the adjunct role, affecting the responses. Adjunct faculty members who chose not to participate may be different from those who completed it. Despite anonymous data collection, there may be hidden fears and concerns from adjunct faculty members feeling pressured to participate or alternatively, worried about how lack of participation could affect future employment at their institutions. In addition, due to the delivery of the survey via Web-based email, individuals could have answered the survey on more than one occasion. The SurveyMonkey Web site limited this threat by allowing only one survey submission per computer.

\section{Threats to External Validity}

In addition, there are limitations in transferability due to the specific population and geographic region being studied. External validity is the ability of a researcher to make inferences or generalizations about findings observed in a study applied to other persons at other times (Trochim \& Donnelly, 2008). Threats to external validity include the following: the interactions of selection and treatment, interaction of setting and treatment, and interaction of history and treatment (Creswell, 2009) and were considered in this dissertation study. The threat from interaction of selection and treatment limits the ability of a researcher to generalize the findings to individuals who do not have the same characteristics of these participants (Creswell, 2009). In this dissertation study, the researcher specifically solicited adjunct clinical nursing faculty in AD professional nursing programs. This dissertation study elicited findings from participants in the 
northeastern US, and therefore, the results may not transfer to other AD professional nursing programs outside of this area. In addition, the limitation of this study to $\mathrm{AD}$ adjunct clinical nursing faculty limits transferability of findings to other types of nursing faculty and other types of nursing programs. Furthermore, findings from this group cannot be transferred to all adjunct nursing faculty (didactic, laboratory, and/or clinical) in other programs (diploma, associate, or baccalaureate). Lastly, because the results of the study were time bound, the researcher cannot generalize the results to past or future situations (Polit \& Beck, 2012). The threat was limited by developing a clear research plan for potential replication in other geographic locations to determine if the same results occur.

\section{Chapter Summary}

This chapter provided an analysis of the findings of this dissertation research study, which was the first to address adjunct clinical nursing faculty members' predictive factors of intent to stay teaching. As a result of this dissertation research, it was found that working a full-time job outside of the adjunct clinical nursing position negatively affected intent to stay teaching. Additionally, evidence was provided to support job satisfaction, motivator, and hygiene scores positively affected intent to stay teaching.

This dissertation study confirmed the relevance of Herzberg et al.'s (1959) twofactor motivator-hygiene theory for the study of AD adjunct clinical nursing faculty members' intent to stay teaching. Results revealed that clinical nursing faculty members have an overall positive perspective of their job while experiencing some levels of dissatisfaction. Both hygiene and motivator factors strongly supported intent to stay. 
This dissertation study also confirmed the use of the Adjunct Faculty Survey and the Nurse Educators' Intent to Stay in Academe Scale survey based on Herzberg's theory. Adjunct clinical nursing faculty indicated an overall positive intent-to-stay score, acknowledging particular categories that rated lower than established studies. The recognition of these particular categories rating lower than established studies raises concern for this faculty group. Specific areas that rated lowest and require administrative attention included the following: autonomy, quality of students, recognition, teaching schedule, and work preference. Suggestions were made in an attempt to mitigate these low ratings. Future studies are needed to evaluate the success of enhancement of motivator and hygiene factors with intent to stay. The number of adjunct nursing faculty hired in nursing education is expected to continue to grow. Support of job satisfaction, motivator, and hygiene factors must become the priority for this faculty group to promote intent to stay teaching! 


\section{References}

Accreditation Commission for Education in Nursing. (2013). ACEN 2013 standards and criteria: Associate. Retrieved from http://www.acenursing.net/manuals/SC2013_ASSOCIATE.pdf

Al-Omari, A. A., Qablan, A. M., \& Khasawneh, S. M. (2008). Faculty members' intentions to stay in Jordanian public universities. International Journal of Applied Educational Studies, 1(1), 25-42.

Allen, D. E., Ploeg, J., \& Kaasalainen, S. (2012). The relationship between emotional intelligence and clinical teaching effectiveness in nursing faculty. Journal of Professional Nursing, 28(4), 231-240. doi: 10.1016/j.profnurs.2011.11.018

Altuntaş, S. (2014). Factors affecting the job satisfaction levels and quit intentions of academic nurses. Nurse Education Today, 34(4), 513-519. doi:

10.1016/j.nedt.2013.07.002

American Association of Colleges of Nursing. (2014). Special survey on vacant faculty positions for academic year 2013-2014. Retrieved from http://www.aacn.nche.edu/leading-initiatives/research-data/vacancy13.pdf American Association of Colleges of Nursing. (2015). Nursing faculty shortage fact sheet. Retrieved from http://www.aacn.nche.edu/mediarelations/FacultyShortageFS.pdf

American Association of Community Colleges. (n.d.). Community college trends and statistics. Retrieved from http://www.aacc.nche.edu/AboutCC/Trends/Pages/default.aspx 
Robert Wood Johnson Foundation Future of Nursing Initiative Institute of Medicine Forum on Education. (2010). American Association of Community Colleges written testimony. Retrieved from http://www.aacc.nche.edu/Resources/aaccprograms/health/Documents/iomtestimo ny_02222010.pdf

Amicucci, B. (2012). What nurse faculty have to say about clinical grading. Teaching \& Learning in Nursing, 7(2), 51-55. doi: 10.1016/j.teln.2011.09.002

Anderson, N. (2014, February 11). New federal health-care rules define workload of parttime college instructors. The Washington Post. Retrieved from http://www.washingtonpost.com/local/education/new-federal-health-care-rulesdefine-workload-of-part-time-college-instructors/2014/02/11/6b1b29c4-934511e3-b46a-5a3d0d2130da_story.html

Antony, J. S., \& Hayden, R. A. (2011). Job satisfaction of American part-time college faculty: Results from a national study a decade later. Community College Journal of Research and Practice, 35(9), 689-709. doi: 10.1080/10668920801949513

Baker, S. L., Fitzpatrick, J. J., \& Griffin, M. Q. (2011). Empowerment and job satisfaction in associate degree nurse educators. Nursing Education Perspectives, 32(4), 234-239. doi: 10.5480/1536-5026-32.4.234

Bell-Scriber, M. J., \& Morton, A. M. (2009). Clinical instruction: Train the trainer. Nurse Educator, 34(2), 84-87. doi: 10.1097/NNE.0b013e31819ae753

Benner, P., Sutphen, M., Leonard, V., \& Day, L. (2010). Educating nurses: A call for radical transformation. San Francisco, CA: Jossey-Bass. 
Berent, G. R., \& Anderko, L. (2011). Solving the nurse faculty shortage. Nurse Educator, 36(5), 203-207. doi: 10.1097/NNE.0b013e3182297c4a

Bettinger, E. P., \& Long, B. T. (2010). Does cheaper mean better? The impact of using adjunct instructors on student outcomes. The Review of Economics and Statistics, 92(3), 598-613.

Bittner, N. P., \& O'Connor, M. (2012). Focus on retention: Identifying barriers to nurse faculty satisfaction. Nursing Education Perspectives, 33(4), 251-254.

Boord, M. (2010). Analysis of adjunct faculty at Des Moines Area Community College: Use and application of Herzberg's motivation-hygiene theory to predict job satisfaction in teaching improvement and professional development (Doctoral dissertation). Retrieved from ProQuest Dissertations \& Theses Global. (Order No. $3438673)$

Boyer, E. L. (1990). Scholarship reconsidered: Priorities of the professoriate. New York, NY: John Wiley \& Sons.

Brady, M. S. (2007). Educational innovations. Recruitment and retention of associate degree nursing faculty. Journal of Nursing Education, 46(4), 190-192.

Candela, L., Gutierrez, A., \& Keating, S. (2013). A national survey examining the professional work life of today's nursing faculty. Nurse Education Today, 33(8), 853-859. doi: 10.1016/j.nedt.2012.10.004

Candela, L., Gutierrez, A. P., \& Keating, S. (2015). What predicts nurse faculty members' intent to stay in the academic organization? A structural equation model of a national survey of nursing faculty. Nurse Education Today, 35(4), 580-589. doi: 10.1016/j.nedt.2014.12.018 
Cangelosi, P. R., Crocker, S., \& Sorrell, J. M. (2009). Expert to novice: Clinicians learning new roles as clinical nurse educators. Nursing Education Perspectives, 30(6), 367-371.

Carlson, J. S. (2015). Factors influencing retention among part-time clinical nursing faculty. Nursing Education Perspectives, 36(1), 42-45. doi: 10.5480/13-1231

Caruth, G. D., \& Caruth, D. L. (2013). Adjunct faculty: Who are these unsung heroes of academe? Current Issues in Education, 16(3), 1-11.

Cash, P. A., Daines, D., Doyle, R. M., \& von Tettenborn, L. (2009). Quality workplace environments for nurse educators: Implications for recruitment and retention. Nursing Economic\$, 27(5), 315-321.

Cashwell, A. L. (2009). Factors affecting part-time faculty job satisfaction in the Colorado Community College system. (Doctoral dissertation). Retrieved from ProQuest Dissertations \& Theses Global. (Order No. 3400990)

Caton, B., Conner, E., DeWitt, J., Jones, D., \& Stubbs, N. (2007). Student-to-faculty ratios, teaching loads, and salaries in associate degree nursing programs in the central United States. Teaching and Learning in Nursing, 2(1), 17-21.

Charlier, H. D., \& Williams, M. R. (2011). The reliance on and demand for adjunct faculty members in America's rural, suburban, and urban community colleges. Community College Review, 39(2), 160-180. doi: 10.1177/0091552111405839

Clark, H. G., Moore, B. A., Johnston, L. B., \& Openshaw, L. (2011). Using adjuncts in social work education: Challenges and rewards. Social Work Education, 30(8), 1012-1021. doi: http://dx.doi.org/10.1080/02615479.2010.534450 
The College Board. (n.d.). Why commmunity college? Retrieved from https://professionals.collegeboard.com/guidance/college/community-college

Couch, J. J. (2014). An examination of adjunct faculty job satisfaction and loyalty in Christian higher education. (Doctoral dissertation). Retrieved from ProQuest Dissertations \& Theses Global. (Order No. 3624178)

Cranford, J. S. (2013). Bridging the gap: Clinical practice nursing and the effect of role strain on successful role transition and intent to stay in academia. International Journal of Nursing Education Scholarship, 10(1), 1-7. doi: 10.1515/ijnes-20120018

Creech, C. J. (2008). Are we moving toward an expanded role for part-time faculty? Nurse Educator, 33(1), 31-34.

Creswell, J. W. (2009). Research design: Qualitative, quantitative, and mixed methods approaches (3rd ed.). Thousand Oaks, CA: Sage Publications.

Crotty, M. (2010). The foundations of social research: Meaning and perspective in the research process. Thousand Oaks, CA: Sage Publications.

Cruickshank, J. (2012). Positioning positivism, critical realism and social constructionism in the health sciences: A philosophical orientation. Nursing Inquiry, 19(1), 71-82. doi: 10.1111/j.1440-1800.2011.00558.x

Dahlke, S., Baumbusch, J., Affleck, F., \& Kwon, J.-Y. (2012). The clinical instructor role in nursing education: A structured literature review. The Journal of Nursing Education, 51(12), 692-696. doi: 10.3928/01484834-20121022-01 
Dempsey, L. M. (2007). The experiences of Irish nurse lecturers role transition from clinician to educator. International Journal of Nursing Education Scholarship, 4(1), 1-12. doi: 10.2202/1548-923x.1381

Derby-Davis, M. J. (2014). Predictors of nursing faculty's job satisfaction and intent to stay in academe. Journal of Professional Nursing, 30(1), 19-25. doi: 10.1016/j.profnurs.2013.04.001

deYoung, S., \& Bliss, J. (1995). Nursing faculty-An endangered species? Journal of Professional Nursing, 11(2), 84-88.

Dickson, C., Walker, J., \& Bourgeois, S. (2006). Facilitating undergraduate nurses clinical practicum: The lived experience of clinical facilitators. Nurse Education Today, 26(5), 416-422. doi: 10.1016/j.nedt.2005.11.012

Diegel, B. L. (2013). Perceptions of community college adjunct faculty and division chairpersons: Support, mentoring, and professional development to sustain academic quality. Community College Journal of Research \& Practice, 37(8), 596-607. doi: 10.1080/10668926.2012.720863

DiMaria, F. (2012). Tenure and America's community colleges. Education Digest: Essential Readings Condensed for Quick Review, 78(1), 44-47.

Duffy, N., Stuart, G., \& Smith, S. (2008). Assuring the success of part-time faculty. Nurse Educator, 33(2), 53-54. doi: 10.1097/01.nne.0000299502.09658.97

Dunham-Taylor, J., Lynn, C. W., Moore, P., McDaniel, S., \& Walker, J. K. (2008). What goes around comes around: Improving faculty retention through more effective mentoring. Journal of Professional Nursing, 24(6), 337-346. 
Duphily, N. H. (2011). The experience of novice nurse faculty in an associate degree education program. Teaching \& Learning in Nursing, 6(3), 124-130. doi: 10.1016/j.teln.2011.01.002

Economic Modeling Specialists International. (2014). Where value meets values: The economic impact of community colleges. Retrieved from http://www.aacc.nche.edu/About/Documents/USA_AGG_MainReport_Final_021 114.pdf

Evans, J. D. (2013). Factors influencing recruitment and retention of nurse educators reported by current nurse faculty. Journal of Professional Nursing, 29(1), 11-20. doi: 10.1016/j.profnurs.2012.04.012

Falk, N. L. (2007). Strategies to enhance retention and effective utilization of aging nurse faculty. Journal of Nursing Education, 46(4), 165-169.

Fang, D., \& Bednash, G. D. (2014). Attrition of full-time faculty from schools of nursing with baccalaureate and graduate programs, 2010 to 2011. Nursing Outlook, 62(3), 164-173. doi: 10.1016/j.outlook.2013.12.002

Fjortoft, N., Mai, T., \& Winkler, S. R. (2011). Use of adjunct faculty members in classroom teaching in departments of pharmacy practice. American Journal of Pharmaceutical Education, 75(7), 129-129. doi: 10.5688/ajpe757129

Fjortoft, N., Winkler, S. R., \& Mai, T. (2012). Pharmacy practice department chairs' perspectives on part-time faculty members. American Journal of Pharmaceutical Education, 76(4), 1-5. doi: 10.5688/ajpe76459 
Flaherty, C. (2012). Who deserves affordable care? Inside Higher Ed. Retrieved from https://www.insidehighered.com/news/2012/12/05/higher-education-officialslook-washington-guidance-adjuncts-and-affordable-care-act

Forbes, M. O., Hickey, M. T., \& White, J. (2010). Adjunct faculty development: Reported needs and innovative solutions. Journal of Professional Nursing, 26(2), 116-124. doi: 10.1016/j.profnurs.2009.08.001

Foxall, M., Megel, M. E., Grigsby, K., \& Billings, J. S. (2009). Faculty retirement: Stemming the tide. Journal of Nursing Education, 48(3), 172-175. doi: 10.3928/01484834-20090301-07

Gappa, J. M., \& Leslie, D. W. (1993). The invisible faculty: Improving the status of parttimers in higher education. San Francisco, CA: Jossey-Bass Publishers.

Garbee, D. D., \& Killacky, J. (2008). Factors influencing intent to stay in academia for nursing faculty in the southern United States of America. International Journal of Nursing Education Scholarship, 5(1), 1-15. doi: 10.2202/1548-923x.1456

Gardner, S. S. (2014). From learning to teach to teaching effectiveness: Nurse educators describe their experiences. Nursing Education Perspectives, 35(2), 106-111. doi: $10.5480 / 12-821.1$

Gazza, E. A. (2009). The experience of being a full-time nursing faculty member in a baccalaureate nursing education program. Journal of Professional Nursing, 25(4), 218-226. doi: 10.1016/j.profnurs.2009.01.006

Gazza, E. A., \& Shellenbarger, T. (2005). Successful enculturation: Strategies for retaining newly hired nursing faculty. Nurse Educator, 30(6), 251-254. 
Gazza, E. A., \& Shellenbarger, T. (2010). The lived experience of part-time baccalaureate nursing faculty. Journal of Professional Nursing, 26(6), 353-359. doi: 10.1016/j.profnurs.2010.08.002

George, D., \& Mallery, M. (2010). SPSS for Windows step by step: A simple guide and reference. 17.0 update (10 ed.). Boston, MA: Pearson.

Gillespie, M., \& McFetridge, B. (2006). Nurse education-The role of the nurse teacher. Journal of Clinical Nursing, 15(5), 639-644. doi: 10.1111/j.13652702.2006.01344.x

Gilmore, M. (2008). Predictors of success in associate degree nursing programs. Teaching \& Learning in Nursing, 3(4), 121-124.

Halcrow, C., \& Olson, M. R. (2008). Adjunct faculty: Valued resource or cheap labor? Focus on Colleges, Universities, and Schools, 2(1), 1-8.

Harty, L. H. (2008). Nurse faculty job satisfaction in West Virginia. (Master's thesis), Mountain State University, Ann Arbor. Retrieved from ProQuest Dissertations \& Theses Global. (Order No. 1454184)

Heinrich-Heine Universität Düsseldorf. (2014). G*Power 3.1. Retrieved from http://www.psycho.uni-duesseldorf.de/abteilungen/aap/gpower3/

Herzberg, F. (1968). One more time: How do you motivate employees? Harvard Business Review, 46(1), 53-62.

Herzberg, F., Mausner, B., \& Snyderman, B. (1959). Motivation to work (2 ed.). London, England: John Wiley \& Sons.

Hessler, K., \& Ritchie, H. (2006). Faculty forum. Recruitment and retention of novice faculty. Journal of Nursing Education, 45(5), 150-154. 
Hewitt, P., \& Lewallen, L. P. (2010). Ready, set, teach! How to transform the clinical nurse expert into the part-time clinical nurse instructor. The Journal of Continuing Education in Nursing, 41(9), 403-407. doi: 10.3928/00220124-20100503-10

Housel, N., Gandy, J., \& Edmondson, D. (2010). Clinical instructor credentialing and student assessment of clinical instructor effectiveness. Journal of Physical Therapy Education, 24(2), 26-34.

Hoyt, J. E. (2012). Predicting the satisfaction and loyalty of adjunct faculty. Journal of Continuing Higher Education, 60(3), 132-142.

Hoyt, J. E., Howell, S. L., \& Eggett, D. (2007). Dimensions of part-time faculty job satisfaction: Development and factor analysis of a survey instrument. Mountain Plains Adult Education Association Journal of Adult Education, 36(2), 23.

Hoyt, J. E., Howell, S. L., Glines, L. J., Johnson, C., Spackman, J. S., Thompson, C., \& Rudd, C. (2008). Assessing part-time faculty job satisfaction in continuing higher education: Implications for the profession. Journal of Continuing Higher Education, 56(1), 27-38.

Institute of Medicine. (2010). The future of nursing: Leading change, advancing health. Retrieved from http://iom.edu/Reports/2010/The-Future-of-Nursing-LeadingChange-Advancing-Health.aspx

Isaacson, J. J., \& Stacy, A. S. (2009). Rubrics for clinical evaluation: Objectifying the subjective experience. Nurse Education in Practice, 9(2), 134-140. doi: 10.1016/j.nepr.2008.10.015 
James, S. G., \& Binder, D. A. (2011). The care and feeding of part-time faculty: A model to retain community college adjuncts. National Forum of Educational Administration \& Supervision Journal, 28(3), 21-30.

Jamshidi, L. (2012). The challenges of clinical teaching in nursing skills and lifelong learning from the standpoint of nursing students and educators. Procedia-Social and Behavioral Sciences, 46, 3335-3338. doi: 10.1016/j.sbspro.2012.06.062

Kaufman, K. (2007a). Headlines from the NLN. Introducing the NLN/Carnegie national survey of nurse educators: Compensation, workload, and teaching practice. Nursing Education Perspectives, 28(3), 164-167.

Kaufman, K. (2007b). Headlines from the NLN. More findings from the NLN/Carnegie national survey: How nurse educators spend their time. Nursing Education Perspectives, 28(5), 296-297.

Koharchik, L. (2014). Delineating the role of the part-time clinical nurse instructor. American Journal of Nursing, 114(5), 65-67. doi: 10.1097/01.NAJ.0000446781.07147.3e

Kramer, A. L., Gloeckner, G. W., \& Jacoby, D. (2014). Roads scholars: Part-time faculty job satisfaction in community colleges. Community College Journal of Research \& Practice, 38(4), 287-299. doi: 10.1080/10668926.2010.485005

Landrum, R. E. (2009). Are there instructional differences between full-time and parttime faculty? College Teaching, 57(1), 23-26.

Lane, K. A., Esser, J., Holte, B., \& McCusker, M. A. (2010). A study of nurse faculty job satisfaction in community colleges in Florida. Teaching \& Learning in Nursing, 5(1), 16-26. doi: 10.1016/j.teln.2009.05.001 
Lee, P. B. (2014). Recruitment, retention, job satisfaction of nurse educators in Arkansas. (Doctoral dissertation), University of Arkansas. Retrieved from EBSCOhost (Order No. 3629226)

Liu, X. S., \& Ramsey, J. (2008). Teachers' job satisfaction: Analyses of the teacher follow-up survey in the United States for 2000-2001. Teaching \& Teacher Education, 24(5), 1173-1184. doi: 10.1016/j.tate.2006.11.010

Lodhi, A. S., Raza, S. A., \& Dilshad, M. (2013). Investigating factors affecting faculty retention at business schools. Journal of Educational Research, 16(2), 21-33.

McDermid, F., Peters, K., Jackson, D., \& Daly, J. (2012). Factors contributing to the shortage of nurse faculty: A review of the literature. Nurse Education Today, 32(5), 565-569. doi: 10.1016/j.nedt.2012.01.011

McDonald, P. J. (2010). Transitioning from clinical practice to nursing faculty: Lessons learned. Journal of Nursing Education, 49(3), 126-131. doi: 10.3928/0148483420091022-02

McNeil-Hueitt, T. D. (2003). The unseen educators: Job satisfaction and adjunct community college instructors in the southeastern region of North Carolina. (Doctoral dissertation), Capella University, Ann Arbor. Retrieved from ProQuest Dissertations \& Theses Global. (Order No. 3100240)

Meixner, C., Kruck, E. S., \& Madden, L. T. (2010). Inclusion of part-time faculty for the benefit of faculty and students. College Teaching, 58(4), 141-147.

Munroe, B. H. (2005). Statistical methods for health care research (5th ed.). Philadelphia, PA: Lippincott. 
Murray, J. P. (2007). Recruiting and retaining rural community college faculty. New Directions for Community Colleges, 2007(137), 57-64. doi: 10.1002/cc.270

National Center for Education Statistics. (2012). Number of instructional faculty in degree-granting postsecondary institutions, by employment status, sex, control, and level of institution: Selected years, fall 1970 through fall 2011. Retrieved from http://nces.ed.gov/programs/digest/d13/tables/dt13_315.10.asp?current=yes.

National League for Nursing. (2010a). 2010 NLN nurse educator shortage fact sheet. Retrieved from http://www.ctleaguefornursing.org/upload/files/NurseFacultyShortage.pdf

National League for Nursing. (2010b). National League for Nursing releases faculty census data. Retrieved from http://www.nln.org/newsroom/news-releases/newsrelease/2010/09/22/national-league-for-nursing-releases-faculty-census-data-114

Pearch, W. J., \& Marutz, L. (2005). Retention of adjunct faculty in community colleges. Community College Enterprise, 11(1), 29-44.

Peters, M. A., \& Boylston, M. (2006). Mentoring adjunct faculty: Innovative solutions. Nurse Educator, 31(2), 61-64.

Polit, D. F., \& Beck, C. T. (2012). Nursing research: Generating and assessing evidence for nursing practice (9th ed.). Philadelphia, PA: Lippincott.

Price, J. L., \& Mueller, C. W. (1981). A casual model of turnover for nurses. Academy of Management Journal, 24, 543-565.

Roberts, K. K., Chrisman, S. K., \& Flowers, C. (2013). The perceived needs of nurse clinicians as they move into an adjunct clinical faculty role. Journal of Professional Nursing, 29(5), 295-301. doi: 10.1016/j.profnurs.2012.10.012 
Roberts, S. J., \& Glod, C. (2013). Faculty roles: Dilemmas for the future of nursing education. Nursing Forum, 48(2), 99-105. doi: 10.1111/nuf.12018

Rosser, V. J. (2004). Faculty members' intentions to leave: A national study on their worklife and satisfaction. Research in Higher Education, 45(3), 285-309. doi: http://dx.doi.org/10.1023/B:RIHE.0000019591.74425.f1

Rosser, V. J., \& Townsend, B. K. (2006). Determining public 2-year college faculty's intent to leave: An empirical model. Journal of Higher Education, 77(1), 124147.

Roughton, S. E. (2013). Nursing faculty characteristics and perceptions predicting intent to leave. Nursing Education Perspectives, 34(4), 217-225.

Ruel, S. P. (2009). Factors influencing nurse faculty's job satisfaction and intent to stay. (Doctoral dissertation). Retrieved from Dissertations \& Theses Global. (Order No. 3367202)

Ryan, J., Healy, R., \& Sullivan, J. (2012). Oh, won't you stay? Predictors of faculty intent to leave a public research university. Higher Education, 63(4), 421-437. doi: $10.1007 / \mathrm{s} 10734-011-9448-5$

Santisteban, L., \& Egues, A. L. (2014). Cultivating adjunct faculty: Strategies beyond orientation. Nursing Forum, 49(3), 152-158. doi: 10.1111/nuf.12106

Sawatzky, J. V., \& Enns, C. L. (2009). A mentoring needs assessment: Validating mentorship in nursing education. Journal of Professional Nursing, 25(3), 145150. doi: 10.1016/j.profnurs.2009.01.003 
Schmidt, B., \& MacWilliams, B. (2011). Admission criteria for undergraduate nursing programs. Nurse Educator, 36(4), 171-174. doi:

10.1097/NNE.0b013e31821fdb9d

Schoening, A. M. (2013). From bedside to classroom: The nurse educator transition model. Nursing Education Perspectives, 34(3), 167-172.

Schulz, S. D. (2009). Predicting job satisfaction among Iowa community college adjunct faculty members: Use and application of Herzberg's motivation-hygiene theory. (Doctoral dissertation). Retrieved from ProQuest Dissertations \& Theses Global. (Order No. 3389145)

Stenerson, J., Blanchard, L., Fassiotto, M., Hernandez, M., \& Muth, A. (2010). The role of adjuncts in the professoriate. Peer Review, 12(3), 23-26.

Tabachnick, B. G., \& Fidell, L. S. (2007). Using multivariate statistics (5 th ed.). Boston, MA: Pearson.

Teel, C., Smith, A., \& Thomas, D. (2008). Spread too thin: Faculty perspectives about faculty-student ratios. The Kansas Nurse, 83(9), 3-6.

Thirolf, K. Q. (2012). The faculty identities of community college adjuncts teaching in the humanities: A discourse analysis study. Community College Journal of Research \& Practice, 36(4), 269-278. doi: 10.1080/10668926.2012.637864

Thirolf, K. Q. (2013). How faculty identity discourses of community college part-time faculty change over time. Community College Journal of Research \& Practice, 37(3), 177-184. doi: 10.1080/10668926.2013.739511 
Tomanek, J. K. (2010). Job satisfaction of community college adjunct faculty at Midwestern Community College. (Doctoral dissertation). Retrieved from ProQuest Dissertations \& Theses Global. (Order No. 3438738)

Tourangeau, A. E., Thomson, H., Saari, M., Widger, K., Ferron, E. M., \& MacMillan, K. (2012). Determinants of nurse faculty intention to remain employed. Open Journal of Nursing, 2(3), 254-261. doi: 10.4236/ojn.2012.23039

Trochim, W. M. K., \& Donnelly, J. P. (2008). The research methods knowledge base. Mason, $\mathrm{OH}$ : Cengage.

U.S. Census Bureau. (2013). Men in nursing occupations: American community survey highlight report. Retrieved from https://www.census.gov/people/io/files/Men_in_Nursing_Occupations.pdf

U.S. Department of Education, National Center for Education Statistics. (2002). A profile of part-time faculty: Fall 1998, NCES 2002-08 (NIH working paper 2002-08). Washington, DC: National Center for Eduation Statistics. Retrieved from http://nces.ed.gov/pubs2002/200208.pdf.

U.S. Department of Labor, Bureau of Labor Statistics. (2013). Employment projections 2012 - 2022. Retrieved from http://www.bls.gov/news.release/archives/ecopro_12192013.pdf.

U.S. Department of Labor, Bureau of Labor Statistics. (2015a). Occupational employment and wages, nursing instructors and teachers, postsecondary, May 2014. Retrieved from http://www.bls.gov/oes/current/oes251072.htm. 
U.S. Department of Labor, Bureau of Labor Statistics. (2015b). Occupational employment and wages, registered nurses, May 2014. Retrieved from http://www.bls.gov/oes/current/oes291141.htm.

Urwin, S., Stanley, R., Jones, M., Gallagher, A., Wainwright, P., \& Perkins, A. (2010). Understanding student nurse attrition: Learning from the literature. Nurse Education Today, 30(2), 202-207. doi: 10.1016/j.nedt.2009.07.014

Valadez, J. R., \& Anthony, J. S. (2001). Job satisfaction and commitment of two-year college part-time faculty. Community College Journal of Research \& Practice, 25(2), 97-108. doi: 10.1080/10668920150218489

Wagoner, R. L. (2007). Part-time faculty satisfaction across missions and disciplines. New Directions for Community Colleges, 2007(140), 75-81. doi: 10.1002/cc.307

Wallin, D. L. (2004). Valuing professional colleagues: Adjunct faculty in community and technical colleges. Community College Journal of Research \& Practice, 28(4), 373-391. doi: 10.1080/10668920490424087

Waltman, J., Bergom, I., Hollenshead, C., Miller, J., \& August, L. (2012). Factors contributing to job satisfaction and dissatisfaction among non-tenure-track faculty. Journal of Higher Education, 83(3), 411-434.

Weidman, N. A. (2013). The lived experience of the transition of the clinical nurse expert to the novice nurse educator. Teaching and Learning in Nursing, 8(3), 102-109. doi: 10.1016/j.teln.2013.04.006

West, E. (2010). Managing adjunct professors: Strategies for improved performance. Academy of Educational Leadership Journal, 14(4), 21-36. 
West, M. M., Borden, C., Bermudez, M., Hanson-Zalot, M., Amorim, F., \& Marmion, R. (2009). Enhancing the clinical adjunct role to benefit students. Journal of Continuing Education in Nursing, 40(7), 305-310. doi: 10.3928/0022012420090623-05

Whalen, K. S. (2009). Work-related stressors experienced by part-time clinical affiliate nursing faculty in baccalaureate education. International Journal of Nursing Education Scholarship, 6(1), 1-18. doi: 10.2202/1548-923x.1813

Wiens, S., Babenko-Mould, Y., \& Iwasiw, C. (2014). Clinical instructors' perceptions of structural and psychological empowerment in academic nursing environments. Journal of Nursing Education, 53(5), 265-270. doi: 10.3928/01484834-2014042101

Wilson, R. (2012). 2 tracks for faculty. The Chronicle of Higher Education. Retrieved from http://eric.ed.gov/?id=EJ990354

Wyles, B. A. (1998). Adjunct faculty in the community college: Realities and challenges. New Directions for Higher Education, 1998(104), 89-93. doi: 10.1002/he.10409

Xu, Y. J. (2008). Faculty turnover: Discipline-specific attention is warranted. Research in Higher Education, 49(1), 40-61. doi: 10.1007/s11162-007-9062-7 


\section{Appendix A}

IRB Approvals

NOVA SOUTHEASTERN UNIVERSITY

Office of Granss sind Contracts

Institutsonal Roview Bourd

\section{MEMORANDUM}

To: Julic Woodworth, PhDc, RN, CNE

Health Professions Division - College of Nursing

From: Jo Ann Kleier, PhD, EdD, ARNP

Institutional Review Board

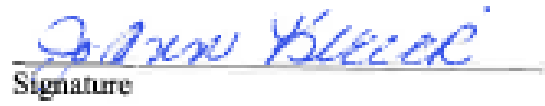

Date: June 14,2015

Re: Predictive Factors Impacting Intent to Siuy Teaching for Assaciate Degree Adjunct Clinical Nurse Faculty

I have reviewed the above-referenced research protocol at the center level. Based on the information provided, I have defermined that this study is exempt from further IRB review. You may proceed with your study as described to the IRB. As principal investigator, you must adhere to the following requirements:

1) COVSENT: If recruitment procodures include consent forms these must be obtained in such a manner that they are clearly understood by the subjects and the process affords subjects the opportunity to ask questions, obtain detailed answers from those directly involved in the research, and have sufficient time to consider their participation after they have been provided this information. The subjects must be given a copy of the signed consent document, and a copy must be placed in a secure file separate from de-identified participant information. Record of informed consent must be retained for a minimum of three years from the conclusion of the study.

2) ADVERSE EVENTS/REACTIONS: The principal investigator is required to notify the IRB chair and me (954-262-5369 and 954-262-1978 respectively) of any adverse reactions of unanticipated events that may develop as a result of this study. Reactions or events may include, but are not limited to, injury, depression as a result of participation in the study, life-threatening situation, death, or loss of confidentiality/anonymity of subject. Approval may be withdrawn if the problem is serious.

3) AMENDMENTS: Any changes in the study (e.g., procedures, number or types of subjects, consent forms, investigators, etc.) must be approved by the IRB prior to implementation. Please be advised that changes in a study may require further review depending on the nature of the change. Please contact me with any questions regarding ameadments or changes to your study.

The NSU IRB is in compliance with the requirements for the protection of human subjects prescribed in Part 46 of Title 45 of the Code of Federal Regulations (45 CFR 46) revised June 18, 1991.

Cc: Protocol File

Office of Grants and Contracts (if stedy is funded)

3301 College Avemus • Fort Leuderdale, FL 33314-7796 • (954) 262-5369

Fax: (954) 262-3977 * Ettail inga Qusu nova.edu * Web site: waw.novzedalewis oge 


\section{IRB Approval}

\section{Monroe Community College}

State University of New York

Institutional Review Board
James R. Cronmiller, Chairperson

Jeanne Dowden

Angel Andreu

Vilma Patterson

Joan Moorehead

Patricia Williams, Administrator

June 15, 2015

Julie Woodworth

Nova Southeastern University

3301 College Ave

Fort Lauderdale, FL 33314

Dear Ms. Woodworth,

Title of Study: “Predictive Factors Impacting Intent to Stay Teaching for Associate Degree Adjunct Clinical Nurse Faculty"

Principal Investigator: Julie Woodworth

As chairman of Monroe Community College's (MCC) Institutional Review Board I reviewed the following materials submitted by Julie Woodworth:

- Abstract

- Study Proposal

- Signed Monroe Community College Expedited Form

- Survey Questions

After thorough review of all forms the research submission is approved under the expedited category.

- If you feel your project will continue past the one year date of initial study approval you will need to submit a renewal form to MCC IRB prior to the renewal deadline of June 15, 2016. Please submit that renewal form one month (May 2016) prior to the renewal deadline.

- Report any increased risk to study participants.

- Any change in protocol form may not be implemented without prior IRB approval.

- Failure to comply with any of the above requirements will result in the suspension or revocation of IRB approval.

Please contact me if you have any questions or need additional information.

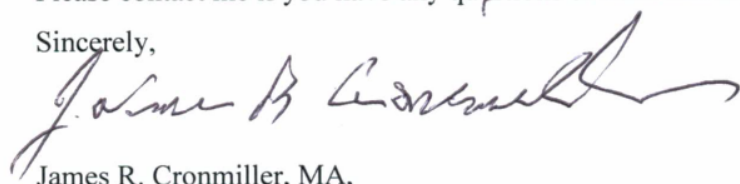

R. Cronmiller, MA,

Chairman, Institutional Review Board

Monroe Community College 


\section{FLCC IRB Approval}

Finger Lakes Community College 3325 Marvin Sands Drive Canandaigua, NY 144248395 p: 585.394.FLCC f: 585.394 .5005

Finger Lakes Community College is a supportive, learning-centered environment that empowers our students, provides enriching life experiences, and enhances the quality of life throughout our community.

Date: $8 / 25 / 2015$

To: Julie Woodworth

From: Mary McLean-Scanlon

Subject: IRB Approval - Project Name: Nova Southeastern University

Your project, identified above, was reviewed by Finger Lakes Community College's Institutional Review

Board and has received Expedited Approval.

This approval is limited to the activities referenced in the approved protocol narrative. If your project undergoes any changes, these changes must be reported to our office prior to implementation. In addition, you must report any problems involving the conduct of the study or subject participation.

Policy requires you to maintain, as a part of your records, any documents pertaining to the use of human subjects in your research. The principal investigator is responsible for retaining informed consent documents for a period of three years after the project. This includes any information or materials conveyed to, and received from the subjects as well as any consent forms, data and analysis results.

Please notify FLCC's IRB when your project in complete.

Thank you for your cooperation. Please do not hesitate to contact our office if you have any questions or require additional assistance. I wish you success in your research.

Cordially,

Mary Mclean-Scanlon Director of Institutional Effectiveness Institutional Review Board, Chair Finger Lakes Community College 585-785-1778 mary.mcleanscanlon@flcc.edu 


\section{ECC IRB Approval}

$\underline{6 / 5 / 15}$

Date Submitted

Institutional Review Board

File Number

\section{Expedited Protocol Summary Form}

Predictive Factors Impacting Intent to Stay Teaching for Associate Degree Adjunct Clinical Nurse Faculty

\begin{tabular}{|c|c|c|c|}
\hline \multicolumn{4}{|l|}{ Title of Research Project } \\
\hline Julie Woodworth, PhDc, RN, MSN & \multicolumn{2}{|c|}{ cell 5857489814} & jw1550@nova.edu \\
\hline Principal Investigator/Project Director & Department & Phone Extension & il address \\
\hline Diane Whitehead & & Nursing Education & $954-262-1982$ \\
\hline
\end{tabular}

Anticipated Funding Source: None

Projected Duration of Research: 2

months Projected Starting Date: September 2015

Other organizations and/or agencies, if any, involved in the study: Nova Southeastern University

SUMMARY ABSTRACT: Please supply the following information below: BRIEF description of the participants, the location(s) of the project, the procedures to be used for data collection, whether data will be confidential or anonymous, disposition of the data, who will have access to the data.

I am a student at Nova Southeastern University and am completing this research for completion of my dissertation requirements. The participants for this study are adjunct (or part-time) clinical nurse faculty teaching in an ACEN accredited associate degree nursing programs. I would like to capture adjunct clinical nurse faculty who are working at the North and City campuses. In September 2015, an email will be sent to the Associate Vice President/Department Head or designee of the associate degree nursing program. The email will include details of the study with an explanation that consent will be implied by clicking on the link to the survey. Associate Vice President/Department Head or designee will be asked to disseminate the study information and survey link to all adjunct clinical nurse faculties employed during the 2015 calendar year via available email. A follow up email will be sent to the Associate Vice President/Department Head or designee approximately two weeks following the first to ask for dissemination of the information and survey link to adjunct clinical nurse faculty again. The website survey will remain available for two more weeks at which time the survey will be closed and data securely downloaded directly from Survey Monkey secure server into Microsoft Excel and imported into Statistical Package for the Social Sciences (SPSS) for analysis. All responses will be anonymous and viewed only by the researcher. All data will be stored in a password protected computer stored in a locked file cabinet for three years, then destroyed. Findings from this study will be reported using group averages in aggregate form only. 
RESPONSIBILITIES OF THE PRINCIPAL INVESTIGATOR:

- Any additions or changes in procedures in the protocol will be submitted to the IRB for written approval prior to these changes being implemented

- Any problems connected with the use of human subjects once the project has begun must be communicated to the IRB Chair

- The principal investigator is responsible for retaining informed consent documents for a period of three years after the project.

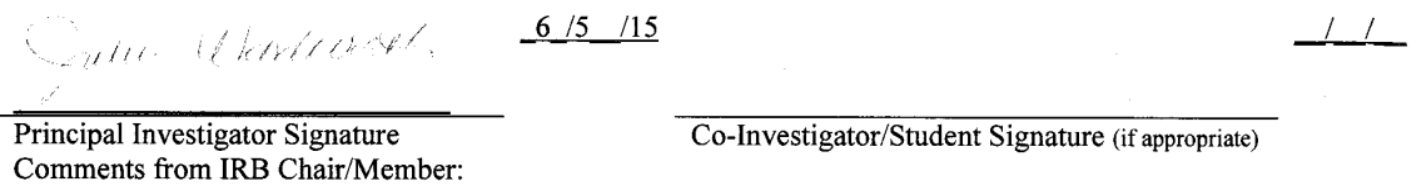

\begin{tabular}{|l|}
\hline Signature of IRB Committee Chair: \\
\hline Signature of IRB Member: \\
\hline IRB Chair: Check 1 box:
\end{tabular}




\section{GCC IRB Approval}

July 10,2015

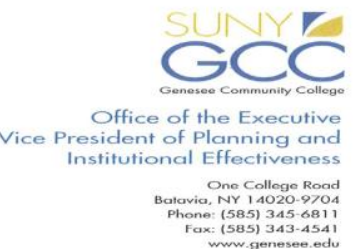

Re: Julie Woodworth

Doctoral Research Project

To: Nova Southeastern University Institutional Review Board

My name is William Emm and I am the Executive Vice President for Planning \& Institutional Effectiveness. I have reviewed the survey proposal of Julie Woodworth and have found it to present no harm to Genesee Community College, or to any of its employees or students.

The information being sought is non-invasive information and as such maintains confidentiality. We, therefore, support the research of Julie Woodworth and grant permission for her to conduct a survey in

support of her research project at Genesee Community College.

Attached you will find GCC's approved IRB Request form. If you have any questions please contact me at 585-343-0055 ext. 6202.

Sincerely,

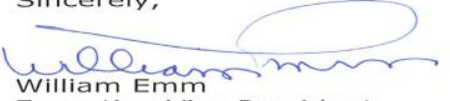

Executive Vice President

Executive Vice President

Albion Arcade Batavia Dansville Lima Medina Warsaw 


\section{JCC Chair Approval to Complete Study}

Columbare, Dawn [DawnColumbare@mail.sunyjcc.edu]

To: M Julie Woodworth

Tuesday, March 31, 2015 7:24 AM

You replied on 6/30/2015 4:25 PM.

_. Yes, you have my approval.

Julie Woodworth

Actions

To: M DawnColumbare@mail.sunyjcc.edu

Sent Items

Monday, March 30, 2015 6:59 PM

Dr Columbare,

My name is Julie Woodworth and I am pursuing my PhD in Nursing Education at Nova Southeastern University. I was hoping for your guidance in my upcoming dissertation study focused on associate degree programs in New York State. As a professor of nursing at Niagara County Community College I work with adjunct clinical faculty and see that many of them persist in the role, however many do not. I am interested in studying what factors promote adjunct faculty intent to stay teaching.

I will be obtaining IRB approval from Nova Southeastern University, however I am wondering if I would be able to obtain permission from you to do my survey study with your adjunct clinical nurse faculty or if IRB approval would be needed before proceeding.

I appreciate your time and reply to this email to guide my study,

Julie A. Woodworth, PhDc, RN, CNE

Professor of Nursing

Niagara County Community College 
Cherie Mavissakalian

NCCC Chair Approval to Complete Study

To:

$\mathrm{M}$

Julie Woodworth

Tuesday, June 02, 2015 10:09 AM

Professor Woodworth,

Your research information can be sent to the adjunct faculty in our contact list. Please indicate whether you want faculty from this current semester, school year, or inclusive of previous school years. Further IRB permission is not required.

Cherie A. Mavissakalian MS, RN

Professor /Department Head

Nursing Education

(716)614-5940 Office

(716)614-6827 Fax

mavissak@niagaracc.suny.edu

Julie Woodworth

Actions

To:

M

Cherie Mavissakalian

Sent Items

Monday, June 01, 2015 9:35 PM

Professor Mavissakalian,

My name is Julie Woodworth and I am pursuing my PhD in Nursing Education at Nova Southeastern University. I was hoping for your guidance in my upcoming dissertation study focused on associate degree programs in New York State. As a professor of nursing at Niagara County Community College I work with adjunct clinical faculty and see that many of them persist in the role, however many do not. I am interested in studying what factors promote adjunct faculty intent to stay teaching.

I will be obtaining IRB approval from Nova Southeastern University, however I am wondering if I would be able to obtain permission from you to do my survey study with your adjunct clinical nurse faculty or if IRB approval would be needed before proceeding.

I appreciate your time and reply to this email to guide my study,

Julie A. Woodworth, PhDc, RN, CNE

Professor of Nursing

Niagara County Community College 


\section{Appendix B}

\section{Permission to Utilize Adjunct Faculty Satisfaction Tool}

From: Jeffery Hoyt [hoytj@fau.edu]

Sent: Monday, November 17, 2014 7:19 PM

To: Julie Woodworth

Subject: RE: Part-time Faculty Job Satisfaction Survey

Feel free to use it as you wish, no problem. Wish you well on your work. Jeff

From: Jeffery Hoyt [hoytj@fau.edu]

Sent: Monday, November 17, 2014 7:19 PM

To: Julie Woodworth

Subject: RE: Part-time Faculty Job Satisfaction Survey

Feel free to use it as you wish, no problem. Wish you well on your work. Jeff

-----Original Message-----

From: Julie Woodworth [mailto:jwoodworth@niagaracc.suny.edu]

Sent: Saturday, November 15, 2014 5:28 PM

To: Jeffery Hoyt

Subject: Part-time Faculty Job Satisfaction Survey

Dr. Hoyt,

I am a professor of nursing at Niagara County Community College in NYS and I am beginning my dissertation for my PhD in nursing education through Nova Southeastern University in Florida. In the community college where I teach, I have noticed an exponential increase in the hiring of adjunct faculty to teach a majority of our courses. Specifically in nursing this impacts the clinical teaching component.

I am very interested in the Dimensions of Part-time Faculty Job Satisfaction survey that you helped to develop to measure adjunct faculty satisfaction (2008) and loyalty (2012). I am hoping to study community college adjunct clinical nurse faculty's satisfaction and loyalty (retention). I would like to utilize your instrument with your permission with a few additions/revisions in the teaching role.

I appreciate your time and any feedback that you could offer on my research idea,

Julie Woodworth PhDc Nova Southeastern University 


\section{Appendix C}

\section{Adjunct Faculty Survey}

Directions: Read each item and rate it using the following scale: $1=$ Strongly Disagree, 2 $=$ Disagree, $3=$ Somewhat Disagree, $4=$ Somewhat Agree, $5=$ Agree, $6=$ Strongly agree.

\section{Overall Job Satisfaction}

\begin{tabular}{|l|l|llllll|}
\hline 1 & $\begin{array}{l}\text { I am completely satisfied with my job teaching as an adjunct faculty } \\
\text { member at the university. }\end{array}$ & 1 & 2 & 3 & 4 & 5 & 6 \\
\hline 2 & I am dissatisfied with aspects of my job as an adjunct faculty member.* & 1 & 2 & 3 & 4 & 5 & 6 \\
\hline 3 & $\begin{array}{l}\text { Considering everything, I have an excellent job as an adjunct faculty } \\
\text { member. }\end{array}$ & 122 & 3 & 4 & 5 & 6 \\
\hline
\end{tabular}

\section{Loyalty}

\begin{tabular}{|c|c|c|}
\hline 4 & $\begin{array}{l}\text { I would highly recommend teaching at the university to other qualified } \\
\text { people. }\end{array}$ & 123456 \\
\hline 5 & I would prefer to teach somewhere else instead of at the university.* & 123456 \\
\hline 6 & I am very proud to tell others that I teach at the university. & 1233456 \\
\hline
\end{tabular}

Recognition

\begin{tabular}{|c|c|c|}
\hline 7 & I am often thanked for teaching here. & 12234556 \\
\hline 8 & I rarely receive any appreciation for teaching part time at the university.* & 1233456 \\
\hline 9 & $\begin{array}{l}\text { Adjunct faculty is recognized for their teaching contribution at the } \\
\text { university. }\end{array}$ & 123456 \\
\hline
\end{tabular}

\section{Work Preference}

\begin{tabular}{|c|c|c|}
\hline 10 & I really enjoy teaching courses. & 1233456 \\
\hline 11 & I almost always look forward to teaching courses. & 123456 \\
\hline 12 & I would prefer to do work other than teaching.* & 1223456 \\
\hline
\end{tabular}

\section{Personal Growth}

\begin{tabular}{|c|c|c|}
\hline 13 & $\begin{array}{l}\text { I have enhanced my teaching ability by learning several new teaching } \\
\text { methods or techniques during this past year. }\end{array}$ & 123456 \\
\hline 14 & My teaching skills and abilities have substantially improved this past year. & 123456 \\
\hline 15 & I am putting in extra time and effort to become a better teacher. & 1233456 \\
\hline
\end{tabular}

Autonomy

\begin{tabular}{|c|c|c|}
\hline 16 & $\begin{array}{l}\text { I have a lot of freedom to develop and modify course content to meet the } \\
\text { needs of my students. }\end{array}$ & 123456 \\
\hline 17 & $\begin{array}{l}\text { I have a satisfactory level of autonomy to select material or texts for my } \\
\text { courses. }\end{array}$ & 123456 \\
\hline 18 & $\begin{array}{l}\text { I would like more freedom to determine the content, materials, or texts for } \\
\text { my courses.* }\end{array}$ & 123456 \\
\hline
\end{tabular}

Faculty Support

\begin{tabular}{|l|l|llll}
\hline 19 & $\begin{array}{l}\text { Full-time faculty or department chairs on the main campus are always } \\
\text { available and accessible to me when I need assistance. }\end{array}$ & 123456 \\
\hline
\end{tabular}




\begin{tabular}{|c|c|c|}
\hline 20 & $\begin{array}{l}\text { Full-time faculty and department chairs on the main campus lack interest } \\
\text { and care very little about my success as a teacher. } *\end{array}$ & 1233456 \\
\hline 21 & $\begin{array}{l}\text { I feel very comfortable requesting assistance from full-time academic } \\
\text { faculty or department chairs on the main campus when I have questions. }\end{array}$ & 123456 \\
\hline
\end{tabular}

Honorarium

\begin{tabular}{|c|c|c|}
\hline 22 & I feel that I am well compensated for my teaching. & 123456 \\
\hline 23 & I am paid fairly for the amount of work I do to teach courses. & 123456 \\
\hline 24 & I am dissatisfied with the pay I receive for teaching courses.* & 123456 \\
\hline
\end{tabular}

Quality of Students

\begin{tabular}{|l|l|llllll|}
\hline 25 & $\begin{array}{l}\text { I am completely satisfied with the quality and caliber of students in my } \\
\text { classes (clinical). }\end{array}$ & 1 & 2 & 3 & 4 & 5 & 6 \\
\hline 26 & Students lack motivation or the academic skills to succeed in my courses.* & 1 & 2 & 3 & 4 & 5 & 6 \\
\hline 27 & $\begin{array}{l}\text { Students here are highly engaged and very interested in their academic } \\
\text { work. }\end{array}$ & 12 & 2 & 3 & 4 & 5 & 6 \\
\hline
\end{tabular}

Teaching Schedule

\begin{tabular}{|l|l|llllll|}
\hline 28 & I am required to teach at times that are inconvenient for me. ${ }^{*}$ & 1 & 2 & 3 & 4 & 5 & 6 \\
\hline 29 & $\begin{array}{l}\text { The times that I teach my classes (clinical) work well with my other } \\
\text { commitments. }\end{array}$ & 1 & 2 & 3 & 45 & 5 & 6 \\
\hline 30 & The times scheduled for my class (clinical) has been convenient. & 1 & 2 & 3 & 4 & 5 & 6 \\
\hline
\end{tabular}

Classroom Facilities

\begin{tabular}{|c|c|c|}
\hline 31 & $\begin{array}{l}\text { The classroom (clinical) space where I meet with students could be } \\
\text { improved.* }\end{array}$ & 123456 \\
\hline 32 & $\begin{array}{l}\text { The classrooms (clinical) where I teach have multimedia equipment that } \\
\text { adequately meets pedagogical needs. }\end{array}$ & 123456 \\
\hline 33 & The classroom (clinical) space where I teach is excellent & 123456 \\
\hline
\end{tabular}

*Negatively worded questions are reverse coded to match the direction of positive questions.

(Hoyt, 2012) 


\section{Appendix D}

Permission to use the Nurse Educators' Intent to Stay Teaching in Academe Scale

Hi Julie, you have permission to use the Nurse Educators' Intent to Stay Teaching in Academe Scale (Derby, 2009). Please share the psychometrics and the findings of your study with me.

Dr. Derby-Davis

Julie Woodworth

Actions

To:

$\mathrm{M}$

mderby@nova.edu

Sent Items

Wednesday, April 08, 2015 5:27 PM

Dear Dr Derby-Davis

I am writing to ask your permission to use your instrument, the Nurse Educators' Intent to Stay Teaching in Academe Scale tool, in a dissertation research study that I am proposing for the spring or fall, 2015 term in the northeastern United States. I am surveying adjunct clinical nurse faculty teaching within associate degree (AD) nursing programs.

The purpose of the study is to contribute to the overall understanding of $A D$ adjunct clinical nurse faculty and examine the relationship between demographic variables and job satisfaction factors with intent to stay teaching.

This research will employ the Nurse Educators' Intent to Stay Teaching in Academe Scale tool with a Job Satisfaction Survey by Hoyt (2012) to AD adjunct clinical nurse faculty.

I am happy to provide you with any additional information if that is helpful. Thank you for your thoughtful consideration of my request. I look forward to your reply.

Sincerely,

Julie A. Woodworth, PhDc, RN, CNE

PhD Student Nova Southeastern University

and

Professor of Nursing

Niagara County Community College 


\section{Appendix E}

Nurse Educators' Intent to Stay in Academe Scale

Directions: Using the scale provided below, please indicate to what extent you disagree or agree with each of the following statements.

1. Indicates that you Strongly Disagree

2. Indicates that you Disagree

3. Indicates that you Agree

4. Indicates that you Strongly Agree

\begin{tabular}{|c|c|c|}
\hline 1 & $\begin{array}{l}\text { I would lose more than I gain if I changed my profession as a nurse } \\
\text { educator in academe. }\end{array}$ & 1234 \\
\hline 2 & $\begin{array}{l}\text { I have invested too much of myself in nursing education to consider } \\
\text { changing professions. }\end{array}$ & 1234 \\
\hline 3 & I plan to continue my career in nursing education. & 1234 \\
\hline 4 & $\begin{array}{l}\text { I have other options, but they are not as attractive as working as a nursing } \\
\text { educator in academe. }\end{array}$ & 1234 \\
\hline 5 & $\begin{array}{l}\text { Leaving my position as a nurse educator in academe would have many } \\
\text { negative consequences. }\end{array}$ & 1234 \\
\hline 6 & $\begin{array}{l}\text { The sense of success that I receive from working with students keeps me } \\
\text { working as a nurse educator in academe. }\end{array}$ & 1234 \\
\hline 7 & I would miss the academic environment if I left nursing education. & 1234 \\
\hline 8 & $\begin{array}{l}\text { The autonomy that I have as a nurse educator would be lost if I left } \\
\text { academia. }\end{array}$ & 1234 \\
\hline 9 & I would miss the flexibility of my work schedule if I left nursing academe. & 1234 \\
\hline 10 & $\begin{array}{l}\text { I would miss the opportunity to participate in research if I left nursing } \\
\text { academe. }\end{array}$ & 1234 \\
\hline 11 & I would miss the interactions with my colleagues if I left nursing academe. & 1234 \\
\hline 12 & I plan to remain in academia beyond my retirement years. & 1234 \\
\hline 13 & If I had to redo my career choices I would choose nursing academe again. & 1234 \\
\hline
\end{tabular}

(Derby, 2009) 


\section{Appendix F}

\section{Demographic Data Survey}

1. How many years have you been employed as an adjunct faculty at the current university (round to the nearest whole number)?

ㄴs than 1 year

$\circ \quad 1-2$

○ $\quad 3-4$

○ 5-6

○ More than 6

2. How many years of teaching experience do you have in nursing education (round to the nearest whole number)?

ㄴ Less than 1 year

○ $\quad 1-2$

○ $\quad 3-4$

○ 5-6

○ More than 6

3. What is your age?

4. What is the highest level of education you have completed?

○ Baccalaureate Degree in Nursing

○ Master's Degree in Nursing

○ Master's Degree in other field

$\circ \quad$ PhD in Nursing

$\circ \quad$ DNP 
O Other (please specify)

5. What is your primary race?

- White

○ Black/African-American

○ American Indian or Alaska Native

$\circ \quad$ Asian

- Native Hawaiian or other Pacific Islander

○ From multiple races

O Other (please specify)

6. What is your gender?

○ Male

○ Female

7. What is your employment status outside of this adjunct position?

○ No employment outside of this adjunct position

- Work another part-time job in academia

- Work another part-time job in the field

○ Work full-time outside of this employment

Other (please specify) 


\section{Appendix G \\ Letter of Introduction}

Title of Study: Predictive Factors Impacting Intent to Stay Teaching for Associate Degree Adjunct Clinical Nurse Faculty

Principal investigator Co-investigator

Julie Woodworth, PhDc, RN, CNE

Diane Whitehead

3111 Saunders Settlement Rd

College of Nursing

Sanborn, NY 14132

3200 South University Drive

(585) 7489814

Ft. Lauderdale, FL 33328

954-262-1982

Institutional Review Board

Nova Southeastern University

Human Research Oversight Board (Institutional Review Board or IRB)

(954) 262-5369/Toll Free: 866-499-0790

$\underline{\text { IRB@nsu.nova.edu }}$

Institutional Review Board- James Cronmiller

Monroe Community College

1000 E. Henrietta Rd

Rochester, NY 14623

(585) 292- 2740

Institutional Review Board- Joan Castro VPAA

Erie Community College

6205 Main St

Williamsville, NY 14221

(716) 851-1361

Director of Nursing -Dawn Columbare Jamestown Community College 


\author{
525 Falconer $\mathrm{St}$ \\ Jamestown, NY 14701 \\ (716) 338-1171 \\ Professor and Chairperson - Mary Coriale \\ Finger Lakes Community College \\ 3325 Marvin Sands Drive \\ Canandaigua, NY 14424 \\ (585) 785-1344 \\ Department Chairperson - Cherie Mavissikalian \\ Niagara County Community College \\ 3111 Saunders Settlement Rd \\ Sanborn, NY 14132 \\ (716) 614-5941 \\ Institutional Review Board- William Emm \\ Genesee Community College \\ One College Rd \\ Batavia, NY 14020 \\ (585) 345-0055
}

Description of Study: Julie Woodworth is a doctoral student at Nova Southeastern University. This study is being conducted for the purpose of satisfying the dissertation requirement for a $\mathrm{PhD}$ of Nursing Education degree. The purpose of this study is to investigate predictor factors of intent to stay teaching for adjunct clinical nurse faculty teaching in associate degree programs. This study will provide information that can be utilized to promote intent to stay teaching for this faculty group.

If you agree to participate, you will be asked to complete the attached questionnaire that will take approximately 15 minutes of your time. This questionnaire will help to identify demographic variables and job satisfaction factors as predictors of intent to stay teaching. This data obtained will be used to identify factors for support of adjunct clinical nurse faculty in the role as clinical faculty.

Risks/Benefits to the Participant: Risks associated with participation in this study includes: psychological discomfort and a potential loss of confidentiality of information. Participants may experience a certain amount of psychological discomfort as a result of thinking of employment and disclosing demographic data, rating job satisfaction, and intent to stay teaching. If you experience this feeling of psychological discomfort, please withdraw from the study by exiting the survey. All data received will be accessible to only the researcher. Employers will not have access to this information. Furthermore, all 
responses are anonymous and will not be linked to the participant. Data will be reported in aggregate form to reduce the risks.

There are no direct benefits to for agreeing to be in this study. Please understand that although you may not benefit directly from participation in this study, you have the opportunity to enhance predictor factors of promotion of intent to stay teaching for adjunct clinical nurse faculty. If you have any concerns about the risks/benefits of participating in this study, you can contact the investigator and/or the university's human research oversight board (the Institutional Review Board or IRB) at the numbers listed above.

Cost and Payments to the Participant: There is no cost for participation in this study. Participation is completely voluntary and no payment will be provided.

Confidentiality: Information obtained in this study is strictly confidential and anonymous. All data will be reported in aggregate form and secured in a locked filing cabinet. Your name will not be collected nor used in the reporting of information in publications or conference presentations.

Participant's Right to Withdraw from the Study: You have the right to refuse to participate in this study and the right to withdraw from the study at any time without penalty.

I have read this letter and I fully understand the contents of this document and voluntarily consent to participate. All of my questions concerning this research have been answered. If I have any questions in the future about this study they will be answered by the investigator listed above or his/her staff.

I understand that the completion of this questionnaire and answering yes to the first question on the survey gives my consent to participate in this study. Please click on the link provided:

https://www.surveymonkey.com/r/CommunitycollegeNurseFacultySurvey

Thank you for your participation,

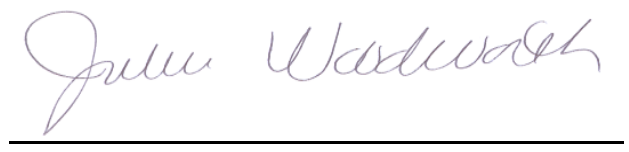

Julie Woodworth PhDc, RN, CNE 